Hélio Miguel dos Reis Almeida

\title{
Mesoscale Variability of the Brazil Current in the Santos Bight: is it locally or remotely forced?
}

\begin{abstract}
A thesis submitted in partial fulfillment of the requirements for the degree of Master of Sciences in Oceanography, with emphasis in Physical Oceanography, Instituto Oceanográfico, Universidade de São Paulo.
\end{abstract}

Advisor: Prof. Dr. Ilson Carlos Almeida da Silveira.

São Paulo

2017 


\title{
Universidade de São Paulo Instituto Oceanográfico
}

\section{Mesoscale variability of the Brazil Current within the Santos Bight: is it locally or remotely forced?}

\author{
by \\ Hélio Miguel dos Reis Almeida \\ Versão Corrigida
}

A thesis submitted in partial fulfillment of the requirements for the degree of Master of Sciences in Oceanography, with emphasis in Physical Oceanography, Instituto Oceanográfico, Universidade de São Paulo.

Evaluated in 1 

"Mudar pra melhor, com certeza, quer dizer que ia mudar melhor. Já tava bom, diz que ia mudar ele pra melhor, não tava muito bom. Tava meio ruim também, tava ruim, agora parece que piorou." Unknown author, 2013

"Nós vamos deixar uma meta aberta. Quando a gente atingir a meta, nós dobramos a meta."

Dilma Rousseff, 2015 


\section{Acknowledgements}

My most heartfelt thanks goes to my advisor, professor, mentor and above all that, a dear friend prrofessor Ilson Silveira. These two years of my MSc would not have been the same without his advising, help and encouragement to always pursue my goals. I feel truly thankful that he took a leap of faith on me. It has been inspiring to work with you and to learn from you and your constant teaching passion. Working with you for sure shaped the researcher that I will be, and for that I will always be thankful. Thanks for teaching me in several ways how nonlinear both science and life are.

Secondly, a thanks to my parents who always stood strong no matter what and despite the distance always encouraged me. For that I will always be thankful. This chapter in my life would not be possible without their support.

I deeply thank professor Wandrey Watanabe who gave a fundamental help in the most difficult times of this work. Thank you for the helpful insights and precious suggestions. It was a privilege to work and learn with you.

I would like to thank the IO-USP professors Belmiro Castro, Paulo Polito and Olga Sato for their precious teaching. I proudly present myself as physical oceanographer today and a big part of that is because of you.

I also thank professor Glenn Flierl for his precise insights and discussions. His help was crucial to the development of this work and it was a privilege to discuss my findings with him.

I am deeply thankful to my brother Nuno Almeida who through good and bad times, troughs and crests of happiness, was there for me. I could not be more thankful to you. You learned to calm my spirit and to always have the right word to say. You're the best brother in the world.

I am truly thankful to my labmates, Filipe Pereira, Ágata Braga, Daniel Melo, Guido, Fabrício Lapolli, Vadim Harlamov, Giuliana Lukine Tiago Biló, André Palóczy and Gilberto Watanabe. Thank you for the coffee breaks and good talks.

Although being labmates I am specially thankful to Pinguim (Dante Napolitano) and Patola 
(Patrícia Baldasso) for being more than that and supporting me in a period that even I could not. Part of the tenacity that I had in this two years was because of your support and advices.

I could not be more thankful to Iury Sousa who, although knowing me for only two years, became my younger brother on the other side of the ocean. Thank you for keeping up with my temper and for being there through good and bad times.

My dear Débora, there are not enough words to express how much I am thankful to have you in my life. You made the problems seem small and easier to smile. Thank you for always supporting me and believing in me even more than myself. Thanks for the help and support and the laughs even after rough days.

I would like to thank to Nancy, the nice Japanese who became a dear friend during these two years. I am deeply thankful for the conversations and the coffee breaks and ginger in this final stage to relieve the stress.

I also like to thank to my São Paulo friends Matheus Cortezi, Mariana Benites, Márcio Borges, Dalton, Thiago Almeida, Guilherme Caneli, Ana Paula Loureiro, Aninha Losnak.

A special thanks to Kamila and her family, Priscila Verlaine, Gui Bezerra, Shyveres, Hadassa, Rosangela and Adauto. I can't fully express how thankful I am to you all for all the unconditional help in the first stage of the adventure. You will always be my Brazilian family.

I would like to thank to my friends in Portugal, Hugo Oliveira, Inês Vaz, Tiago Pereira, Evelyn Santos, Diana Nunes, Cristiana Sengo, Américo Ribeiro, Juan Oliveira, Filipe Tártaro, Pedro Neves. Despite the distance and timezone they were always there for me during these years. Always managed time to keep in touch and were there during good and bad moments.

A special thanks to my professor and mentor professor João Miguel Dias who was always there to talk about everything and any thought along the path. I also thank him for being the responsible for my early passion for physical oceanography. I owe to him the early passion and will to teach.

I want to thank the Petróleo Brasileiro SA (PETROBRAS) for providing the CERES V data set. I also deeply thank Dr. Wellington Ceccopieri Belo coordinator and idealizer of the CERES project and an enthusiastic responsible for the LaDO-PETROBRAS partnership and supported high-quality research.

Thanks to the Coordination of Improvement of Personal Higher Education (CAPES) that provided the funding through the project "Rede de Estudos da Corrente do Brasil na Margem Continental Sudeste-Sul (REMARSUL)". 
Last but not least, because all the reasons above and even more, thanks Brazil. 


\section{List of Figures}

1.1 Schematics of the surface circulation of the South Atlantic. Black solid lines represent streamlines of the main currents and arrows represent the currents direction. The South Atlantic Subtropical Gyre $\left(\sim 10^{\circ} \mathrm{S}-40^{\circ} \mathrm{S}\right.$, red solid lines $)$ is delimited by the South Equatorial Current (north), the Brazil Current (west) and South Atlantic Current (south). The gray shades indicate the major topographic features on the region. Adapted from Talley et al. (2011). . . . . . . . . . . . .

1.2 The Brazil Current thickening along the Brazilian margin: (A) a three-dimensional sketch of the South Equatorial Current (SEC) and Brazil Current (BC) and the water masses being transported by both flow; (B) diagramatic representation of the three SEC bifurcations, i.e. surface, pycnoclinic and intermediate. The arrows represent poleward flow if pointing to the left or equatorward flow, if pointing to the right. Thicker arrows aim to represent the water mass at which the core of the BC, Intermediate Western Boundary Current (IWBC), North Brazil Under Current (NBUC) and Deep Western Boundary Current (DWBC) are found.

1.3 The Santos Bifurcation ( $\mathrm{SBi}$ ) structure as inferred from trajectories of ARGO floats to the SBi: (A): original ARGO trajectories with floats which veered to the north to join the IWBC are marked in green, and the ones which veered south to join the $\mathrm{BC}$ are marked in cyan. The few magenta trajectories correspond to float immersions greater than 1050 dbar. (B): Averaged float velocities in $1^{\circ} \times 1^{\circ}$ boxes. Blue arrows are averaged velocities less than $5 \mathrm{~cm} \mathrm{~s}^{-1}$, yellow arrows averaged velocities greater $5 \mathrm{~cm} \mathrm{~s}^{-1}$. According to Legeais et al. (2013). . . . .

1.4 Schematic of the two patterns by which Western Boundary Currents (WBCs) separate from the continental margins: (A) smooth separation and Western Boundary Current (WBC) extension formation. (B) reflection with a zonallydamped stationary wave formed. Adapted from da Silveira et al. (1999). . . . . 
1.5 Schematics of Stommel's explanation for a weaker and shallowed BC compared to a stronger and deeper Gulf Stream (GS). The net volume transport budget includes the wind and buoyancy driven flows. blue represents northward flow and red, southward flow. Adapted from Stommel (1965). . . . . . . . . . . . .

1.6 The four-layer Meridional Overturnig Circulation (MOC) global configuration proposed by Schmitz (1995).

1.7 The updated Stommel (1961) conceptual model for the BC vertical structure based on combined wind and MOC forcings. . . . . . . . . . . . .

1.8 The study area geographical limits and a schematic representation of mean large scale circulation within. The arrow colors represent distinct water masses being transported by the flow regime: Tropical Water (TW)-South Atlantic Central Water (SACW) (red), Antarctic Intermediate Water (AAIW)-Upper Circumpolar Deep Water (UCDW) (green) and North Atlantic Deep Water (NADW) (blue). Gray shades indicate the major topographic features on the region. . . . . . .

1.9 Sea Surface Temperature (SST) field for the Santos Basin (SB) at 14/08/2005 with the BC meandering from Cape São Tomé (CST) to Cape Santa Marta (CSM). Data from level 4 Multiscale Ultrahigh Resolution (MUR) of the Group for High Resolution Sea Surface Temperature (GHRSST) analysis provided by NASA. Quiver of geostrophic velocity from AVISO to the same day. . . . . . .

1.10 Instability wave propagation within the SBi as identified by Fernandes et al.

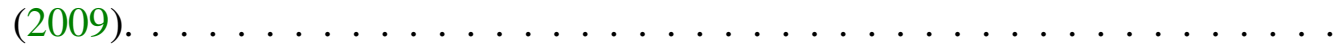

1.11 Linear baroclinic instability phase speed and growth for for MARLIM, C3, and W333 moorings: (A) growth rate and (B) phase speed. Source: Rocha et al.

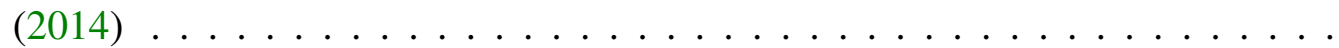

2.1 Comparison between the original AVISO Mean Dynamic Topography (MDT) and the corrected MDT used in this work. (A): blue solid contours the $\bar{\eta}$ provided by AVISO and the red dashed contours the $\bar{\eta}$ calculated from the 22 years data. (B): the percentage of increasing of the $\bar{\eta}$ compared with AVISO provided MDT, black solid line the $\mathrm{BC}$ mean position in calculated $\bar{\eta} . \ldots \ldots \ldots$

2.2 Study area, yellow box the region used to calculate the climatological Brunt-Väisälä profile. Gray shades indicate the major topographic features on the region. . . . 
2.3 Example of annual signal adjustment for 5 years of data at one point in $\mathrm{x}$-axis of the Hovmöller diagram. Green line $D(t)$ is the Sea Level Anomaly (SLA) signal and blue line $Y(t)$ the adjusted seasonal signal. . . . . . . . . . .

2.4 Fast Fourier Transform (FFT) band-pass filter on SLA time series for the grid point at $25.375^{\circ} \mathrm{S}$ and $44.375^{\circ} \mathrm{W}$ for the first 5 years of data. (A): blue line is the raw data, green line the data filtered with FFT. (B): red line is the spectral power $\left[\mathrm{m}^{2}\right.$ day $\left.^{-1}\right]$, yellow dashed line is in the 92 day period position, black dashed lines the limits of $10 \%$ from central period and shaded black area is the portion of the spectre line used to reconstruct the filtered data. . . . . . . . . . . .

2.5 Example of the pathway and wavelength estimate using the SLA correlation coefficient field. (A): SLA [m] fictitious field with a wave signal propagating between 1000 and 1500 in y-axis. Rest of field is random noise. (B): correlation field with a control point where the wave happens, magenta dot the position of control time series. (C): orrelation field with a control point where there is no presence of the wave, magenta dot the position of control time series. . . . . . .

2.6 Radon transform illustrative scheme. The gray square represent the original data being rotated. Blue dashed line represent a relative sum of the radon space at each angle for all $r$ axis, being the angles $0^{\circ}, 45^{\circ}$ and $67.5^{\circ} \ldots \ldots \ldots$

2.7 Mean Dynamic Topography map with filled contours as height in meters. The green line is the path along the BCaxis chosen to do the Hovmöller diagram, starting at the green dot and ending at the red dot, the black dot indicates the mean latitude of the SBi along the green line (Rocha et al., 2014). . . . . . . . 25

2.8 Hovmöller diagram of SLA for 22 year and subset of 2007-2010 . . . . . . . 26

2.9 Spectral mean energy $\left[\mathrm{m}^{2} \mathrm{day}^{-} 1\right]$ for periods between 20 and 180 days, computed to the north of the SBi. Red dot the period of maximum energy. . . . . . .

2.10 Spectral determination of most important wavenumber. (A) Spectral energy of the Hovmöller diagram $\left[\log _{10} \mathrm{~m}^{2}\right.$ day $\left.^{-1} \mathrm{~km}^{-1}\right]$. Blue line the bandpass filter box centered in period of 92 days and range of $\pm 10 \%$. (B) Wavenumber spectrum $\left[\mathrm{m}^{2} \mathrm{~km}^{-1}\right]$, black dots represent spectral resolution and red dot dominant wavenumber. 
2.11 Correlation coefficient field of the SLA filtered data in to 92-D signal. (A): map of correlation coefficient, green dot the position used to correlate with the rest of the field and black line the Hovmöller diagram path used for the BC axis. (B): same correlation coefficient field, black line the new Hovmöller diagram path specific to this wave, green dot is the start and red cross the end of the path. . . 30

2.12 Same as the Figure 2.10 but for the new Hovmöller diagram path in Figure 2.11A. 31

2.13 Hovmöller diagram for six years of data along 92 wave path and data filtered with bi-dimensional finite impulse response (FIR2D) . . . . . . . . . . . 32

2.14 Same as the Figure 2.9 but to the south of the bifurcation. Two red dots represent the periods of 68 and 148 days. . . . . . . . . . . . . .

2.15 Spectral determination of most important wavenumber for each maximum in Figure 2.14. (A): spectral energy of Hovmöller diagram $\left[\log _{10} \mathrm{~m}^{2} \mathrm{day}^{-1}\right.$ $\mathrm{km}^{-1}$ ]. Blue lines represent the box where the spectrum was cut between range of $\pm 10 \%$ of the central period, solid line for 68 day period and dashed for 148 . (B): spectral mean power $\left[\mathrm{m}^{2} \mathrm{~km}^{-1}\right]$, black dots represent spectral resolution and red dot dominant wavenumber, solid line for 68 day and dashed for 148. . . 34

2.16 Same as Figure 2.11 but with data filtered in 68 day period. . . . . . . . . . 35

2.17 Same as Figure 2.15 but for 68 day signal in the new Hovmöller diagram path defined in Figure 2.16 B . . . . . . . . . . . . . . . . . 36

2.18 Same as Figure 2.13 but for 68-D signal in the new Hovmöller diagram path defined in Figure $2.16 \mathrm{~B} \ldots \ldots \ldots \ldots \ldots \ldots$

2.19 Correlation field of data filtered to 148 days period. Path used to Hovmöller of $\mathrm{BC}$ and new pass specific to the wave . . . . . . . . . . . 38

2.20 Spectral determination of wavenumber for 68 day signal. . . . . . . . . . . . . 39

2.21 Same as Figure 2.13 but for 148 day signal in the new Hovmöller diagram path defined in Figure 2.19B . . . . . . . . . . . . . . . . .

2.22 Dispersion relation of known phenomena, green line dispersion relation of barotropic and red line first baroclinic mode linear Rossby waves, black dashed line the nondispersive line (NDL) f, blue dot the 148 day signal and blue star the 92 day signal. 
2.23 Wavenumber frequency spectrum for the 92-D wave pathway. Spectral energy [ $\left.\log _{10} \mathrm{~m}^{2} \mathrm{day}^{-1} \mathrm{~km}^{-1}\right]$, black solid line the dispersion relation of first mode linear Rossby waves (RW), white dashed line the NDL for this waves and blue start the $92-\mathrm{D}$ wave. . . . . . . . . . . . . . . . . . . . . 46

2.24 Same as Figure 2.23 but for the 148 -D wave pathway. . . . . . . . . . . . . . 47

3.1 The CERES V cruise Vessel Mounted Acoustic Doppler Current Profiler (VMADCP) sampling tracks (thick solid black lines). Solid red lines correspond to the transects used in this work to build the velocity sections. The color grading underneath the tracks denotes the bathymetry of the study area. The black dashed line marks the position of the $200 \mathrm{~m}$ isobath, which is the most accepted depth to represent the shelf break in SB. . . . . . . . . . . . . .

3.2 Maps of the CERES V. (A): observational streamfunction $\psi$. (B): the associated interpolation error at $30 \mathrm{~m}$. The gray area represents depths shallower than 100 $\mathrm{m}$; the mangenta dashed curve denotes the shelf break position. . . . . . . .

3.3 Comparison between the (A) CERES V $\psi_{o}$ and (B) AVISO streamfunction $\psi_{a}$ fields during the cruise period. The black solid line delimits the CERES V sampling area. The gray area represents depths shallower than $100 \mathrm{~m}$; the magenta dashed curve denotes the shelf break position.

3.4 Comparison between (A) the AVISO streamfunction field $\left(\psi_{a}\right)$ during the CERES V cruise and (B) its FFT-filtered version for a band centered in 68 days $\left(\psi_{68}\right)$. The gray area represents depths shallower than $100 \mathrm{~m}$; the mangenta dashed curve denotes the shelf break position. . . . . . . . . . . . . .

3.5 The 68-D filtered total and anomaly AVISO streamfunction fields $\left(\psi_{68}\right.$ and $\left.\psi_{68}^{\prime}\right)$ for the CERES V cruise period. The gray area represents depths shallower than $100 \mathrm{~m}$; the mangenta dashed curve denotes the shelf break position. . . . .

3.6 The 68-D wave propagation: (A), (B), (C), (D), (E) and (F). The gray area represents depths shallower than $100 \mathrm{~m}$; the magenta dashed curve denotes the shelf break position. . . . . . . . . . . . . . .

3.7 Hovmöller diagram of the streamfuction anomaly of the AVISO series centered at the CERES V period. The black arrows mark the anticyclone (crest) and the cyclone (trough) of the $68-\mathrm{D}$ wave captured by the cruise sampling. The magenta dashed line denotes the CSM location. . . . . . . . . . . . . . . 
3.8 The Jacobian between the CERES V $\psi$ field and the filtered AVISO $\psi$ field. .

3.9 The VMADCP tracks (black thick solid lines) overlaid on the CERES V 30m streamfunction field. The red thick solid line highlights the two transects which vertical structure will be shown and described in this subsection. The gray area represents depths shallower than $100 \mathrm{~m}$; the mangenta dashed curve denotes the shelf break position. . . . . . . . . . . . . . . . . 58

3.10 Vertical section of the VMADCP profiled velocity of transect \#3 (the northern red transect in Figure 3.9). The black area represents the topography, and the magenta dashed line the position of outermost station of lowered Acoustic Doppler Current Profiler (LADCP) top-bottom profile carried out during the cruise and described by Biló (2015). . . . . . . . . . . . . . . . . . . . . . .

3.11 Southern red transect in Figure 3.9. Filed contour of cross-transect velocity, black area the shelf break and slope and magenta dashed line the limit of LADCP collected during the cruise and used by Biló (2015) . . . . . . . . . . . . . . . 


\section{List of Tables}

2.1 Main spectral characteristics of each dominant signal to south and north of SBi. 41 


\section{List of Acronyms}

AAIW Antarctic Intermediate Water

ADT Absolute Dynamic Topography

BC Brazil Current

CF Cape Frio

CFE Cape Frio Eddy

CODAS Common Ocean Data Access System

CSM Cape Santa Marta

CST Cape São Tomé

DWBC Deep Western Boundary Current

EAC East Australian Current

FFT Fast Fourier Transform

FFT2D two dimensional Fast Fourier Transform

FIR2D bi-dimensional finite impulse response

GS Gulf Stream

IWBC Intermediate Western Boundary Current

KC Kuroshio Current

LADCP lowered Acoustic Doppler Current Profiler

MC Malvinas Current 
MDT Mean Dynamic Topography

MOC Meridional Overturnig Circulation

NADW North Atlantic Deep Water

NBUC North Brazil Under Current

NDL nondispersive line

OA Objective Analysis

PE primitive equation

PV potential vorticity

QG quasi-geostrophic

RC Recirculation Cell

RW Rossby waves

SAC South Atlantic Current

SACW South Atlantic Central Water

SASG South Atlantic Subtropical Gyre

SB Santos Basin

SBi Santos Bifurcation

SEC South Equatorial Current

SLA Sea Level Anomaly

SST Sea Surface Temperature

TW Tropical Water

UCDW Upper Circumpolar Deep Water

VMADCP Vessel Mounted Acoustic Doppler Current Profiler

VTR Vitória-Trindade Ridge 
WBC Western Boundary Current

WBCs Western Boundary Currents

WOA13 World Ocean Atlas 13 


\section{Contents}

Page

List of Figures $\quad$ ix

List of Tables $\quad$ x

List of Acronyms $\quad$ xi

$\begin{array}{ll}\text { Abstract } & \text { xvi }\end{array}$

Resumo $\quad$ xviii

1 Introduction 1

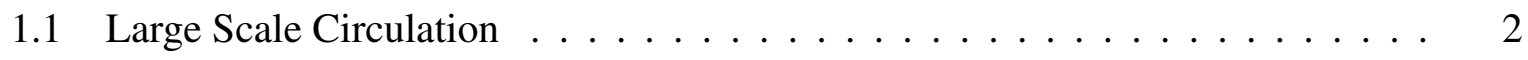

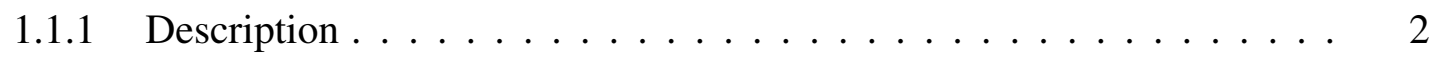

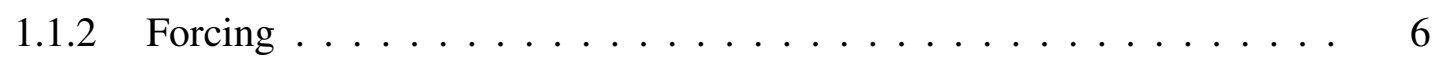

1.2 The Study Area . . . . . . . . . . . . . . . . . . . 8

1.3 The $\mathrm{BC}$ mesoscale variability $\ldots \ldots \ldots \ldots \ldots \ldots$

1.4 Thesis Hypothesis and Objectives . . . . . . . . . . . . . . . 13

1.4.1 Hypothesis . . . . . . . . . . . . . . . . . . 13

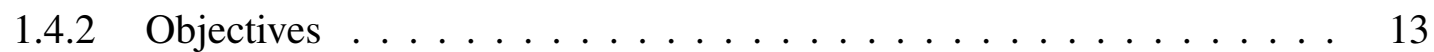

2 Mesoscale Variability from Satellite Altimetry $\quad 15$

2.1 Datasets . . . . . . . . . . . . . . . . . . . . . 15

2.1 .1 Altimetry ........................... 15

2.1.2 Climatological hydrographic data . . . . . . . . . . . . . . 17




2.2.1 Annual signal removal . . . . . . . . . . . . . . . . . 18

2.2 .2 Fast Fourier Transform . . . . . . . . . . . . . . . . . . . . . 19

2.2 .3 Correlation field . . . . . . . . . . . . . . . . 21

2.2 .4 Radon Transform . . . . . . . . . . . . . . . . . . . . . 23

2.2 .5 Explained variance $\ldots \ldots \ldots \ldots \ldots \ldots \ldots$

2.3 Results and Discussion . . . . . . . . . . . . . . . . . . . . 24

2.3.1 North of the Santos Bifurcation . . . . . . . . . . . . . . 27

2.3.2 South of the Santos Bifurcation . . . . . . . . . . . . . 32

3 Quasi-Synoptic Observations $\quad 48$

3.1 Dataset . . . . . . . . . . . . . . . . . . . . . . 48

3.1.1 In situ Quasi-Synoptic Velocity Measurements . . . . . . . . . . . . . . 48

3.2 Methods: Objective Mapping . . . . . . . . . . . . . . . . . . . . . . . . . 49

3.3 Results and Discussion . . . . . . . . . . . . . . . . . 50

3.3.1 Near-Surface Streamfunction Fields . . . . . . . . . . . . . 50

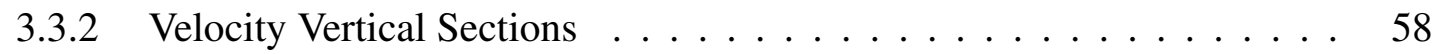

4 Summary and Conclusions $\quad 62$



$\begin{array}{ll}\text { Bibliography } & 72\end{array}$ 


\section{Abstract}

The Brazil Current (BC) is possibly one of the least studied western boundary currents (WBCs) in the world ocean. Its unique vertical structure makes this a different WBC in terms of velocity and transport. Although significant progress has been made over the last decade, the BC system variability within the Santos Bight $\left(\mathrm{SB}, 23^{\circ} \mathrm{S}-28^{\circ} \mathrm{S}\right)$ is very poorly understood despite its strategic role for Brazil in terms of energy. The BC thickens and changes its vertical structure and dynamical modal composition as it crosses the SB. As it enters the bight by trying to contour Cape Frio $\left(\mathrm{Cf}, 23^{\circ} \mathrm{S}\right)$, the $\mathrm{BC}$ is about $500 \mathrm{~m}$ deep. As the current leaves the bight south of Cape Santa Marta (CSM, 28 $\left.{ }^{\circ} \mathrm{S}\right)$ it is $1300 \mathrm{~m}$. These differences in thickness and accompanying velocity vertical shear are due to the impinging branch of the intermediate South Equatorial Current (SEC) generating the so called Santos Bifurcation (SBi). We here investigate the subinertial variability of the BC system within the SB primarily using satellite altimetry data and some traditional spectral analysis techniques. We also analyzed quasi-synoptic observations of an oceanographic cruise, which was part of the IOUSP-PETROBRAS CERES Experiment. We identified that there are different phenomena occurring to the north and to the south of the bifurcation and this might be caused by the SBi feature itself and/or the consequential change in the $\mathrm{BC}$ vertical structure downstream. North of the SBi, we detected oscillations with period of 92 days and a wavelength of $490 \mathrm{~km}$ and which represent about a fifth of the BC variability at $25^{\circ} \mathrm{S}$. The 92-day oscillations are nonlinear vorticity waves, which are originated to the east of $35^{\circ} \mathrm{W}$ and propagate zonally towards the $\mathrm{BC}$ axis. These waves then perturb the current exciting oscillatory motions of the same period and which propagate downstream. South of the SBi axis $\left(\sim 28^{\circ} \mathrm{S}\right)$, we identified two different maxima in the $\omega-k$ spectrum. They correspond to oscillations with periods (wavelengths) of 68 and 148 days $(397 \mathrm{~km}$ and $790 \mathrm{~km})$. The longer wave is also a baroclinic first-mode nonlinear vorticity waves propagating with westward phase speed of the nondispersive planetary Rossby waves of same period. They are originated in the ocean interior and we were able to track its signal as far as $5^{\circ} \mathrm{W}$. The 68 -day waves has its existence 
limited to vicinities of the $\mathrm{BC}$. Phase speeds have approximately the $\mathrm{BC}$ axis orientation and they can only be clearly detected between $\sim 27^{\circ} \mathrm{S}$ and $\sim 32^{\circ} \mathrm{S}$. This propagating signal accounts with a variance of $\sim 21 \%$ on the BC axis. Quasi-synoptic observations allowed the mapping of a anticyclone and a cyclone of such waves. They seem to have modal composition very similar to the $\mathrm{BC}$ itself, which might provide additional evidence of local origin.

Keywords: Brazil Current, Subinertial Variability, Vorticity Waves, Nondispersive Line, Santos Bight. 


\section{Resumo}

A Corrente do Brasil (CB) é provavelmente a Corrente de Contorno Oeste (CCO) menos estudada dos oceanos mundiais. A sua estrutura vertical única es faz dela uma CCO diferente em termos de velocidade e transporte. Apesar dos avanços significativos na última década, a variabilidade da $\mathrm{CB}$ na Bacia de Santos (BS, $\left.23^{\circ} \mathrm{S}-28^{\circ} \mathrm{S}\right)$ ainda é pouco conhecida, apesar do papel estratégico da região na matriz energética brasileira. A CB se espessa mudando a sua estrutura vertical e muda sua estrutura dinâmica no domínio da BS. Na região de Cabo Frio $\left(23^{\circ} \mathrm{S}\right)$ a corrente tem cerca de $500 \mathrm{~m}$ de profundidade. Ao sair da BS na região do Cabo de Santa Marta $\left(28^{\circ} \mathrm{S}\right)$ a corrente se estende até cerca de $1300 \mathrm{~m}$. Estas variações na espessura da corrente e consequente diferença no cisalhamento vertical de velocidade ocorrem devido à presença da Corrente Sul Equatorial em nível intermediário na região gerando a Bifurcação de Santos (BiS). Neste trabalho investigamos a variabilidade subinercial da CB na Bacia de Santos usando primeiramente dado alimétrico e um conjunto de análise espectral. Foram depois estudados fenômenos geradores dessa variabilidade com dados quasi-sinóticos do um cruzeiro oceanográfico CERES V do conjunto IOUSP-PETROBRAS. Foram identificados fenômenos diferentes no norte e sul da Bifurcação de Santos e esta diferença é provavelmente devido à presença da bifurcação ou à mudança que esta causa na estrutura da CB. Ao norte da BiS foi identificada uma oscilação com período de 92 dias e comprimento de onda de $490 \mathrm{~km}$ explicando um quinto da variabilidade da $\mathrm{CB}$ em $25^{\circ} \mathrm{S}$. A oscilação de 92 dias está relacionada com ondas de vorticidade não lineares originadas a leste da corrente em $\sim 35^{\circ} \mathrm{W}$ e se propagam zonalmente até ao eixo da corrente. Estas ondas perturbam a corrente originando oscilações com mesmo período e que propagam ao longo do eixo da corrente. Ao sul da $\operatorname{BiS}\left(\sim 27^{\circ} \mathrm{S}\right)$ foram identificados dois máximos no espectro $k-\omega$. Os máximos correspondem a oscilações com período (comprimento de onda) de 68 e 148 dias (397 e $790 \mathrm{~km}$ ). A onda com maior comprimento de onda é também uma onda de vorticidade de primeiro modo baroclínico não linear propagando para oeste com velocidade de fase de ondas de Rossby não dispersivas. Estas 
ondas são originadas no interior da bacia oceânica e seu sinal foi identificado chegando até $5^{\circ} \mathrm{W}$. A onda de 68 dias existe apenas no domínio da CB. Esta onda propaga fase num eixo aproximadamente paralelo à $\mathrm{CB}$ e são detadas de forma clara apenas entre $\sim 27^{\circ} \mathrm{S}$ e $\sim 32^{\circ} \mathrm{S}$. Esta onda explica uma variância da $\mathrm{CB}$ de $\sim 21 \%$ ao longo do seu eixo. Observações quasisinóticas permitiram mapear um anticiclone e um ciclone associado a essa onda. Os vórtices aparentam uma estrutura modal muito semelhante à da corrente.

Descritores: Corrente do Brasil, Variabilidade Subinercial, Ondas de Vorticidades, Linha não dispersiva, Bacia de Santos. 


\section{Chapter 1}

\section{Introduction}

The Brazil Current (BC) is likely to be the least studied among of all the subtropical Western Boundary Currents (WBCs). While only in the last twenty years, a more thorough kinematic picture of its vertical structure along its poleward path has emerged from the literature, its dynamics is very much unknown. The first scientific article discussing possible dynamical mechanisms which would explain its vigorous meandering off Southeast Brazil was published only in 2008 (Silveira et al., 2008). Moreover, most of the knowledge regarding the BC mesoscale variability is restricted to the so-called "two-cape region" $\left(22^{\circ} \mathrm{S}-24^{\circ} \mathrm{S}\right)$, which encompasses Cape São Tomé (CST), the Campos Bight and Cape Frio (CF).

Due to its recent and growing relevance to Brazil's energy backbone, and of course, due to climate change understanding in the South Atlantic, the area corresponding to the Santos Basin (SB) continental margin should be explored in terms of the BC mesoscale variability as well as the associated sources and triggers. The current thesis aims to describe how and at which time scales the $\mathrm{BC}$ meanders within the $23^{\circ} \mathrm{S}-30^{\circ} \mathrm{S}$ latitude range, as well as speculate about the dynamics associated with such variabilities.

This initial chapter is organized as follows. In section 1.1, we overview the literature comprising the BC mean pattern and its connection to the South Atlantic Subtropical Gyre (SASG). In section 1.3, we revise the known mesoscale variability of the $\mathrm{BC}$. We present thesis motivation and hypothesis, and the overall as well as the specific objectives in section 1.4. 


\subsection{Large Scale Circulation}

\subsubsection{Description}

The WBCs, which close the world ocean subtropical gyres, are probably among the most remarkable and studied large-scale features in Physical Oceanography. These currents are described as narrow jets (width of 100-150 km), which flow poleward and serve as ducts for transporting heat and salt from tropical to subtropical latitudes. Therefore, they play an important role in regulating the climate and may influence the weather in such meridional range.

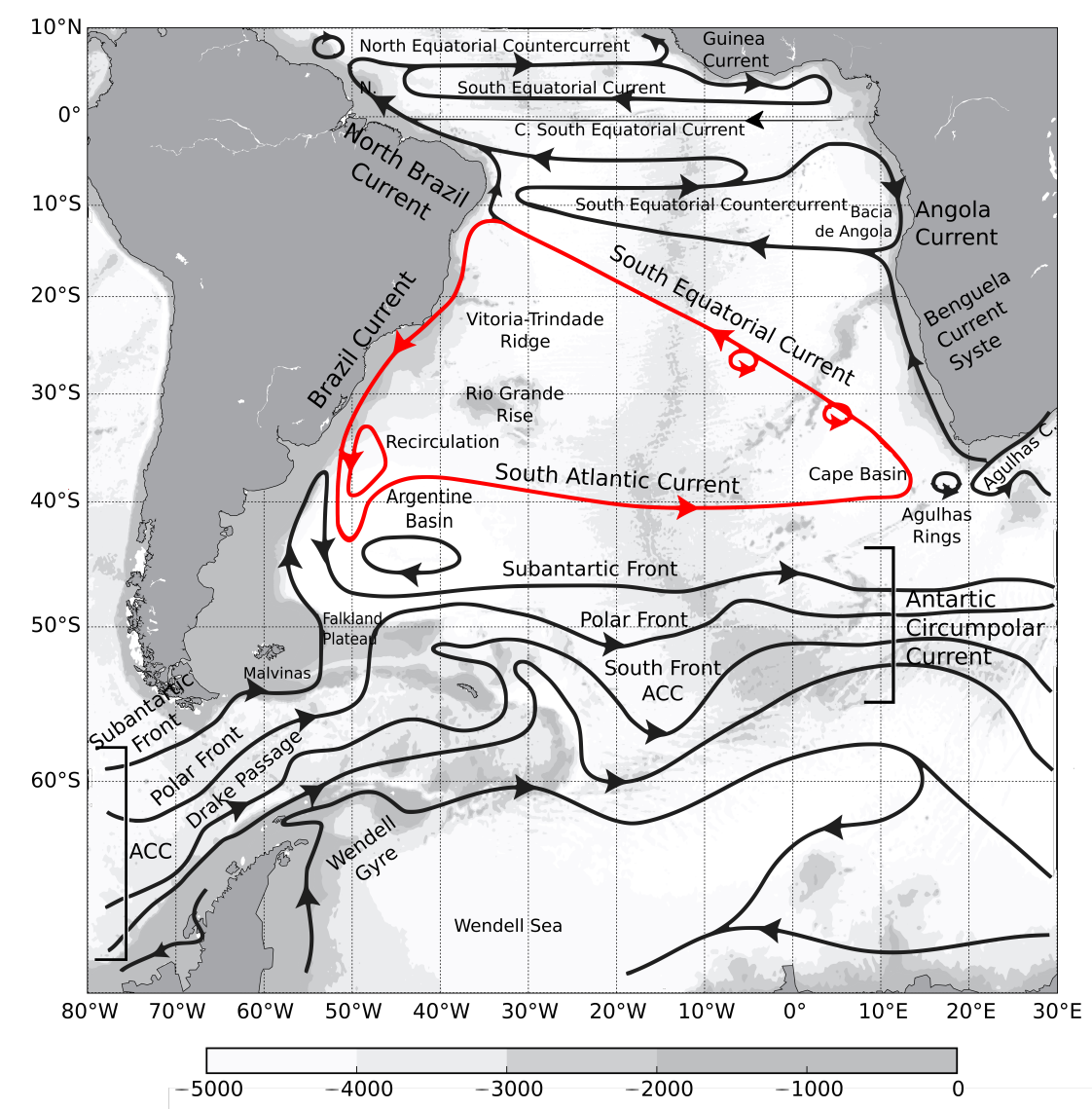

Figure 1.1: Schematics of the surface circulation of the South Atlantic. Black solid lines represent streamlines of the main currents and arrows represent the currents direction. The South Atlantic Subtropical Gyre $\left(\sim 10^{\circ} \mathrm{S}-40^{\circ} \mathrm{S}\right.$, red solid lines $)$ is delimited by the South Equatorial Current (north), the Brazil Current (west) and South Atlantic Current (south). The gray shades indicate the major topographic features on the region. Adapted from Talley et al. (2011).

The BC is the Western Boundary Current (WBC) which closes the SASG (Figure 1.1). Observations have consistently shown the $\mathrm{BC}$ as the weakest and shallowest (averaged over its entire southward path) current compared with other WBCs, such as the Gulf Stream (GS), the Kuroshio Current (KC), the East Australian Current (EAC), and the Agulhas Current (Talley et al., 2011).

The BC structure changes importantly with latitude, as the current thickens and increases its 
volume transport. The thickening of the $\mathrm{BC}$ along its path is due to the unique vertical structure of South Atlantic's South Equatorial Current (SEC). The SEC bifurcates at three different latitudes as it impinges itself on Brazilian continental margin. As consequence of this SEC "stratified" bifurcation structure, the SASG diminishes in meridional extension with depth. The gyre is virtually $30^{\circ}$ wide at surface and only about $12^{\circ}$ at intermediate depths (600-1300 m).

The first (from north to south) of these three bifurcations (Figure 1.2) occurs at $\sim 14^{\circ} \mathrm{S}$ and is responsible for the origin of the BC itself. North of the Vitória-Trindade Ridge (VTR), the BC is basically a mixed-layer, no more than $200 \mathrm{~m}$ thick and transporting $2 \mathrm{~Sv}\left(1 \mathrm{~Sv}=10^{6} \mathrm{~m}^{3} \mathrm{~s}^{-1}\right)$ of Tropical Water (TW) poleward (Soutelino et al., 2011, 2013). The second bifurcation occurs at $\sim 20^{\circ} \mathrm{S}$ and thickens the BC to $500 \mathrm{~m}$ transporting also South Atlantic Central Water (SACW) in addition to TW. Its volume transport can reach 6-10 Sv and a vertical extent (Figure 1.2) which includes the pycnocline (Campos et al., 1995; Silveira et al., 2004). The third and southermost bifurcation is commonly referred in the literature as the Santos Bifurcation (SBi), and occurs at intermediate levels between $25^{\circ} \mathrm{S}$ and $28^{\circ} \mathrm{S}$ (Boebel et al., 1999; Rodrigues et al., 2007; Legeais et al., 2013; Rocha et al., 2014)(Figure 1.3).

This bifurcation decreases the vertical shear changing the $\mathrm{BC}$ from a almost purely baroclinic jet ( $\sim 70 \%$ baroclinic) to a more barotropic ( $~ 56 \%$ barotropic) (Rocha et al., 2014). South of $\mathrm{SBi}$, the $\mathrm{BC}$ is present from the surface and to intermediate levels over the shelf break, continental slope and São Paulo Plateau. It flows poleward transporting TW, SACW, Antarctic Intermediate Water (AAIW) and Upper Circumpolar Deep Water (UCDW) up to more than $18 \mathrm{~Sv}$ (e.g., Zemba, 1991; Stramma and England, 1999; Mémery et al., 2000). Beneath the BC system, there is the Deep Western Boundary Current (DWBC) transports North Atlantic Deep Water (NADW) bordering the Brazilian continental rise and adjacent abyssal plain (e.g., Meinen et al., 2012; Garzoli et al., 2015) (Figure 1.2). 


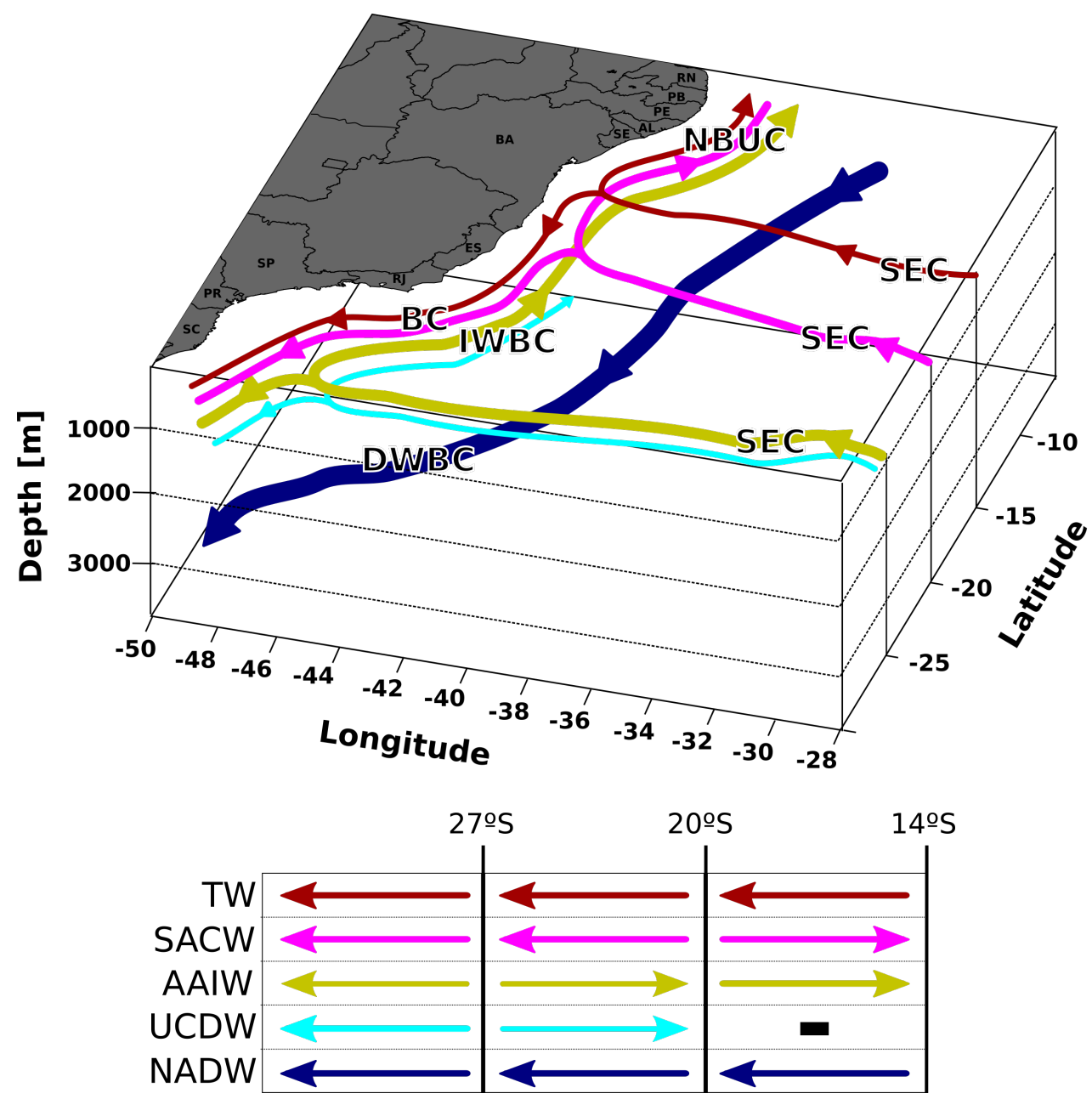

Figure 1.2: The Brazil Current thickening along the Brazilian margin: (A) a three-dimensional sketch of the SEC and BC and the water masses being transported by both flow; (B) diagramatic representation of the three SEC bifurcations, i.e. surface, pycnoclinic and intermediate. The arrows represent poleward flow if pointing to the left or equatorward flow, if pointing to the right. Thicker arrows aim to represent the water mass at which the core of the BC, IWBC, NBUC and DWBC are found.

The $\mathrm{BC}$ separates from the margin at $38^{\circ} \mathrm{S}-40^{\circ} \mathrm{S}$ as it "collides" with the Malvinas Current $(\mathrm{MC})$. Volume transport estimates from the literature are on the 30-46 Sv range poleward (Gordon and Greengrove, 1986; Rodrigues et al., 2010; Rocha et al., 2014; Schmid, 2014). Despite the BC being weaker then the GS, Gordon and Greengrove (1986) identified that the growth rate of the $\mathrm{BC}$ transport along its path $(\sim 5 \%)$ is similar to that of the other WBC.

As all southern hemisphere WBCs, the BC retroflects as it leaves the western boundary (Campos and Olson, 1991; da Silveira et al., 1999). This convoluted way of separating do not yield to a nearly zonal extension to the east of the detachment latitude, as observed in the GS or KC (Figure 1.4). Rather, the $\mathrm{BC}$ wraps itself on a large anticyclonic lobe and a zonally-damped stationary wave pattern develops. The formation of the South Atlantic Current (SAC) occurs only to the west of the retroflection anticyclone. The SAC represents the southern border of the SASG 


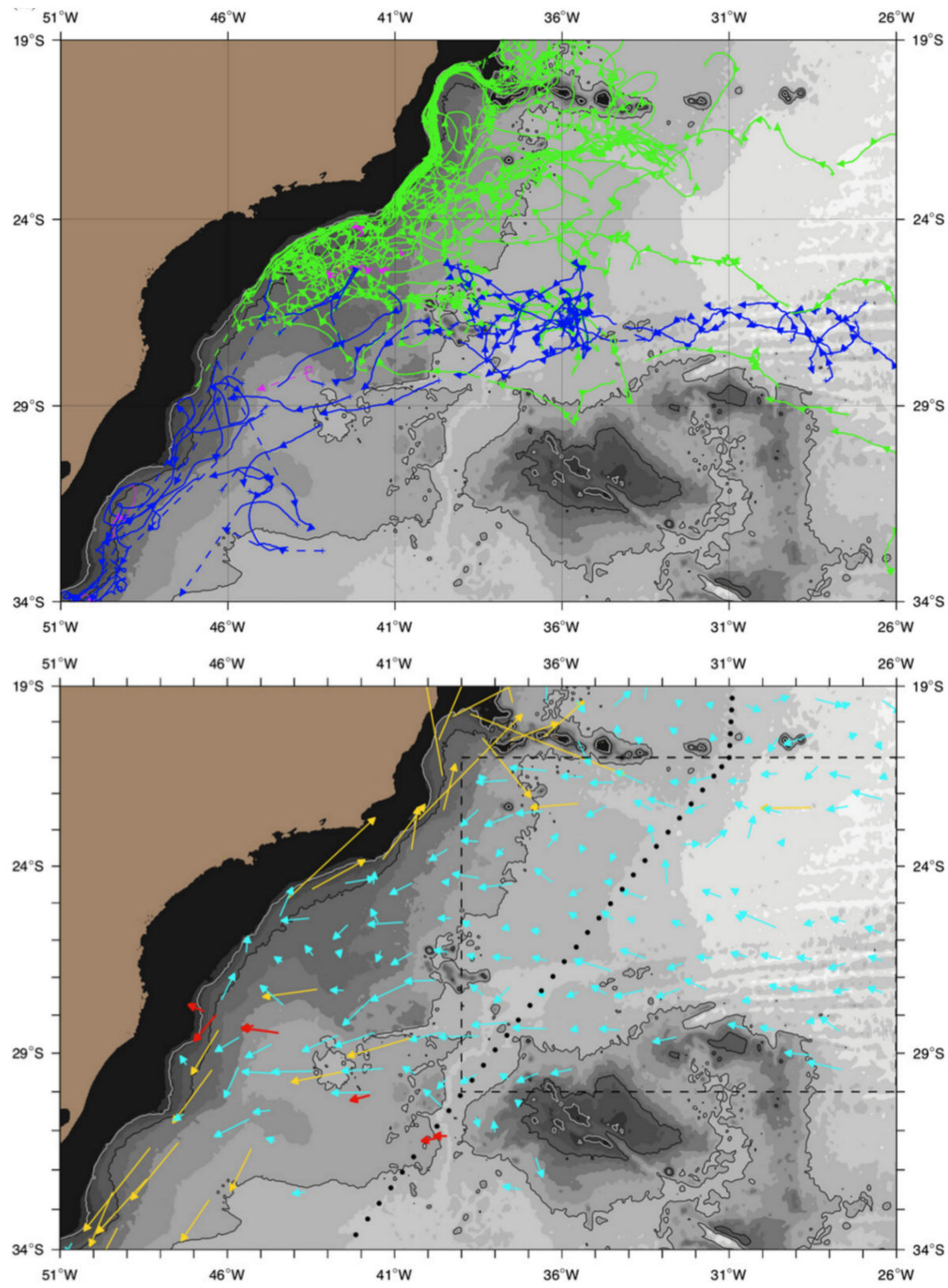

Figure 1.3: The SBi structure as inferred from trajectories of ARGO floats to the SBi: (A): original ARGO trajectories with floats which veered to the north to join the IWBC are marked in green, and the ones which veered south to join the $\mathrm{BC}$ are marked in cyan. The few magenta trajectories correspond to float immersions greater than $1050 \mathrm{dbar}$. (B): Averaged float velocities in $1^{\circ} \times 1^{\circ}$ boxes. Blue arrows are averaged velocities less than $5 \mathrm{~cm} \mathrm{~s}^{-1}$, yellow arrows averaged velocities greater $5 \mathrm{~cm} \mathrm{~s}^{-1}$. According to Legeais et al. (2013).

(see Figure 1.1).

The retroflection lobe can be also interpreted as larger inner Recirculation Cell (RC) centered in $\sim 35^{\circ} \mathrm{S}$. This $\mathrm{RC}$ is elliptical in shape and its northern border can reach as north $32^{\circ} \mathrm{S}$. Its western border forms a counterflow to west of $\sim 53^{\circ} \mathrm{W}$ and which recirculates part of the $\mathrm{BC}$ re-entering the main current at the RC northern tip latitude (Gordon and Greengrove, 1986; Stramma and England, 1999; Vianna et al., 2007; Schmid, 2014). The relative small size of 

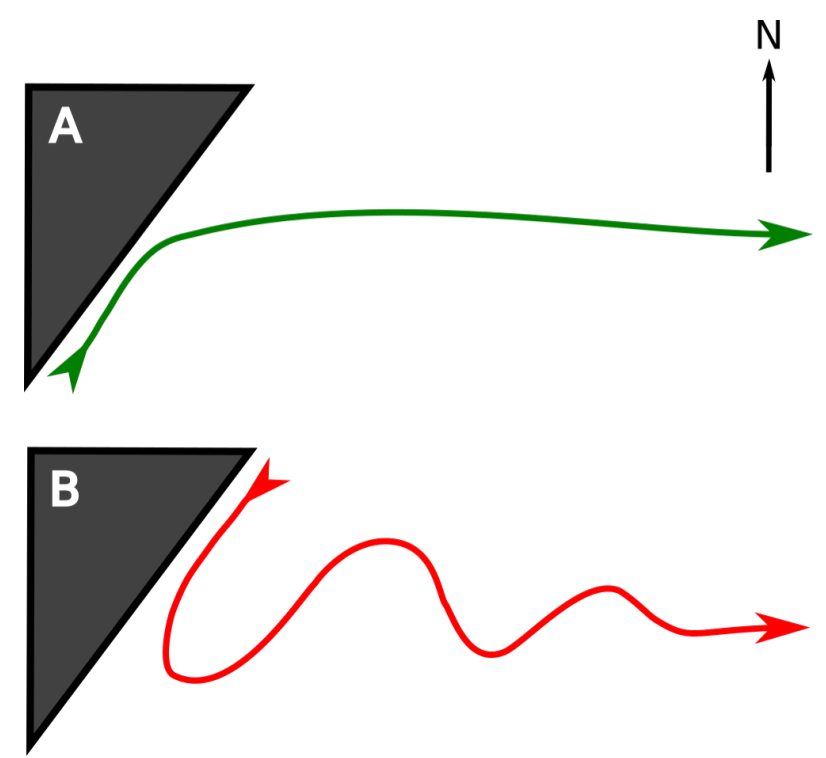

Figure 1.4: Schematic of the two patterns by which WBCs separate from the continental margins: (A) smooth separation and WBC extension formation. (B) reflection with a zonally-damped stationary wave formed. Adapted from da Silveira et al. (1999).

the RC has been attributed to a possible double-subgyre system proposed by Tsuchiya (1985) (from hydrography) and Vianna et al. (2007) (from altimetry and gravimetry): one centered in in $\sim 22^{\circ} \mathrm{S}$ and the other centered in $\sim 32^{\circ} \mathrm{S}$ (Tsuchiya, 1985; Belo, 2011). The RC described here can be thought as the inner recirculation portion of the southern subgyre.

\subsubsection{Forcing}

The WBCs are considered primarily wind-driven and usually extend from the surface to intermediate levels (Pedlosky, 2013). Their generation has been explained by numerous theories, as response to the wind stress and frictional forces (Sverdrup, 1947; Stommel, 1948; Munk, 1950; Hughes and De Cuevas, 2001) or as a result of westward propagating planetary waves (Anderson and Gill, 1975; Young and Rhines, 1982). Focusing on the viscous forcing hypotheses, all WBCs can be thought as the Sverdrup's return current to the wind-driven Sverdrup equatorward flow in the interior (i.e., away from the western boundary layer) of world ocean basins.

However, the simple nature of Sverdrupian return current for the WBCs, which would point the wind stress as the sole driving mechanism can be easily doubted by in situ observations oceanwide. In particular, the meridionally-changing $\mathrm{BC}$ vertical structure presented in the previous subsection illustrates that mass fluxes linked with what today is known as the MOC should be considered as secondary forcing component as well.

Using the Atlantic Ocean as example, observations have shown that the transport of the 
separating GS is at least three times larger than that of the separating BC (Talley et al., 2011). However, there seems to be negligible differences between the strengths of North and South Subtropical High Pressure centers, which supposedly would suffice to explain the WBC generation in both hemisphere. A first explanation for a stronger (weaker) and deeper (shallower) GS (BC) was presented by Stommel (1965). The author proposed that wind-driven and buoyancydriven (or thermohaline) components of the circulation add up (oppose each other) for the GS (BC) (Figure 1.5). The result of the combined forcing, as proposed by Stommel (1965), predicted elegantly the BC between the VTR SEC bifurcation $\left(\sim 20^{\circ} \mathrm{S}\right)$ and the SBi $\left(\sim 25^{\circ} \mathrm{S}\right)$ : a surface boundary current transporting TW near-surface and SACW at pycnocline depths and a counterflow at intermediate levels, the IWBC, transporting AAIW in all its domain and UCDW until it reaches the VTR at about $20^{\circ}$ S (e.g., Stramma and England, 1999; Boebel et al., 1999; Mémery et al., 2000).

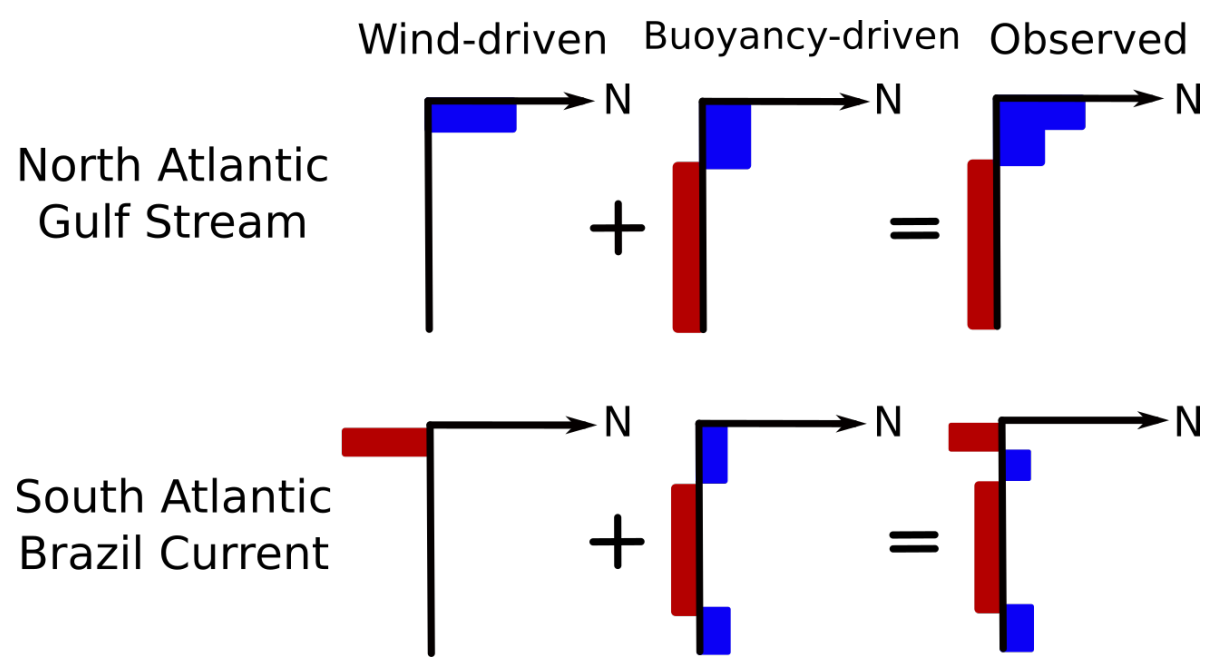

Figure 1.5: Schematics of Stommel's explanation for a weaker and shallowed BC compared to a stronger and deeper GS. The net volume transport budget includes the wind and buoyancy driven flows. blue represents northward flow and red, southward flow. Adapted from Stommel (1965).

The simple thermohaline circulation box model first idealized by Stommel (1961) and used to build the conceptual model presented in Figure 1.5 does not suffice to explain what nowadays is known of the BC vertical structure from its origin to its separation from the margin. It is necessary to add complexity to the Meridional Overturnig Circulation (MOC) and show that different water masses present distinct patterns of density-flux driven flow. Probably the most detailed and complete MOC conceptual model is due to Schmitz (1995). As seen in Figure 1.6, the proposed upper layer (i.e., the vertically averaged surface and pycnocline layers) and the intermediate layer MOC flow patterns, coming from the Indian Ocean, reach the Brazilian conti- 
nental margin at different latitudes and, therefore, weaken the wind-driven $\mathrm{BC}$ unequally in the meridional direction.

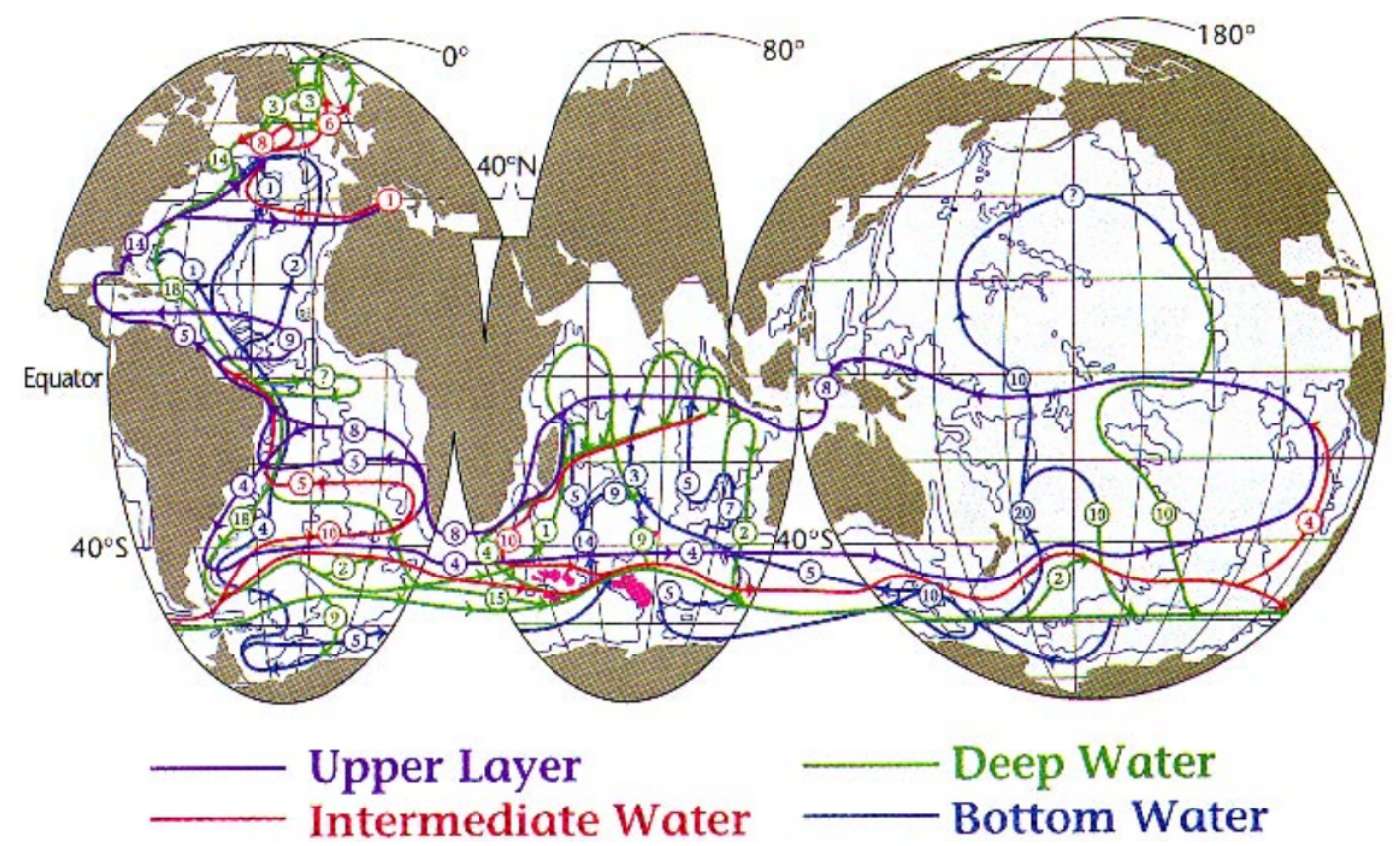

Figure 1.6: The four-layer MOC global configuration proposed by Schmitz (1995).

We can certainly refine the Stommel (1961) for the combined wind and MOC forced BC building upon the ideas of Schmitz (1995). We additionaly split the upper layer in surface and pycnoclinic layers to obtain the "updated" Stommel (1961) conceptual model for the BC vertical structure (Figure 1.7).

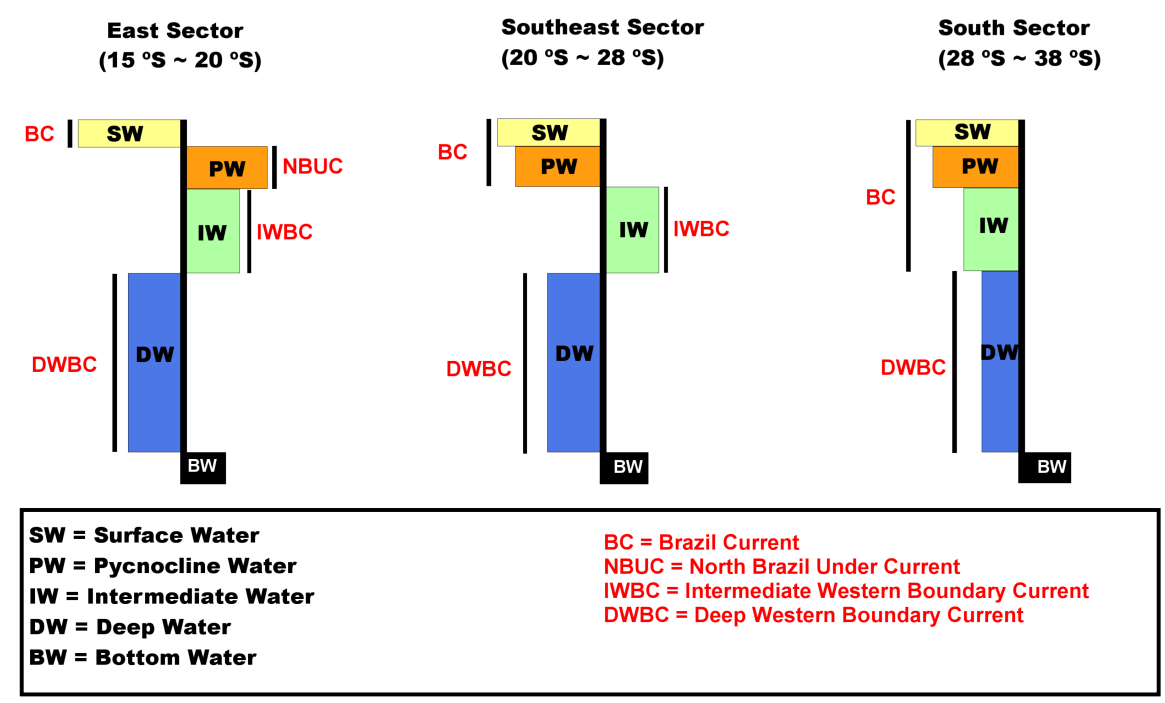

Figure 1.7: The updated Stommel (1961) conceptual model for the BC vertical structure based on combined wind and MOC forcings. 


\subsection{The Study Area}

Our study area (Figure 1.8) comprises the continental margin and abyssal plain adjacent to the $\mathrm{SB}$, which is limited on the north by the CF $\left(22^{\circ}\right)$ and on the south by the Cape Santa Marta (CSM) $\left(28^{\circ}\right)$. In terms of mean flow patterns, the central portion of our investigated area is characterized by the SBi at intermediate levels, and which sets the IWBC origin site within our area. Therefore, the IWBC flows northward opposing a 600m-thick BC flowing southward on the northern half of the area, while a 1300m-thick BC flows southward on the southern half of our domain. The DWBC supposedly flows south entire the whole domain (Meinen et al., 2012; Garzoli et al., 2015).

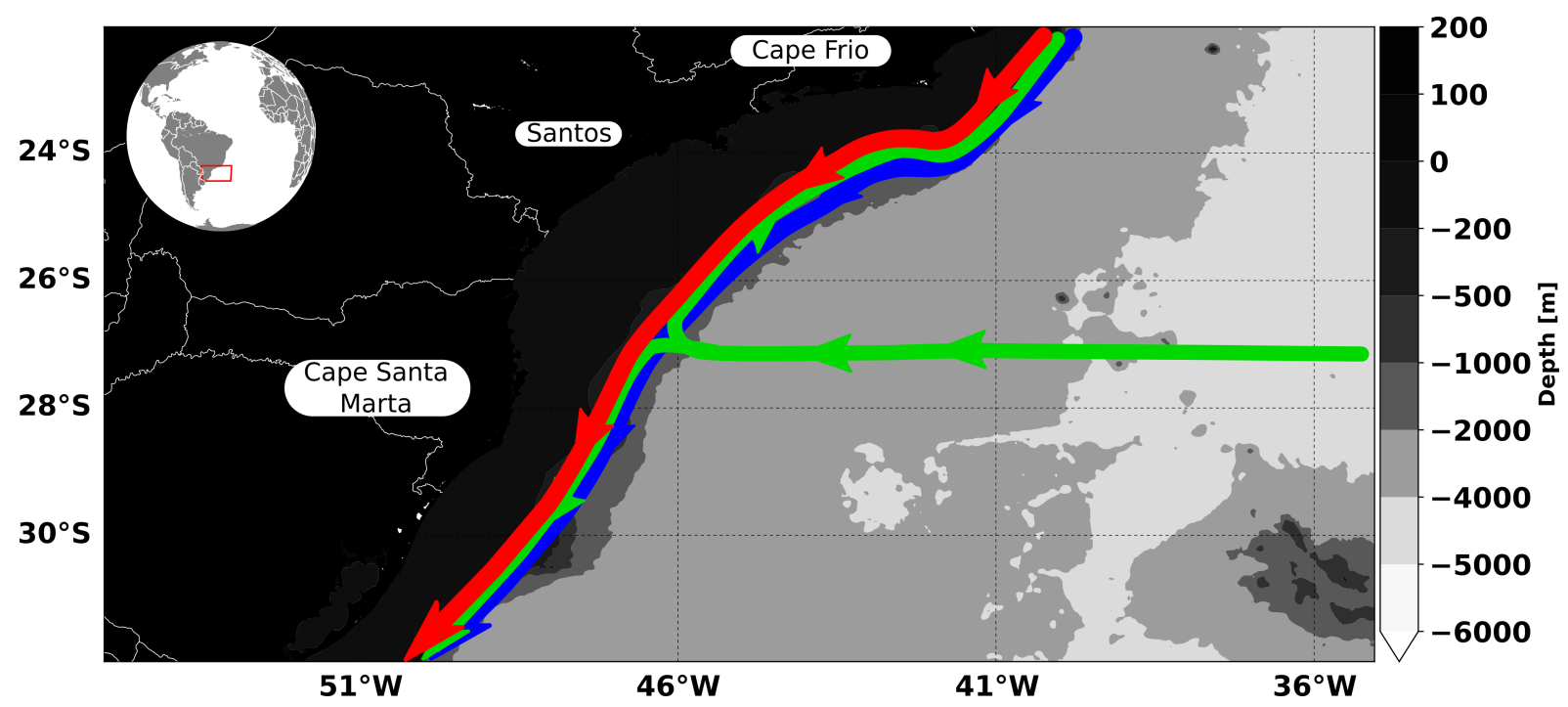

Figure 1.8: The study area geographical limits and a schematic representation of mean large scale circulation within. The arrow colors represent distinct water masses being transported by the flow regime: TW-SACW (red), AAIW-UCDW (green) and NADW (blue). Gray shades indicate the major topographic features on the region.

The study area geomorphology deserves to be highlighted. The continental margin off $\mathrm{CF}$ abruptly changes from a nearly north-south orientation to a northeast-southwest orientation. At southern end of the SB, in the vicinities of CSM, the continental margin orientation veers again and acquires a more north-south display. These changes in margin orientation and in the subsequent $\mathrm{BC}$ axis positions impose some relevant dynamical constraints in mesoscale activity within this region and which will be addressed next. 


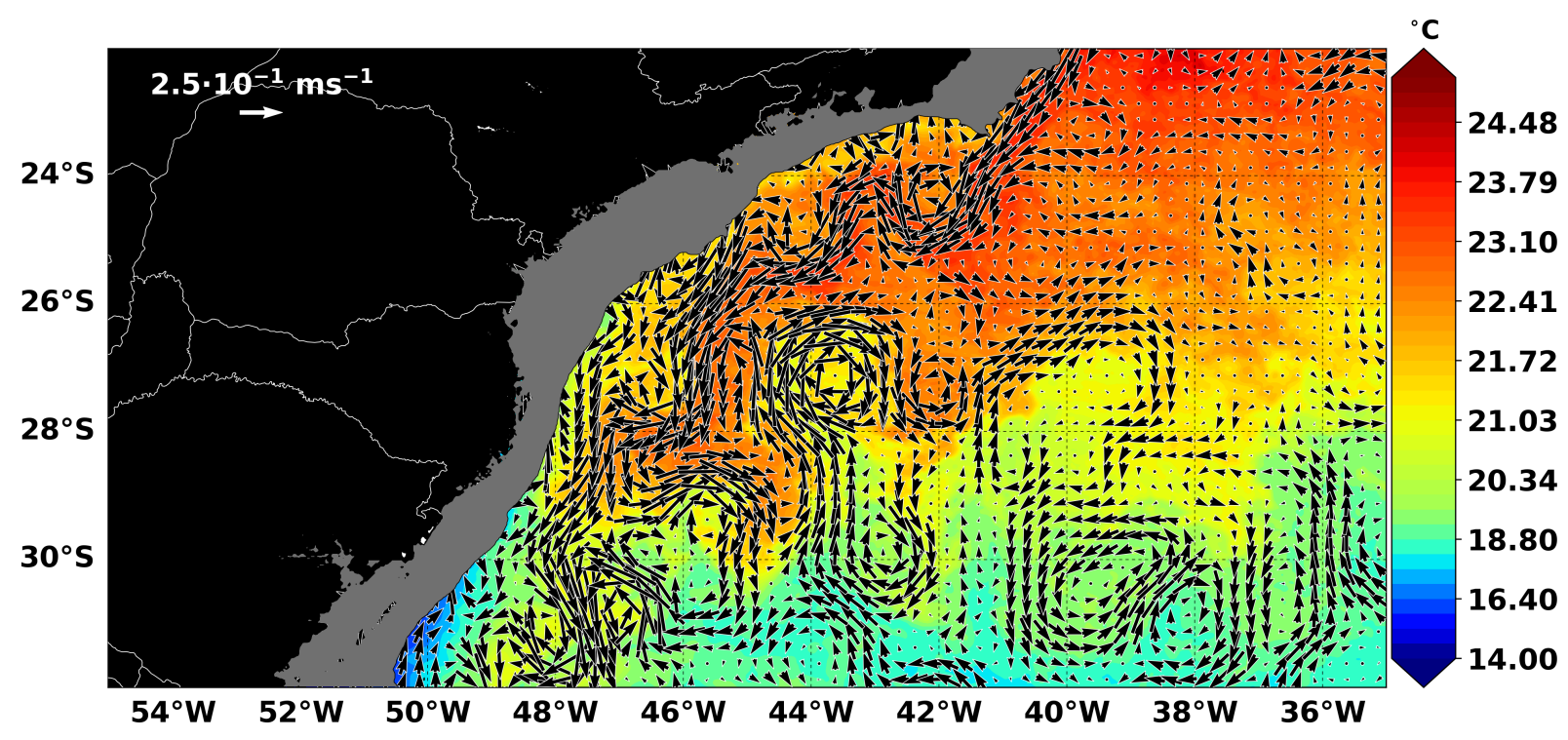

Figure 1.9: SST field for the SB at 14/08/2005 with the BC meandering from CST to CSM. Data from level 4 Multiscale Ultrahigh Resolution (MUR) of the Group for High Resolution Sea Surface Temperature (GHRSST) analysis provided by NASA. Quiver of geostrophic velocity from AVISO to the same day.

\subsection{The BC mesoscale variability}

Besides its complex and unique meridionally-changing vertical structure, the $\mathrm{BC}$ develops vigorous and rich mesoscale phenomena within out study region. We mean here by mesoscale activity the occurrence of mesoscale meanders, eddies and rings of typically hundreds of kilometers in length and of weeks to months in time. These kind of features have been reported by several authors along all the BC path (e.g., Garfield, 1990; Campos et al., 1995; Schmid et al., 1995; Silveira et al., 2008; Oliveira et al., 2009; Soutelino et al., 2013)(Figure 1.9). The BC meandering in the SB has been described with hydrographic data, satellite data and numerical modeling (Campos et al., 1995, 1996; Calado et al., 2008; Lorenzzetti et al., 2009). The relevance of the mesoscale phenomena to the regional biological system should be emphasized (Campos et al., 2000; Calado et al., 2010), as well as their importance to the operation of oil rigs and oil-gas exploitation in the pre-salt reservoirs.

The BC mesoscale dynamics only very recently started to be addressed (Silveira et al., 2008; Mano et al., 2009; Rocha et al., 2014; Biló, 2015). Silveira et al. (2008) were the first to focus on the dynamical mechanisms responsible for generating the finite-amplitude meandering and ring-shedding off the two-cape region. The authors used a current meter mooring at $22.7^{\circ} \mathrm{S}$ and dynamical mode decomposition to characterize the mean current as an essentially baroclinic jet due to the system BC-IWBC. The first dynamical mode structure detected by the authors were due to intense velocity vertical shear associated with the opposing jets. Using a quasi- 
geostrophic (QG) analytical model, Silveira et al. (2008) showed that baroclinic instability was the primary mechanism for meander growth and found the most unstable waves with growth rates of about 0.06 days $^{-1}$, wavelength about $266 \mathrm{~km}$ and virtually zero phase speeds (quasistationary waves).

In the attempt of further understand how the BC-IWBC system generates these unstable waves in SB, Fernandes et al. (2009) used and idealized two-layer shallow water numerical model. They generated the horizontal velocity profiles of the local currents as two opposing Gaussianshaped jets over a realistic bathymetry of the region. The authors obtained weakly unstable waves, $\sim 0.02$ day $^{-1}$ growth rate, with $430 \mathrm{~km}$ and phase speed $\sim-0.2 \mathrm{~m} \mathrm{~s}^{-1}$. These waves growth in amplitude between $20^{\circ} \mathrm{S}-25^{\circ} \mathrm{S}$ but decrease far south of $25^{\circ} \mathrm{S}$ (Figure 1.10). Their results showed the most unstable waves propagating poleward, contrarily to those found by Silveira et al. (2008). The difference on the steering levels is probably mainly due to the simplified vertical structure in two layers.

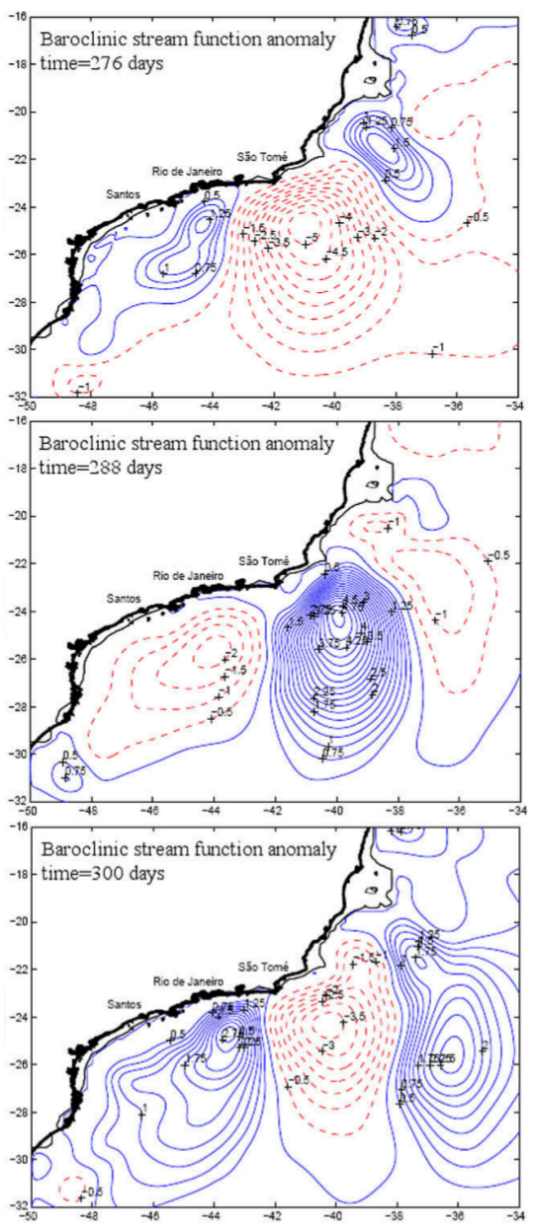

Figure 1.10: Instability wave propagation within the SBi as identified by Fernandes et al. (2009). 

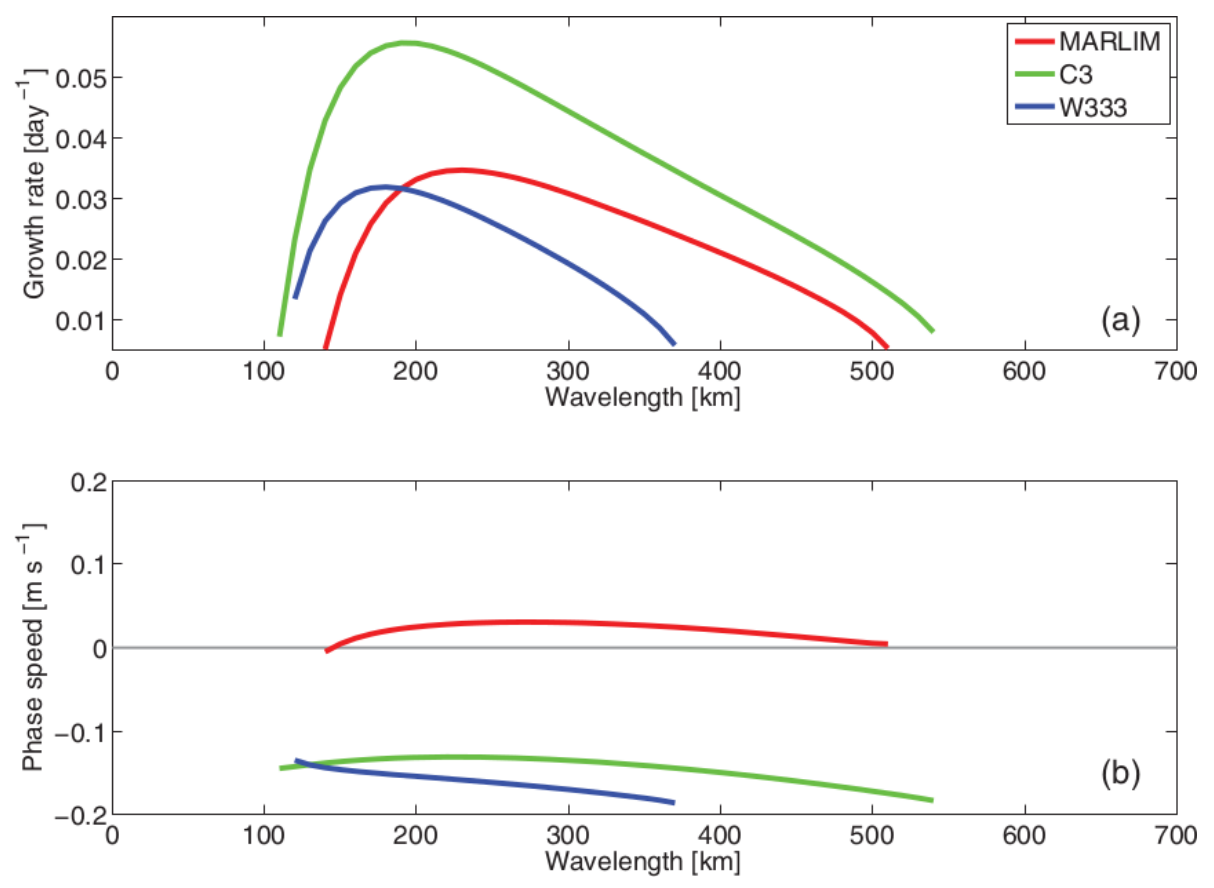

Figure 1.11: Linear baroclinic instability phase speed and growth for for MARLIM, C3, and W333 moorings: (A) growth rate and (B) phase speed. Source: Rocha et al. (2014)

Rocha et al. (2014) pursued the understanding of the baroclinic instability on different BC vertical structures north and south of the SBi employing four current meter mooring lines along the current axis. The authors used a similar analytical approach to that used by Silveira et al. (2008) and found at $22.7^{\circ} \mathrm{S}$ unstable quasi-stationary waves just as Silveira et al. (2008) did. Contrarily to the waves found at $22.7^{\circ}$, the waves at $25^{\circ}$ and $28^{\circ}$ presented significant phase propagation towards south (Figure 1.11). These authors identified the most unstable waves to be shorter than those described by Fernandes et al. (2009) but with similar poleward phase speed.

More recently, Biló (2015) studied the meandering of the $\mathrm{BC}$ at $23^{\circ} \mathrm{S}-30^{\circ} \mathrm{S}$ and found that despite the baroclinic instability be responsible for draining the greatest part of the mean state kinetic energy, the most unstable perturbations are linked to barotropic instabilities. Using a linear primitive equation (PE) model, the author found waves with higher growth rate than of those found by Rocha et al. (2014), but similar phase speed, being $-0.19,-0.24$ and $-0.26 \mathrm{~m}$ $\mathrm{S}^{-1}$ at $24^{\circ} \mathrm{S}, 26^{\circ} \mathrm{S}$ and $30^{\circ} \mathrm{S}$. The author also detected evidence of cyclonic meanders at $\sim 28^{\circ} \mathrm{S}$ using satellite SST and chlorophyll-a data. The author estimated from satellite thermal imagery the occurrence of 5 to 6 events per year of wave patterns with $\sim 219 \mathrm{~km}$ of wavelength. Yet the authors did not provide any insight regarding the dynamics of these cyclones and subsequent anticyclones. Nonetheless, they account for almost $55 \%$ of the BC subinertial variability in the 
region.

The studies listed above have studied the meandering of the $\mathrm{BC}$ and linked its possible driving mechanisms to the structure of the $\mathrm{BC}$ velocity shear and potential vorticity. All the authors have investigated the $\mathrm{BC}$ mesoscale variability as a response to local perturbations in the potential vorticity (PV) field either associated with topographic forcing or volume transport fluctuations. Therefore the possibility of remote sources perturbing the BC mean state has not been addressed so far. These perturbations can appear as a result of westward propagating features such as dispersive baroclinic planetary waves (Johns et al., 1990), the westward propagating Agulhas rings (Guerra, 2011; Azevedo et al., 2012) and nonlinear eddies or waves (Chelton et al., 2011) impinging on the $\mathrm{BC}$.

Additionally, the investigation of the $\mathrm{BC}$ dynamics regionally in the SB is restricted to Oliveira et al. (2009) and Biló (2015). The former author used surface drifter data and the latter, thermal imagery and hydrographic survey data. However, nowadays altimetry data has increased its global coverage and have a spatial resolution that resolves wavelength of instability-like waves Chaigneau et al. (2008). This quasi-synoptic dataset creates the opportunity of studying the BC mesoscale variability in larger domains such as this thesis study area.

\subsection{Thesis Hypothesis and Objectives}

\subsubsection{Hypothesis}

To date the BC variability within the SB has been only linked to either baroclinic or barotropic instability processes and triggered by continental margin changes in orientation (Rocha et al., 2014; Biló, 2015). Even tough the topographic forcing might account for part of the BC meandering, no study has examined so far the current variability caused by PV remote sources.

There have been studies recently showing the importance of westward propagating nonlinear cyclonic and anticyclonic eddies (Chelton et al., 2011). More recently, Polito and Sato (2015) proposed the co-existence of linear Rossby waves and nonlinear eddies and that eddies ride the waves with both features propagating westward. The nonlinear eddy-planetary wave system could transport a considerable amount of energy and enstrophy that could perturb in the BC mean field importantly.

Considering this knowledge gap on how the westward propagating features induce (or not) mesoscale variability in the $\mathrm{BC}$, we aim to test the following hypothesis in this thesis: 
"The Brazil Current presents a relevant subinertial variability within the Santos Bight forced remotely by perturbations caused by westward propagating structures from the interior of the South Atlantic basin.".

\subsubsection{Objectives}

The general objective of this thesis is to investigate the remote forcing of the $\mathrm{BC}$ meandering within the SB. In order to reach this overall goal, the following specific objectives will be sought:

- To characterize the spectral properties of the main variability features of the $\mathrm{BC}$;

- To characterize the origin and propagating direction of the perturbation sources;

- To quantify the variance of the remotes sources inducing perturbations on the BC jet relative to the total variance of the current system; and

- To characterize the vertical structure and velocities of the perturbations.

This thesis is organized as follows. In chapter 2 we address the variability of the $\mathrm{BC}$ using its surface signal measured from satellite altimetry remote observations. In chapter 3 we seek to identify the features detected in the satellite data on in situ observational data from a hydrographic cruise. In chapter 4, we summarize and conclude our findings. Furthermore this thesis ends with recommended future work relating our findings and issues raised which are beyond our work scopus. 


\section{Chapter 2}

\section{Mesoscale Variability from Satellite}

\section{Altimetry}

In this chapter, we study the mesoscale variability of the $\mathrm{BC}$ within the SB seeking for remote sources of perturbation of the BC axis. Nevertheless, we also search for local perturbation sources, which are probably related to either topographic forcing or jet transport fluctuations. However, we first must look for the dominant wave periods and wave lengths associated with the meandering phenomena. Altimetry data is chosen to resolve the $\mathrm{BC}$ front and its deviations, and to conduct our analyses. We are fully aware that the capability of resolving fast and/or short duration phenomena is lost but, on the other hand, we do not have data gaps to deal with due to unfavorable atmospheric conditions (i.e. cloud coverage), such as in infrared based SST satellite data .

\subsection{Datasets}

\subsubsection{Altimetry}

The altimetry time series extends from the beginning of 1994 to the end of 2015 . The series consists of a level 4 Absolute Dynamic Topography (ADT) global field, obtained from a multisatellite coverage (TOPEX/Poseidon, Jason-1, Jason-2, ERS-1, ERS-2 e EnviSat). This image composite series used two type satellite coverage, the European satellites (ERS-1, ERS-2 e EnviSat) with $\sim 35$-day cycle and closer distance between tracks of $\sim 85 \mathrm{~km}$ at the equator and the Americans (TOPEX, Jason-1 e Jason-2) with a $\sim 10$-day cycle, but $\sim 315 \mathrm{~km}$ along-track 
distance. The data set built by encompassing all satellite measurements is interpolated from only two satellites, one European and one American, to keep the statistical accuracy. The twosatellite data is interpolated to a daily and regular cartesian grid of $0.25^{\circ} \times 0.25^{\circ}$ by Ssalto/Duacs 1 and provided by $\mathrm{AVISO}^{2}$.

The AVISO final products are expressed as ADT and SLA. The dynamic topography and the sea level deviations are related to each other by the hydrostatic equation:

$$
\eta(x, y, t)=\frac{\Delta \Phi(x, y, t)}{g}
$$

where $\eta$ is the SLA [in $\mathrm{m}$ ] $\Delta \Phi$ is the geopotential anomaly [in $\mathrm{m}^{2} \mathrm{~s}^{-2}$ ] at surface level, and $g$, the effective gravity. We opt to employ the SLA throughout this work following the AVISO site documentation and will use the terminology dynamical topography and sea level anomalies interchangeably in the text. The data used, ADT, can be thought as the sum between a mean state and its associated perturbations,

$$
\eta_{a}(x, y, t)=\bar{\eta}(x, y)+\eta(x, y, t)
$$

being the $\bar{\eta}(x, y)$ the temporal mean dynamic topography, and $\eta$ its perturbations.

AVISO provides besides ADT $\left(\eta_{a}\right)$ data, a mean state (MDT) $(\bar{\eta})$ field. The latest MDT version was released in April 2014, and it was calculated with 20 years of data from 1993 to 2012. This recent $\bar{\eta}$ field better estimates the mean state of the ocean compared to the previous one (1993-1999), including long-term oscillations and accurate trend estimate of the sea level. The background dynamic topography computed from conventional hydrography and float profiling was calculated relative $1500 \mathrm{~m}$. The most recent ADT was also obtained keeping the spatial filter constant in all grid points with a low pass filter that cut off wavelengths shorter than $65 \mathrm{~km}$ for the whole globe (SSALTO/Duacs, 2014).

As the MDT provided by AVISO is a mean estimated with data until 2012, we needed to correct it using the remainder three year of altimetry data (from 2012-2015), and only after the correction applied, we calculated the SLA using Equation 2.2. Figure 2.1 show the comparison between the original and the corrected MDT as well as difference between both. It is observable that the features in the mean field -as expected - are identical, the position of the $\mathrm{BC}$ axis is the same but the values of the MDT based on the time mean of the ADT set presents an overall higher surface height. We speculate that the differences in height are due to the sea level rise trend.

\footnotetext{
${ }^{1}$ Segment Sol multimissions d' ALTimétrie, d'Orbitographie et de localisation/Data Unification and Altimeter Combination System

${ }^{2}$ Archiving, Validation and Interpretation of Satellite Ocean data
} 

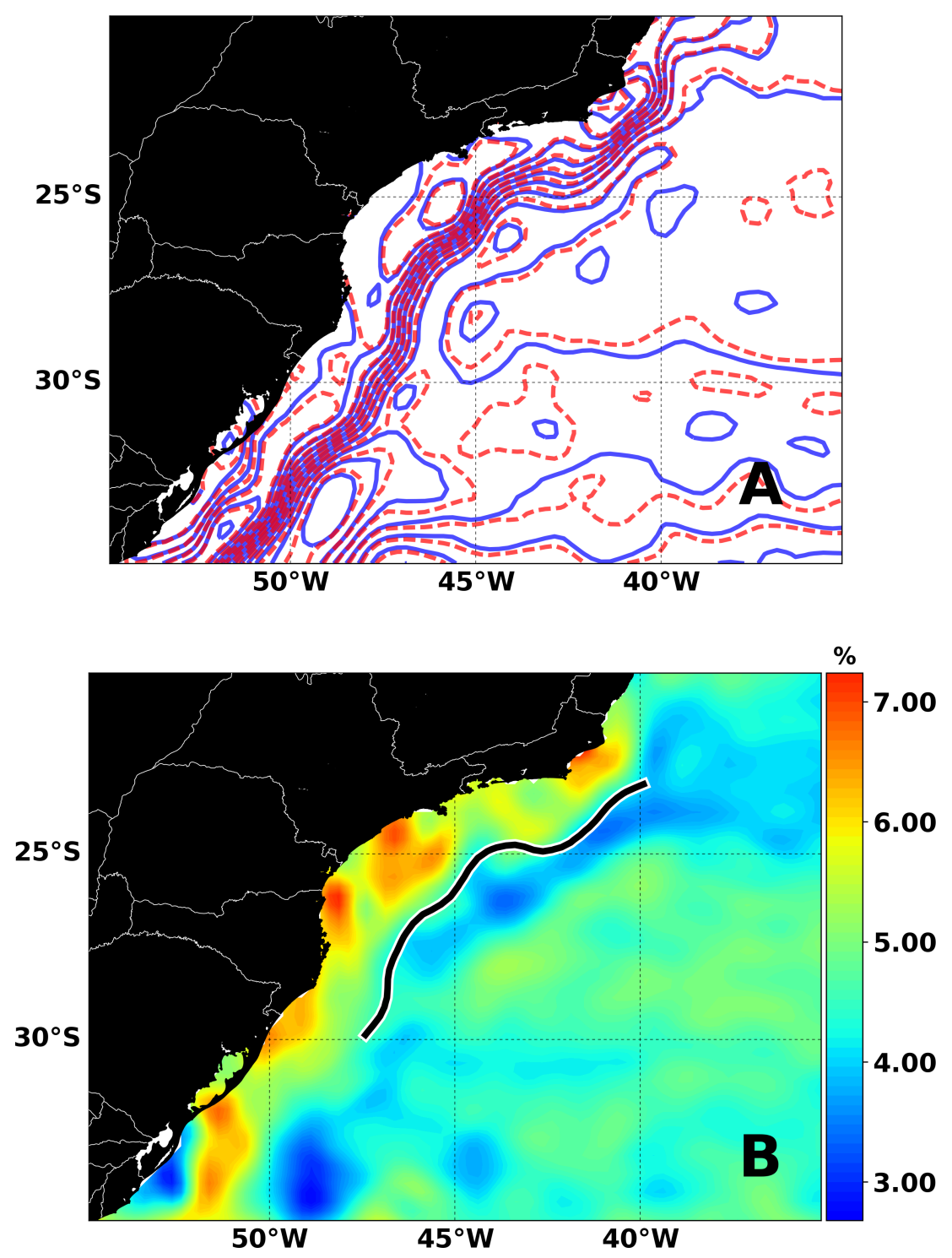

Figure 2.1: Comparison between the original AVISO MDT and the corrected MDT used in this work. (A): blue solid contours the $\bar{\eta}$ provided by AVISO and the red dashed contours the $\bar{\eta}$ calculated from the 22 years data. (B): the percentage of increasing of the $\bar{\eta}$ compared with AVISO provided MDT, black solid line the BC mean position in calculated $\bar{\eta}$.

\subsubsection{Climatological hydrographic data}

It was used to calculate the Brunt-Väisälä frequency three-dimensional climatological fields of temperature (Locarnini et al., 2013) and salinity (Zweng et al., 2013) from World Ocean Atlas 13 (WOA13). This dataset comprehends 57 year of hydrographic data interpolated with objective analysis to a $0.25^{\circ} \times 0.25^{\circ}$ Cartesian grid with 102 depth levels. The Brunt-Väisälä climatological profile was calculated in one area in the basin interior (yellow box in Figure 2.2). 


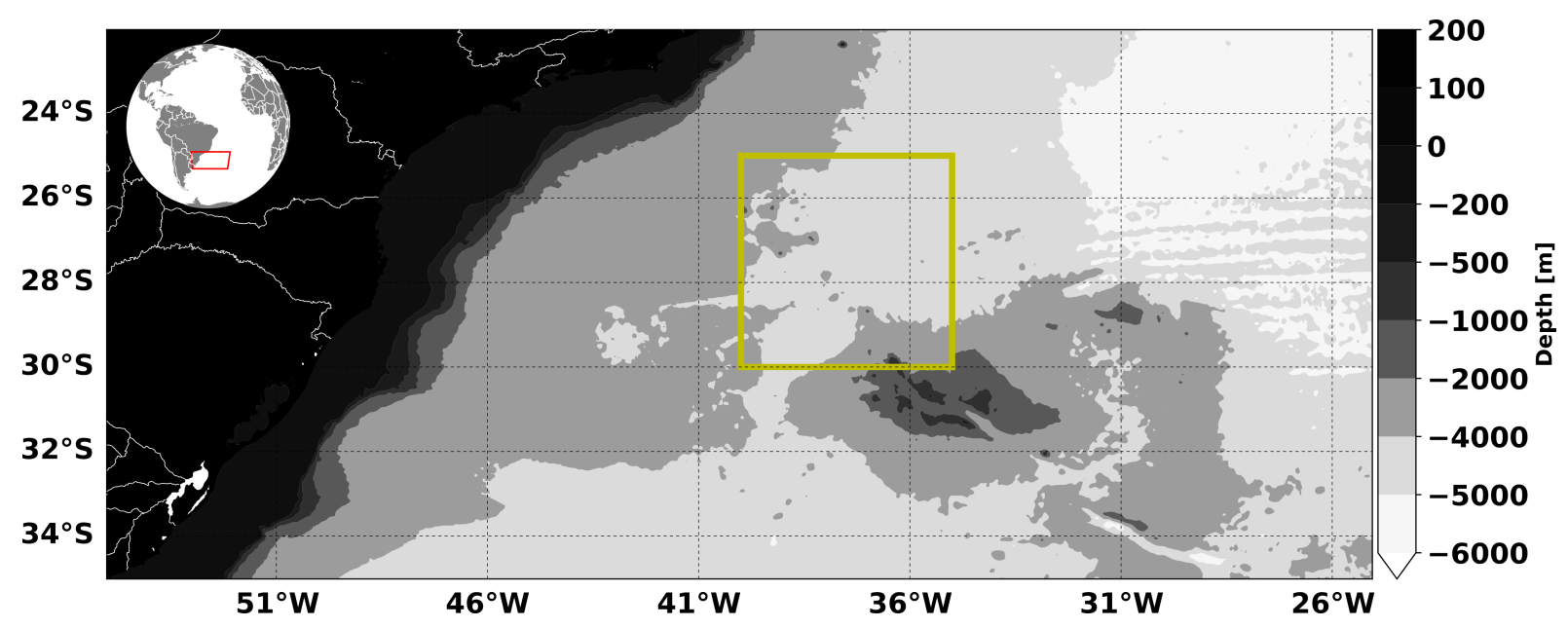

Figure 2.2: Study area, yellow box the region used to calculate the climatological Brunt-Väisälä profile. Gray shades indicate the major topographic features on the region.

\subsection{Methods}

\subsubsection{Annual signal removal}

To remove the annual signal and the seasonal oscillation of the data, we assumed that this annual signal behaves as a sinusoidal function. Then, we can approximate to each data point a function $Y(t)$, defined as

$$
\begin{gathered}
Y(t)=A \sin \left(2 \pi \frac{t}{T_{a}}\right)+B \cos \left(2 \pi \frac{t}{T_{a}}\right), \\
T_{a}=365,
\end{gathered}
$$

with $T_{a}$ and $t$ units in days. After, the equation was adjusted to the data time series minimizing root-mean-square error between data and $Y(t)$ (Figure 2.3). Having this sinusoidal function to seasonal signal then the resultant signal results simply as the subtraction between the data and the seasonal adjusted signal. Being the SLA data at one data point $\left(x_{0}, y_{0}\right)$ and all time series $S L A\left(x_{0}, y_{0}, t\right)$, the data without the seasonal component will be $N\left(x_{0}, y_{0}, t\right)=S L A\left(x_{0}, y_{0}, t\right)-$ $Y(t)$. 


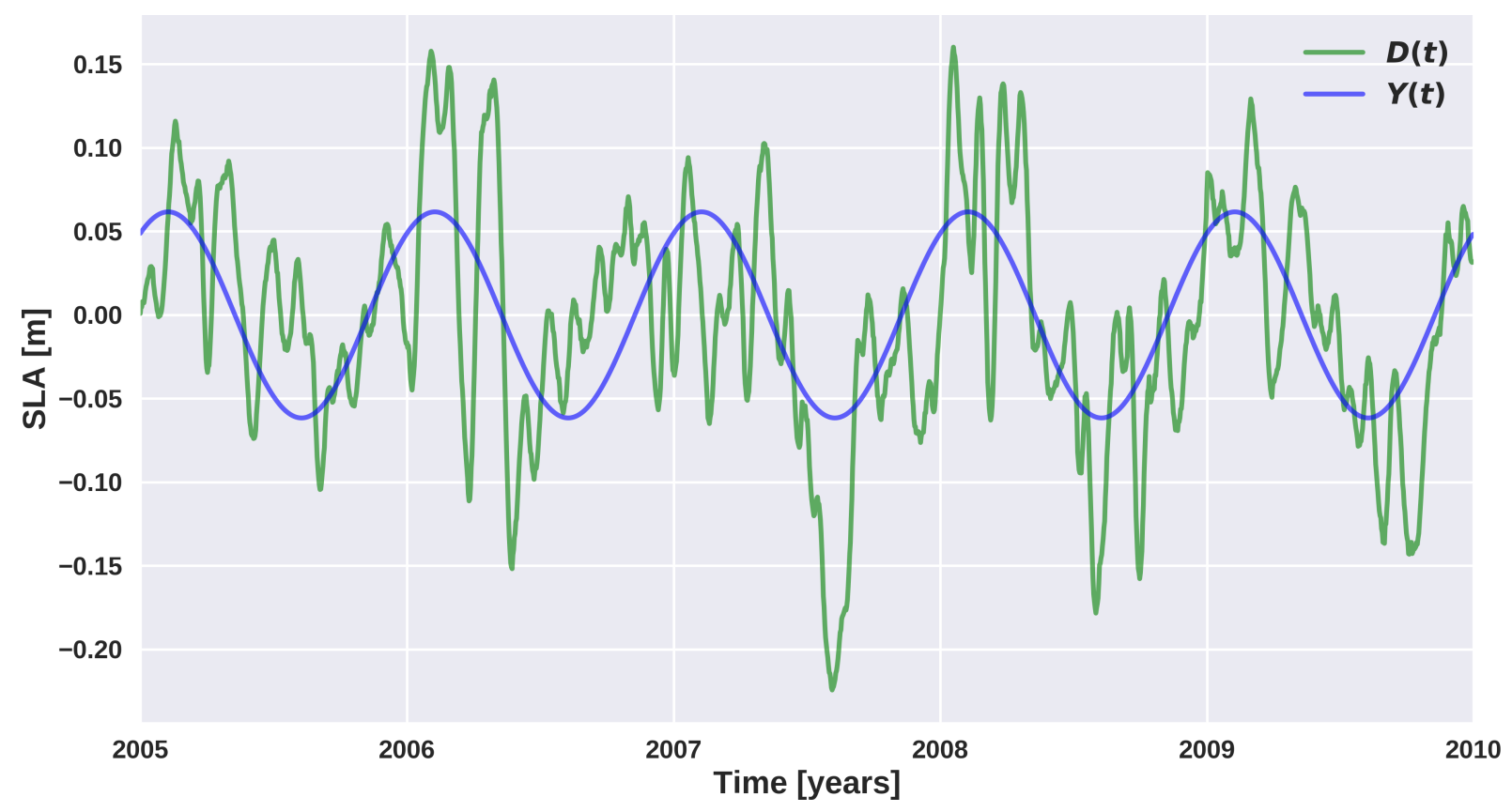

Figure 2.3: Example of annual signal adjustment for 5 years of data at one point in $\mathrm{x}$-axis of the Hovmöller diagram. Green line $D(t)$ is the SLA signal and blue line $Y(t)$ the adjusted seasonal signal.

\subsubsection{Fast Fourier Transform}

The FFT technique is a computational algorithm to compute discrete Fourier Transform, a mathematical technique that decomposes a signal in its multiple complex harmonics. By doing so, one can convert a signal from its original time | space domain to a representation in the wavenumber | frequency domain. In this work we used two types of FFT, the two dimensional Fast Fourier Transform (FFT2D) and the one dimensional FFT.

The FFT2D is a two dimensional approach when the original signal is converted from a timespace domain to a wavenumber-frequency domain. This spectral technique gives as result a wavenumber-frequency $(k-\omega)$ energy spectrum. In the present study we used this technique to determine the two spectral properties of the studied phenomena, wavenumber and frequency.

\section{Frequency determination}

To identify the periods of the main variability phenomena we used the FFT2D of the autocorrelation matrix of the data. The autocorrelation of the data removes random noisy signals without losing the important spectral information. The main frequencies were identified by applying a bandpass filter to the $k-\omega$ spectrum of the autocorrelation with the following criteria:

1. Negative wavenumber and positive frequency, to select only south propagation features; 
2. Frequency higher than $0.0349 \mathrm{day}^{-1}$, separation between mesoscale and large-scale;

3. Frequency lower than $0.3141 \mathrm{day}^{-1}$, nyquist frequency of data aquisition;

4. Wavenumber higher than nyquist wavenumber to remove non-propagating features;

5. Wavenumber lower than $0.0896 \mathrm{~km}^{-1}$, the mesoscale detection limit using AVISO data (Chaigneau et al., 2008).

Having only the portion of the spectrum considered with this criteria we did a mean spectral power with all wavenumber to each frequency. Therefore we calculate which is the mean energy at every frequency considering all wavenumber inside the bandpass filter. This gives the peak of frequency that are more important disregarding the wavenumber.

\section{Wavenumber determination}

To determine the wavenumber we considered each period maxima separately. We performed the FFT2D of the data and to each period $(T)$ we used a bandpass filter with a range of $T$ of $\pm 10 \%$. This filter, for any given $\mathrm{T}$, considered the follow criteria:

1. Negative wavenumber and positive frequency, to select only south propagation features;

2. Frequency higher than $\frac{2 \pi}{1.1 T}$ day $^{-1}$;

3. Frequency lower than $\frac{2 \pi}{0.9 T}$ day $^{-1}$;

4. Wavenumber higher than nyquist wavenumber to remove non-propagating features;

5. Wavenumber lowerer than $0.0896 \mathrm{~km}^{-1}$, the mesoscale detection limit using AVISO data (Chaigneau et al., 2008).

Having the filtered spectrum we calculated the mean power spectral of every wavenumber. This results in a one dimensional wavenumber spectra with higher values of energy in the most important wavenumbers linked to period $T$.

\section{One dimensional FFT}

To calculations used in the present study (i.e., correlation field) we needed the three dimensional $\eta$ data filtered in the time domain. Therefore we also used in this work the one 
dimensional FFT. In order to do that we used the FFT to transform a array of $\eta$ from the time domain to the period domain. To the period spectrum we applied a bandpass filter in the period domain centered in the target period $T$ with a range of $\pm 10 \%$ (Figure 2.4). After determining the band of period we used the inverse FFT to reconstruct the data with phenomena only in the time range of interest.

With the three dimensional $S L A(x, y, t)$ field, for each point in space, the time series of SLA was filtered with the one dimensional FFT as already explained.
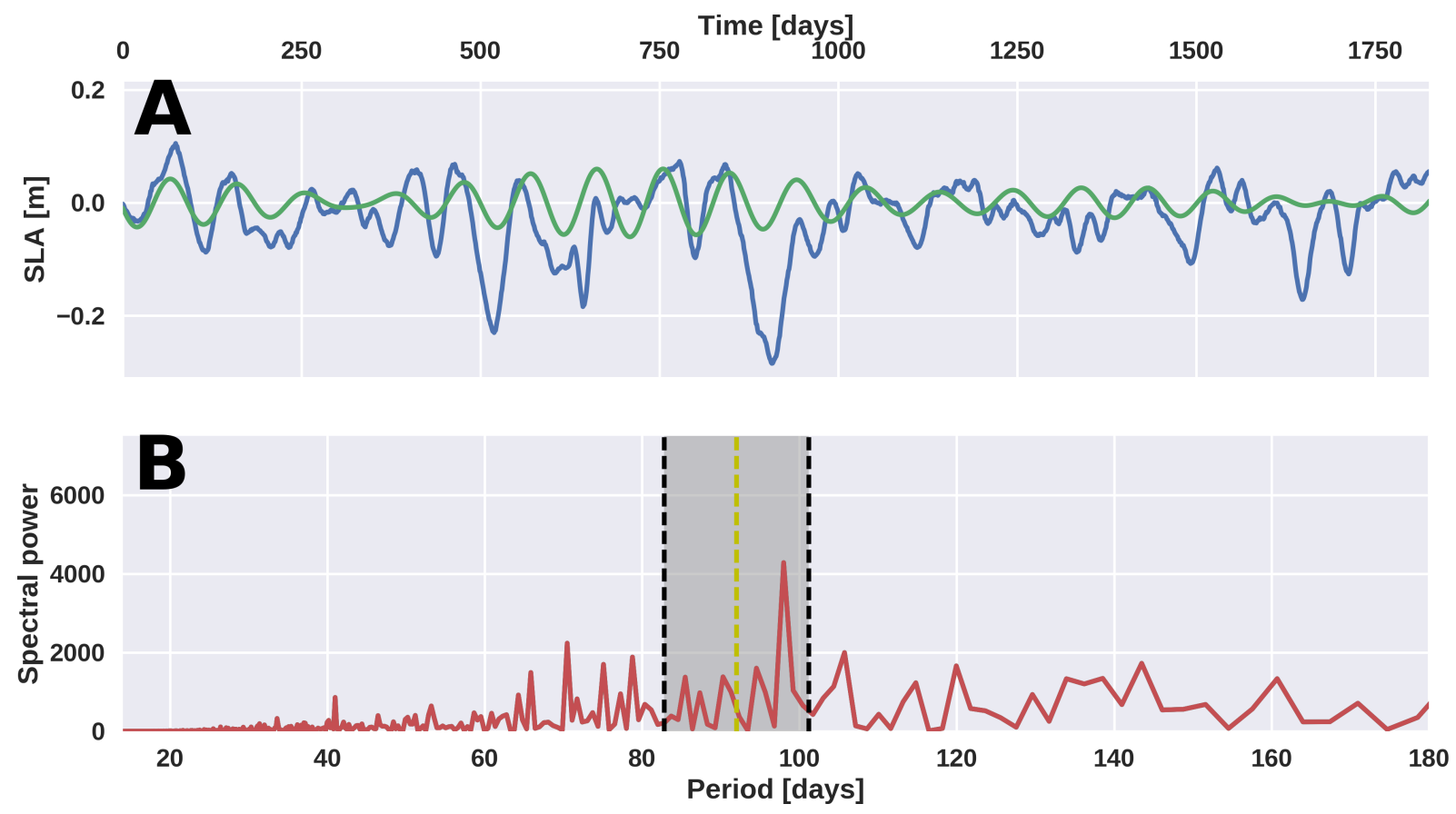

Figure 2.4: FFT band-pass filter on SLA time series for the grid point at $25.375^{\circ} \mathrm{S}$ and $44.375^{\circ} \mathrm{W}$ for the first 5 years of data. (A): blue line is the raw data, green line the data filtered with FFT. (B): red line is the spectral power $\left[\mathrm{m}^{2} \mathrm{day}^{-1}\right]$, yellow dashed line is in the 92 day period position, black dashed lines the limits of $10 \%$ from central period and shaded black area is the portion of the spectre line used to reconstruct the filtered data.

\subsubsection{Correlation field}

Considering a three dimensional field of SLA it is possible to determine the presence of a wave based on the correlation coefficient. This coefficient correlation was calculated between the time series of a point where the wave signal is present and the time series at all spatial grid points.

Considering a test fictitious SLA signal (upper Figure 2.5) with $400 \mathrm{~km}$ wavelength and 70 days of period happening at a restricted region of the SLA field and the remain signal as random noise. Using the correlation coefficient with the point of control in the region where the wave is present we identify troughs and crests of correlation with same wavelength of the troughs and 
crest of SLA. Therefore this method is useful to determine the regions where there is signal of the wave and thus its wavelength. Moreover when using this technique to a point in the field where there is not the presence of the wave the correlation is nearlly zero for every grid-point except the control (lower panel in Figure 2.5).

One important thing to this method is the amplitude of the noise signal compared to the amplitude of the wave signal. To ensure this we used in this method the data previously filtered according to section 2.2.2. Moreover we performed a Monte-Carlo statistical test to study the statistical significance of the correlation. The grid points with correlation lower than the statistical significance value were interpreted as zero.

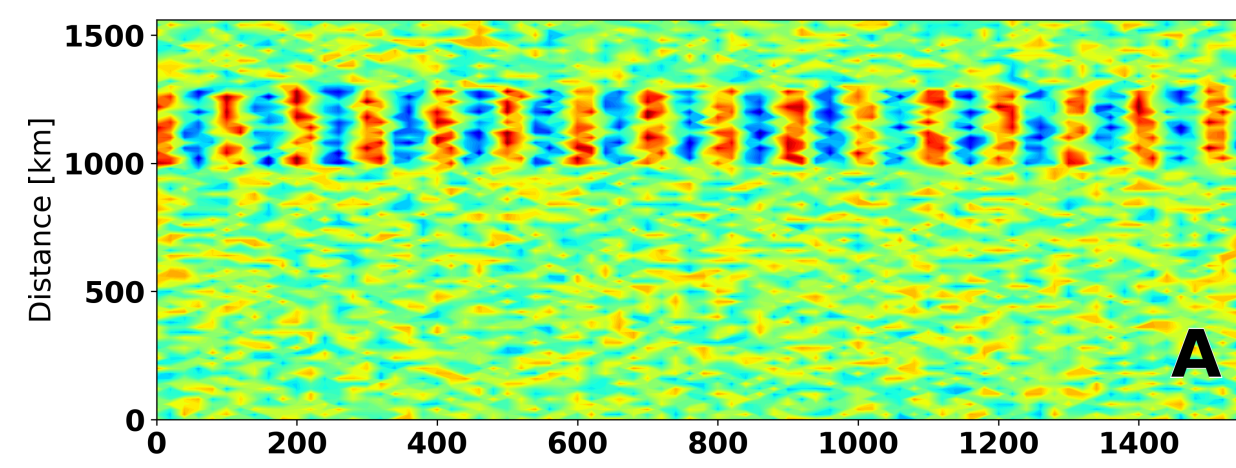
1.44
1.20
0.96
0.72
0.48
0.24
0.00
$-0.24$
$-0.48$
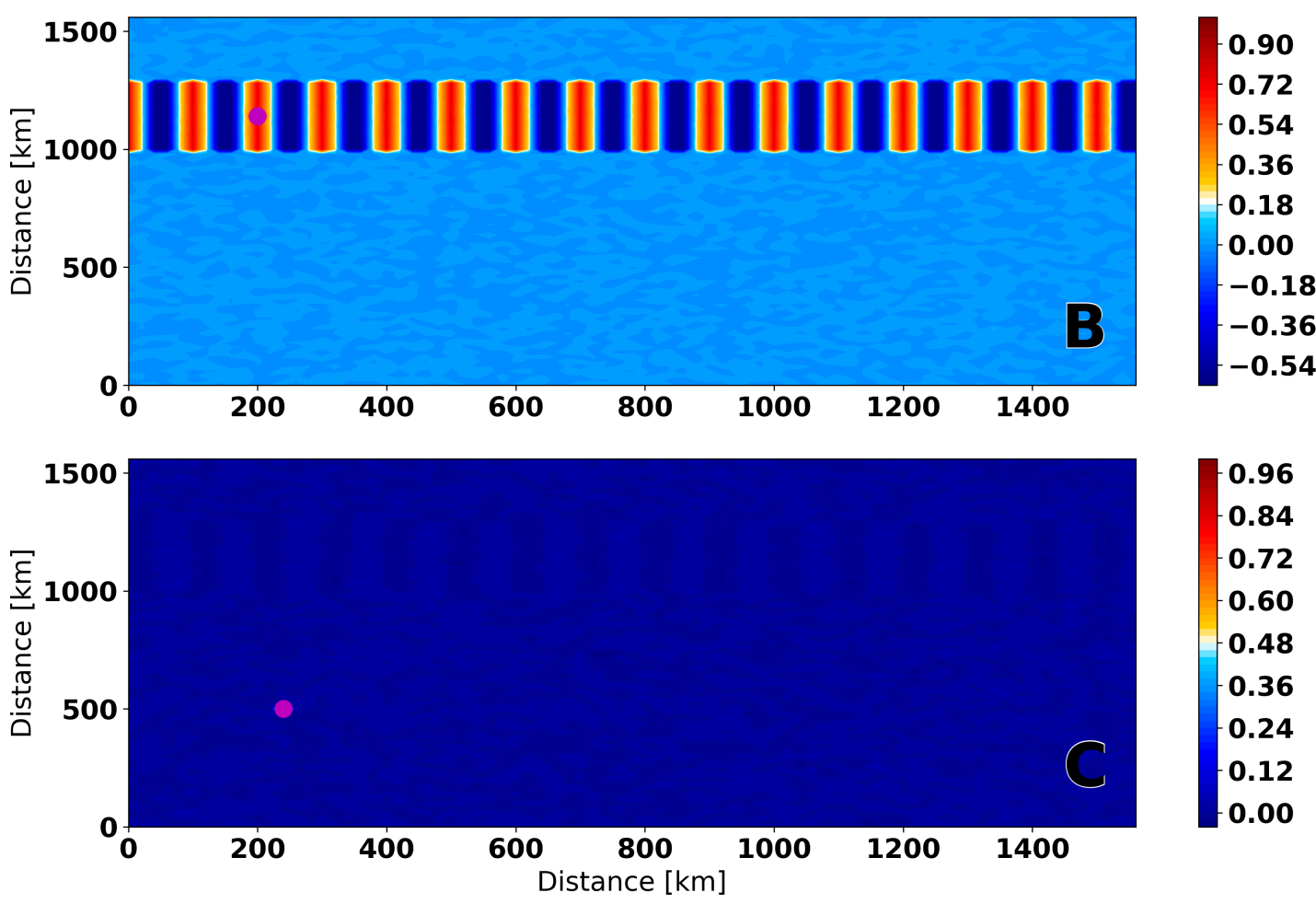

Figure 2.5: Example of the pathway and wavelength estimate using the SLA correlation coefficient field. (A): SLA [m] fictitious field with a wave signal propagating between 1000 and 1500 in y-axis. Rest of field is random noise. (B): correlation field with a control point where the wave happens, magenta dot the position of control time series. (C): orrelation field with a control point where there is no presence of the wave, magenta dot the position of control time series. 


\subsubsection{Radon Transform}

The phase speed of the propagating signal in the filtered data were calculated via Radon transform. Radon space is given for a radius $(r)$ and angle $(\varphi)$ (Figure 2.6). So the projection of a function in $r$ with the angle $\varphi$ is a radon transform

$$
\begin{gathered}
\Re\{h\}(r, \varphi)=\int_{-\infty}^{-\infty} h\left(x^{\prime}, t^{\prime}\right) d s . \\
x^{\prime}=r \cos \varphi-s \sin \varphi \\
t^{\prime}=r \sin \varphi-s \cos \varphi
\end{gathered}
$$

where, $\Re\{h\}$ is the transform of one arbitrary function $h$ and $r$ and $\varphi$ the distance and angle of the Radon space. This method is used to estimate the phase speed of propagating signal when one considers the Hovmöller diagram of the data as the $h$ function. In this sense the function is rotated for $-\pi / 2<\varphi<\pi / 2$ and for each angle the sum is made along the $r$-axis. When $\varphi$ is such that the troughs and crests are aligned with y-axis and perpendicular to $r$-axis, the variance of the sums has a maximum. The phase speed can be inferred from $\varphi$, since $\tan (\varphi)=\frac{\Delta t}{\Delta x}$.

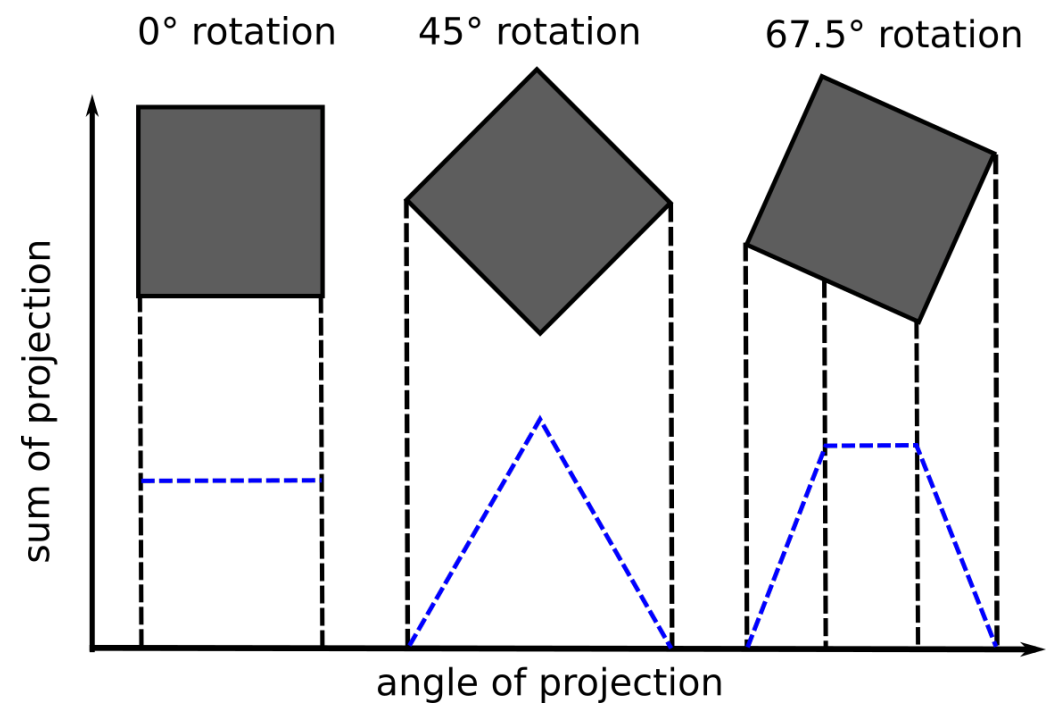

Figure 2.6: Radon transform illustrative scheme. The gray square represent the original data being rotated. Blue dashed line represent a relative sum of the radon space at each angle for all $r$ axis, being the angles $0^{\circ}, 45^{\circ}$ and $67.5^{\circ}$.

\subsubsection{Explained variance}

Considering a time series of SLA $(\eta)$ and the data filtered in some temporal band $\left(\eta_{f}\right)$ it is possible to calculate how much the filtered explains of the total variance of the original data. The explained variance of the original is given by 


$$
v_{f}=1-\frac{\sigma\left(\eta-\eta_{f}\right)^{2}}{\sigma(\eta)^{2}}
$$

where $\eta_{f}$ is the SLA filtered in time.

\subsection{Results and Discussion}

As stated before, the primary goal of this work is to study the remote sources of subinertial variability of the $\mathrm{BC}$ and how they account for the meandering of the jet within the SB.

Considering a QG framework one can recall that

$$
\psi=\frac{g}{f_{0}} \eta_{a}
$$

and considering that $\psi$ can be represented as

$$
\psi(x, y, t)=\bar{\psi}(x, y)+\psi^{\prime}(x, y, t)
$$

the sum of the mean state and the time dependent perturbations, then considering the previous two equations and Equation 2.1,

$$
\psi^{\prime}=\frac{g}{f_{0}} \eta
$$

According to the previous equation the perturbations of the QG streamfunction can be estimated from SLA altimetry field. One technique to present such data and well known to study propagating phenomena is the spatio-temporal diagram, also known as Hovmöller diagram. To make this diagram, a path has been chosen taking in consideration the mean position of the $\mathrm{BC}$ (Figure 2.7). This is defined as the region near the BC with maximum $\nabla \eta$.

Nonetheless, the path chosen and hereafter considered as the BC-axis, was not along the exact center of the current axis, rather it was dislocated approximately $36 \mathrm{~km}$ towards offshore. This was done because the perturbations do not occur exactly along the current axis. Instead, the current usually changes its core position towards offshore as it meanders. Moreover, some of the perturbations seem to propagate along the $\mathrm{BC}$ but not centered in its axis, instead they propagate attached to the current and centered further offshore.

The Hovmöller diagram path chosen to study the variability of the BC starts south of Patos Lagoon $\left(\sim 33^{\circ} \mathrm{S}\right)$ and ends near Cape Frio $\left(\sim 23^{\circ} \mathrm{S}\right)$. One important process within the SB is the 


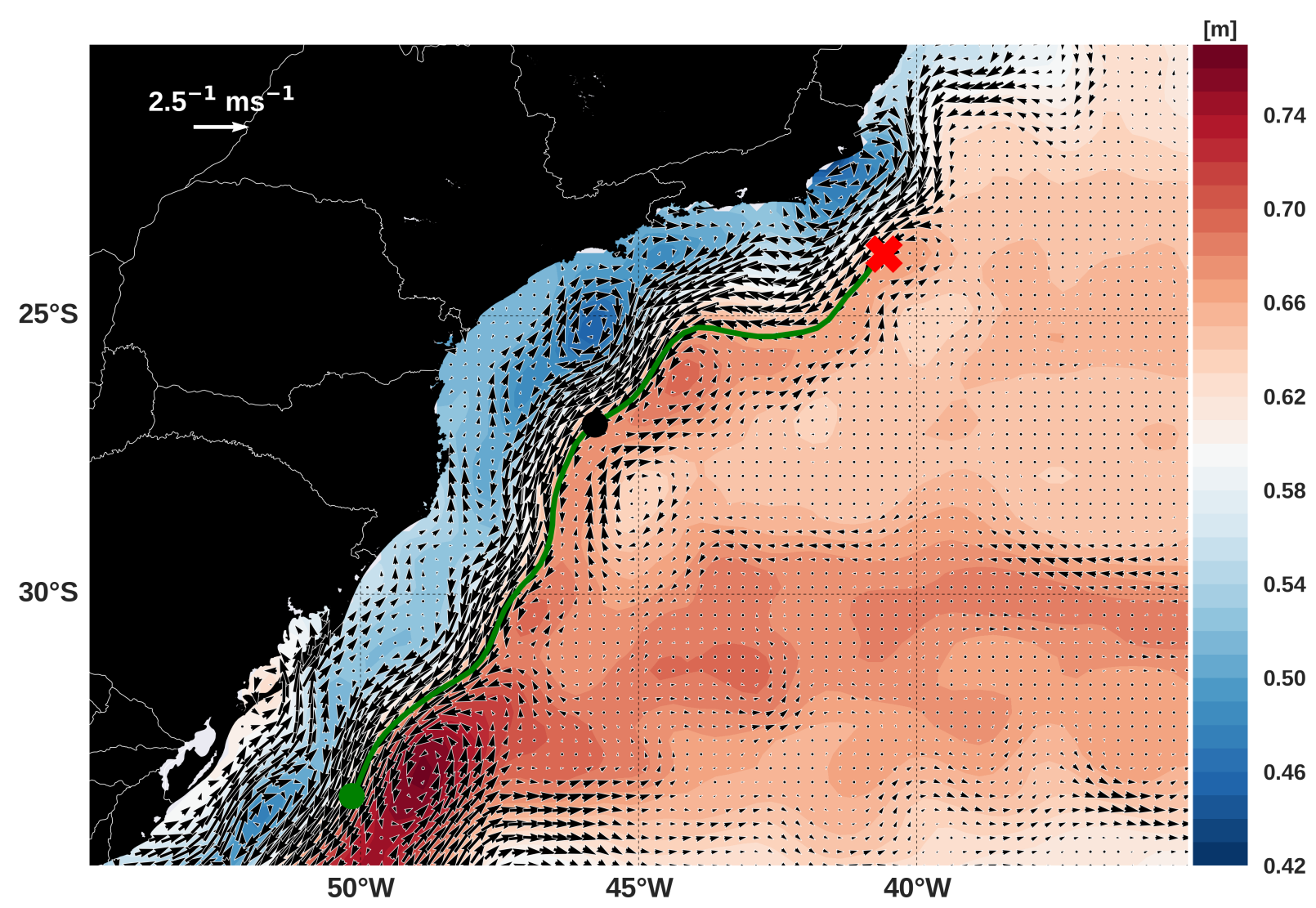

Figure 2.7: Mean Dynamic Topography map with filled contours as height in meters. The green line is the path along the BCaxis chosen to do the Hovmöller diagram, starting at the green dot and ending at the red dot, the black dot indicates the mean latitude of the SBi along the green line (Rocha et al., 2014).

$\mathrm{SBi}$, both its importance and dynamical constraints it imposes have been discussed in section 1.3. Therefore we used its approximate position (black dot in Figure 2.1) and studied the region north and south of the SBi independently.

The $\eta$ for the chosen path was interpolated from the altimetry data. Its seasonal cycle and linear trend have been removed in order to filter out anomalies that are related to annual oscillations and long time trend of the current (subsection 2.2.1). The SLA field in the SB presents signal of southwestward propagation along the BC axis (Figure 2.8). This propagation occurs during the 22 years of data but is not constant in time nor in space. Although there is an alternating pattern of maxima and minima of $\eta$, the time mean of the propagation features changes its mean values during the time series (i.e. difference between 1998-2001 and 2001-2004). This process can be related to decadal or secular oscillation and is not relevant to the present study.

Besides the identified propagation pattern, when looking closer one can also note southward propagation in a broader band of frequency. By looking to a smaller period of data, there seems to happen a time modulation of the SBi position. This modulation occurs in the Hovmöller diagram as a discontinuity of SLA that interrupt the propagation signal. This local maximum 

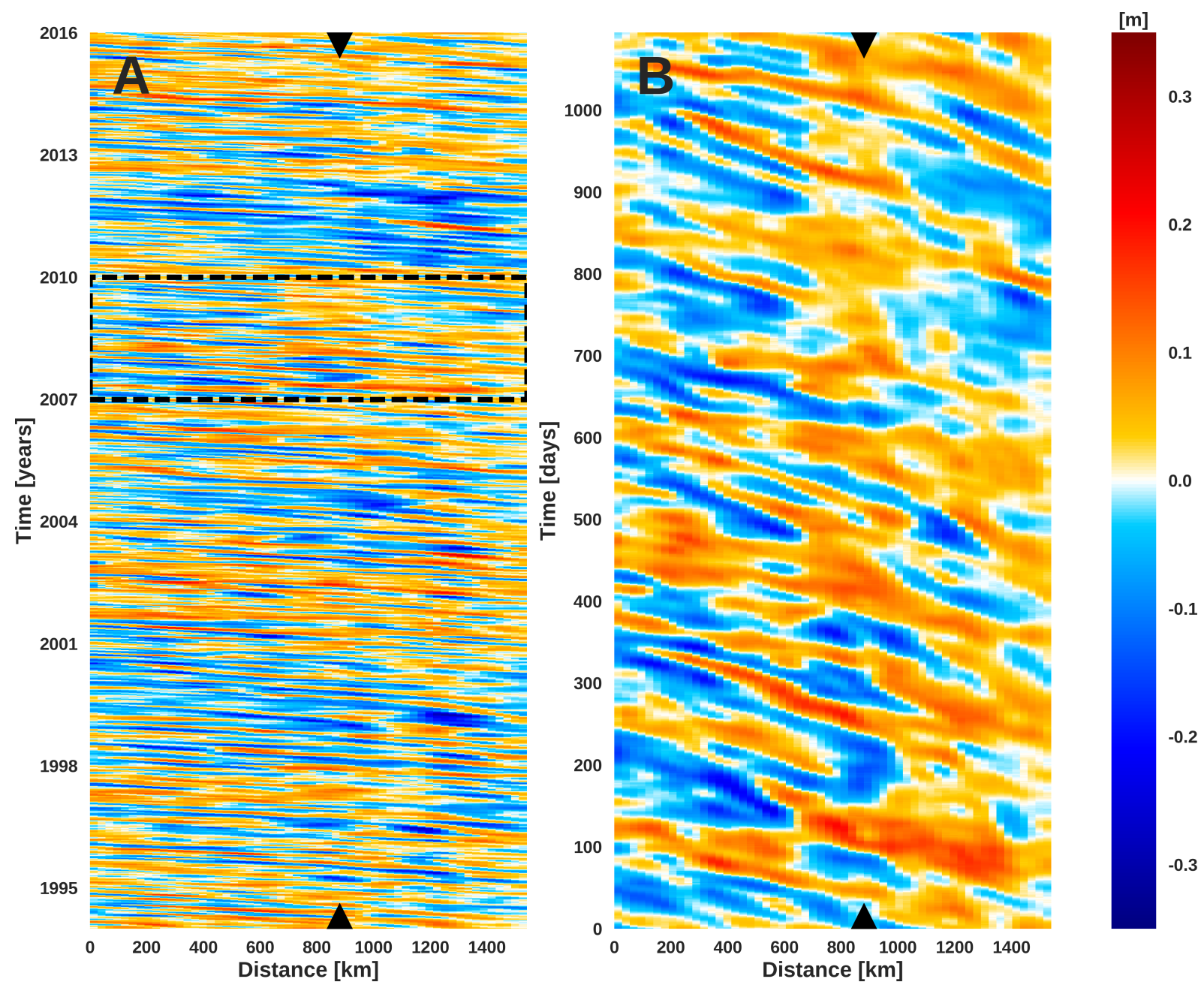

Figure 2.8: Hovmöller diagram of SLA after removed the trend and yearly signal. A) Hovmöller diagram of data time series between 1994 and 2016, black triangles represent the position of the SBi in the Hovmöller diagram. Black dashed lane represent area subseted. B) subset of panel A with day zero as $1^{s t}$ of January of 2007 and ending in $1^{s t}$ of January of 2010, black triangles indicate the position of the SBi

changes its position with time, in early 2007 it was centered at $\sim 1200 \mathrm{~km}$ of distance from southernmost point, and between early 2008 and the end of 2010 it shifted to a smaller distance $(\sim 900 \mathrm{~km})$ therefore to south. This is probably the SBi surface signal and the interruptions is due to its presence at intermediate levels. The difference in distance along the Hovmöller diagram axis represents a variation of $2^{\circ}$, then this changing in position of the abovementioned discontinuity is presumably linked to the long-term variability of the SBi latitude.

Given the regional importance of the SBi and the apparent discontinuity in propagation hereafter the spectral analysis will be applied in two different areas:

- North of the Santos Bifurcation;

- South of the Santos Bifurcation. 


\subsubsection{North of the Santos Bifurcation}

To the north of the bifurcation the frequency mean spectrum presents an energy peak in the period of 92 days (red dot) and two secondary peaks both at around 170 days Figure 2.9. The rest of the energy is almost restricted to periods between 90 and 125 days with no significant signal to periods smaller than 80 days. The second and third maximum values are in 160 and 175 days. (Mata et al., 2006) estimated the limit between low-frequency and mesoscale variability to be of about 170 days. Therefore, since the second and third maximum are either out or in the limit of mesoscale variability band, these periods were not addressed in this study. At the north of the SBi there is a maximum of mesoscale variability with 92 days of period, and this is the peak that we will study. Hereafter this peak will be mentioned as 92-D.

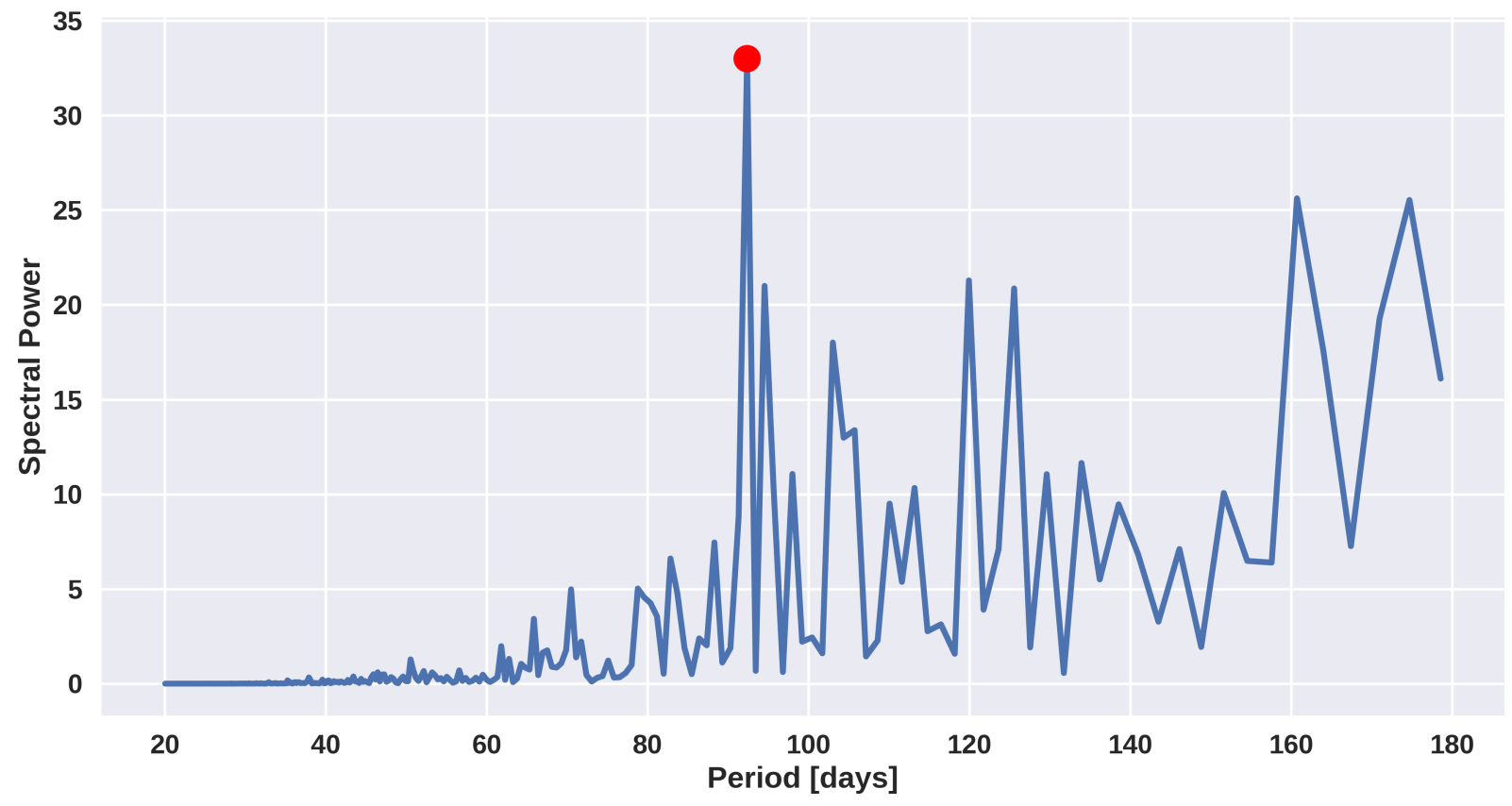

Figure 2.9: Spectral mean energy $\left[\mathrm{m}^{2} \mathrm{day}^{-} 1\right.$ ] for periods between 20 and 180 days, computed to the north of the SBi. Red dot the period of maximum energy.

To determine the wavenumber linked to the variability of 92-D signal we used the method presented in section 2.2.2. The mean spectrum increases towards a maximum of energy in $0.012 \mathrm{~km}^{-1}$ (red dot) and decreases after this value (Figure 2.10). To wavenumbers lower than $-0.020 \mathrm{~km}^{-1}$ the spectrum value is lower than a third of the maximum value. However, this spectrum has a striking limitation in this band of wavenumber. Thus, due to data resolution, the wavenumber peak linket to $92-\mathrm{D}$ phenomena is centered in $-0.012 \pm 0.002 \mathrm{~km}^{-1}$. This range of wavenumber represents a $180 \mathrm{~km}$ range of wavelengths and this effect is enhanced given the proximity to minimum wavenumber resolution. 


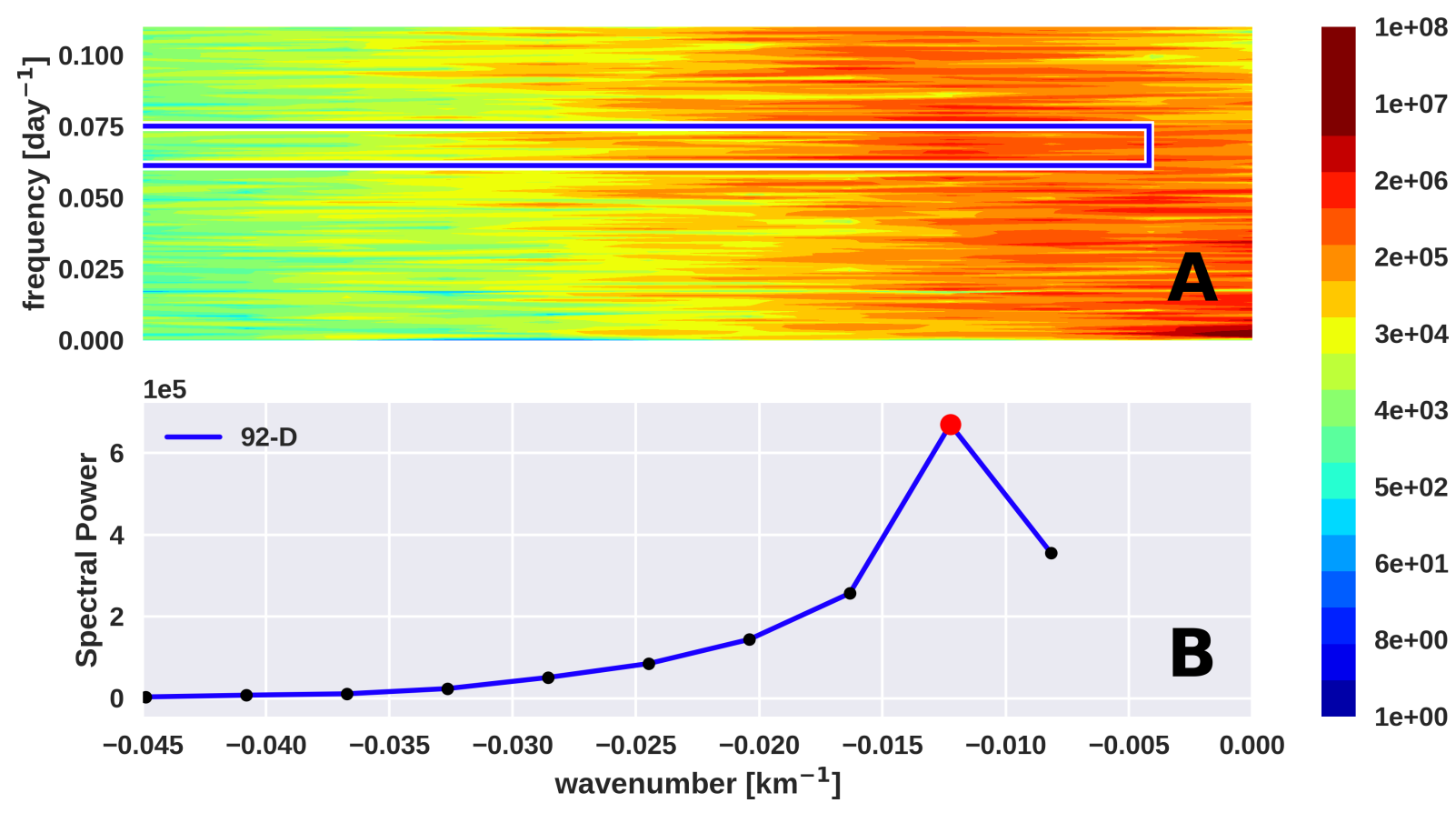

Figure 2.10: Spectral determination of most important wavenumber. (A) Spectral energy of the Hovmöller diagram $\left[\log _{10} \mathrm{~m}^{2} \mathrm{day}^{-1} \mathrm{~km}^{-1}\right]$. Blue line the bandpass filter box centered in period of 92 days and range of $\pm 10 \%$. (B) Wavenumber spectrum $\left[\mathrm{m}^{2} \mathrm{~km}^{-1}\right]$, black dots represent spectral resolution and red dot dominant wavenumber.

The main mesoscale variability of the $\mathrm{BC}$ at the north of the SBi have a characteristic period of 92 days and wavelength of $\sim 513 \mathrm{~km}$. Moreover the signal propagates southwestward, with signal along the $\mathrm{BC}$ axis. However information is needed to its origin site and propagation pathway towards the current.

In order to analyze the propagation pathway through which the 92-D signal reaches the BC we used the methodology explained in subsection 2.2.3. To study only the important signal we first filtered the SLA data in the time domain with a tophat band-pass filter using one dimensional FFT as described in section 2.2.2. This ensures that we remove propagation related to others frequencies rather than 92-D signal. Nonetheless this method is solely a time domain filtering and does not carries spatial information as the wavenumber has been already determined.

This correlation field shows an almost zonal westward propagation reaching the BC to the north of the SBi along $\sim 25^{\circ} \mathrm{S}$. Meridional elongated bands of correlation (i.e $32.5^{\circ} \mathrm{W}$ ) are evident in the 92-D signal correlation field, which suggests a propagation as a wave front rather than a sequence of cyclones and anticyclones. This elongated fronts are restricted to latitudes between $23^{\circ} \mathrm{S}$ and $33^{\circ} \mathrm{S}$.

Zhang et al. (2001) using a current meter mooring and satellite altimetry data identified a maximum mesoscale variability of 100 days to the KC south of Taiwan. The authors identified 
the source of this variability to be westward propagating eddies. However they did not found phase propagation along the current, instead they identified this 100 day signal to be the main source of variability in the KC transport. The authors identified this variability to be caused by barotropic isntabilities. Due to the instabilities the current shift its axis and flows through a different path. Chen et al. (2009) studied the KC near South China Sea with a longer time series of altimetry data and identified the main mesoscale variability to be 94 days. Therefore both authors looked to the same source of variability, given the 6 days difference. The variability signal of the $\mathrm{BC}$ has a close period to the one found for the KC. However it does not seem to be as eddies reaching the current but a westward propagating wave front.

The path defined based on the BC axis (black line in Figure 2.11A) is almost in southwestward direction and the 92-D signal has a westward propagation direction. This difference in the orientation between both causes the northern part of the troughs and crests to reach the BC first. Therefore the arrival of a westward propagation wave can cause an apparent phase propagation along the BC. Nonetheless it appears to exist an actual phase propagation along the BC with a small tough and crest along the BC. This can be either be propagation along the current or the wave front reaching the $\mathrm{BC}$ near CSM.

Using the technique in subsection 2.2.3 it is possible to estimate both the origin and the wavelength of the wave by analyzing the correlation field of the time series of each spatial point (Figure 2.11A). The estimated wavelength for the 92-D is $520 \mathrm{~km}$ and its origin seems to be around $35^{\circ} \mathrm{W}$. In addition to the origin site, this technique allows us to estimate a better propagation path of the wave. This improved path is then used to make a Hovmöller diagram using the same methodology applied to the BC axis case. As previously described, the annual signal of the SLA has been removed and the wavelength of the 92-D is estimated with better accuracy, as explained in section 2.2.2. 


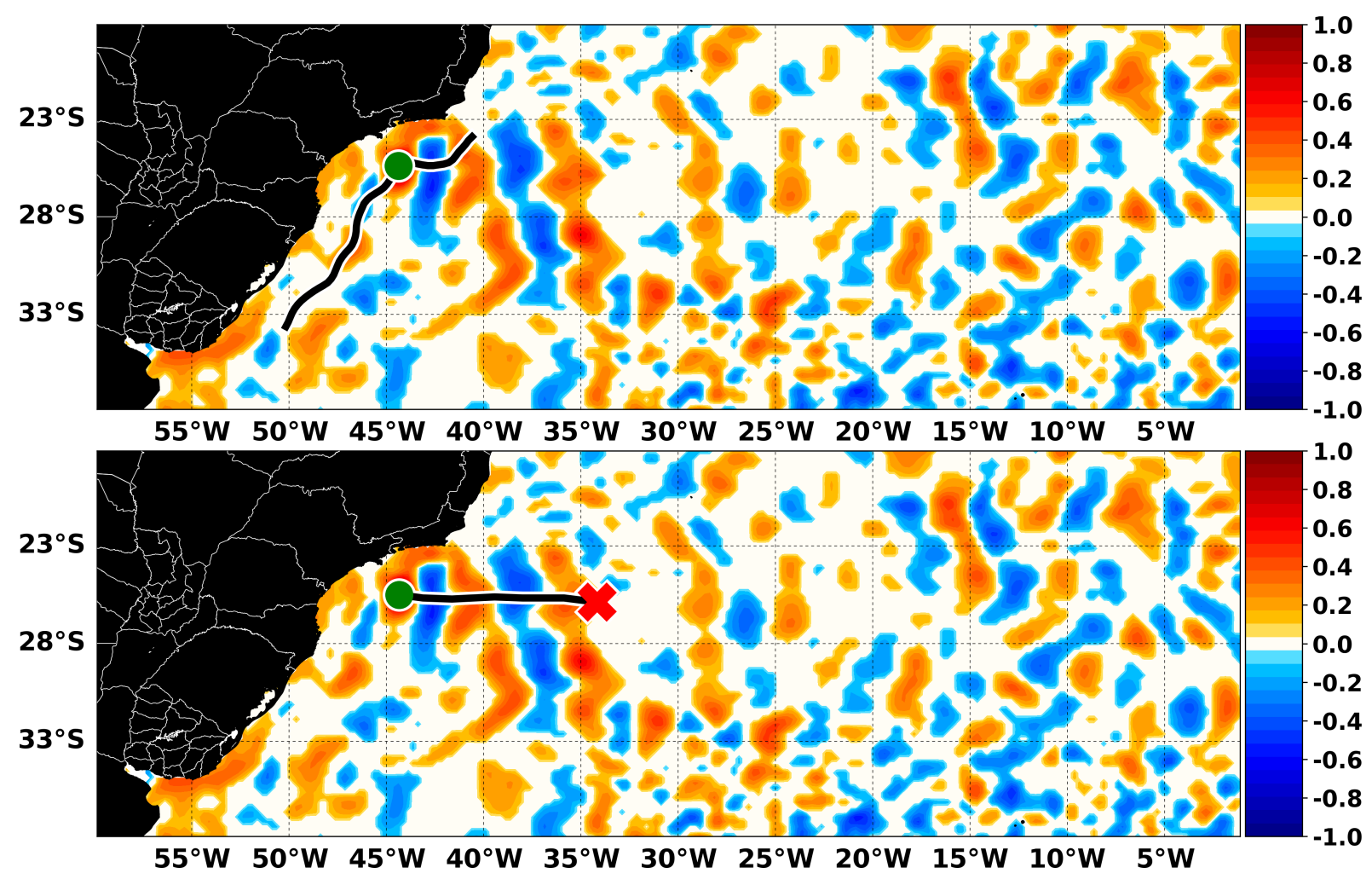

Figure 2.11: Correlation coefficient field of the SLA filtered data in to 92-D signal. (A): map of correlation coefficient, green dot the position used to correlate with the rest of the field and black line the Hovmöller diagram path used for the BC axis. (B): same correlation coefficient field, black line the new Hovmöller diagram path specific to this wave, green dot is the start and red cross the end of the path.

The wavenumber spectrum along the 92-D path yields again a single maximum, at wavenumber $-0.01235 \mathrm{~km}^{-1}$ (508 $\mathrm{km}$ wavelength), and the spectral energy is negligible to features smaller than $205 \mathrm{~km}$ (Figure 2.12). The correlation field pathway is small, only two full wavelengths. A possible explanation for this is that the wave exists only near the current. Due to the small path chosen the wavenumber of maximum energy is near the limit of spectral resolution.

The frequency, wavenumber and pathway of the main BC variability source at north of the SBi have been estimated. With these spectral information, we applied a FIR2D filter in the Hovmöller diagram along the wave pathway. This type of filter preserves only the signal of a specific wave (Polito and Liu, 2003).

Both the original 92-D Hovmöller diagram (zonal) and the filtered one present a westward propagating signal Figure 2.13. In the filtered Hovmöller diagram it is observable that 92-D signal vanishes (i.e., between days 1600 and 1800 in Figure 2.13). This absence of significant signal of 92-D wave in the Hovmöller diagram can be either because we are looking at a intermittent phenomena or it reaches the SB at different latitudes with time. In the last case we do not sample the 92-D in this Hovmöller diagram but it is propagating towards the $\mathrm{BC}$ at latitudes be- 


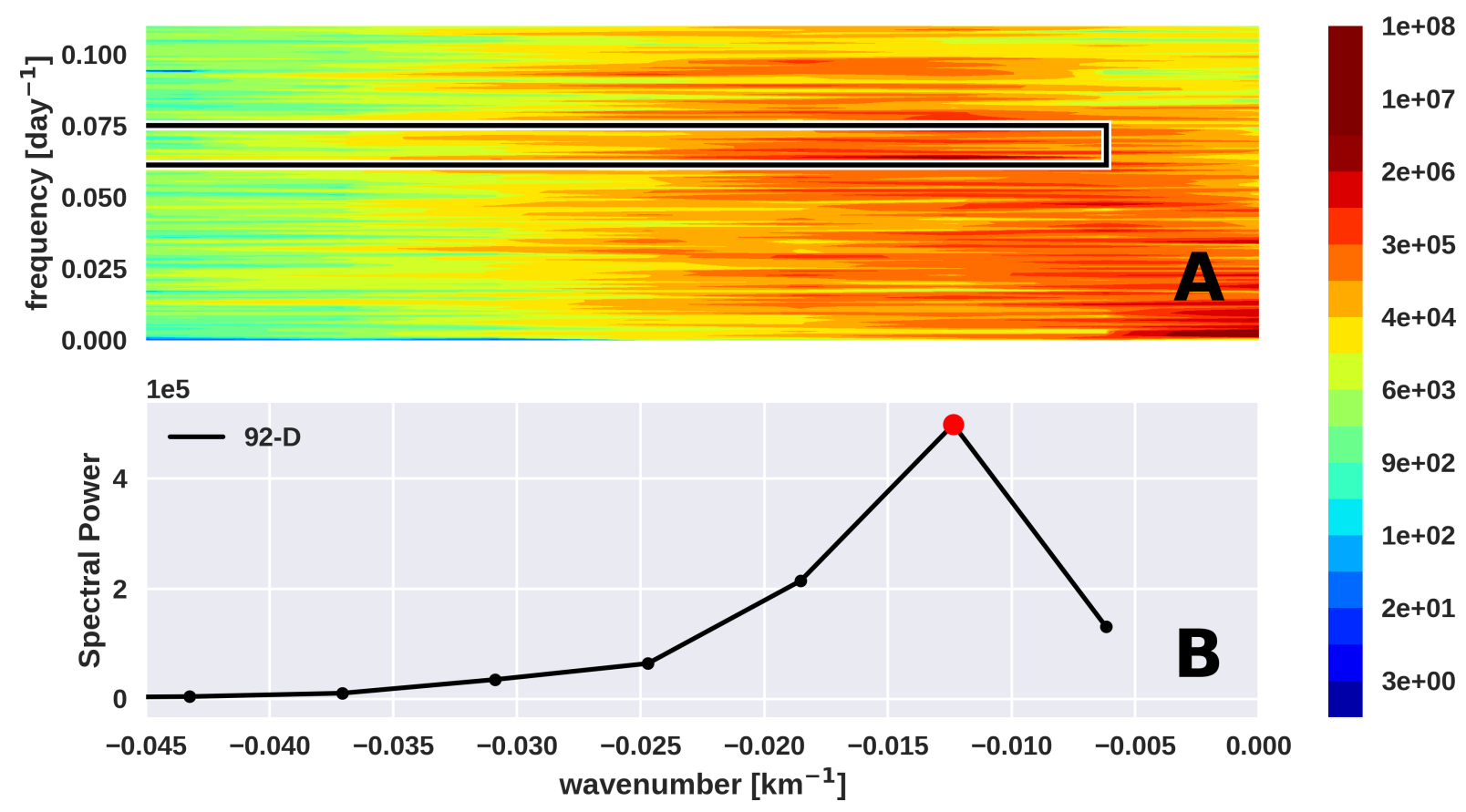

Figure 2.12: Same as the Figure 2.10 but for the new Hovmöller diagram path in Figure 2.11A.

tween $23^{\circ} \mathrm{S}-33^{\circ} \mathrm{S}$ other than $25^{\circ} \mathrm{S}$. Having the filtered Hovmöller diagram to the 92-D pathway we estimated phase speed with the Radon transform method as described in subsection 2.2.4. Having the phase speed we calculated an improved and more accurate wavelength of this wave, $491 \mathrm{~km}$.

Although not being permanent in the filtered Hovmöller diagram the 92-D wave accounts for a variance of the SLA in its pathway of $21 \%$ (see subsection 2.2.5). However, in the BC axis the $92-\mathrm{D}$ signal explains $17 \%$ of the total variance. Even though we have other features along the $25^{\circ} \mathrm{S}$ zonal line the 92-D wave accounts for one fifth of the its variance. 

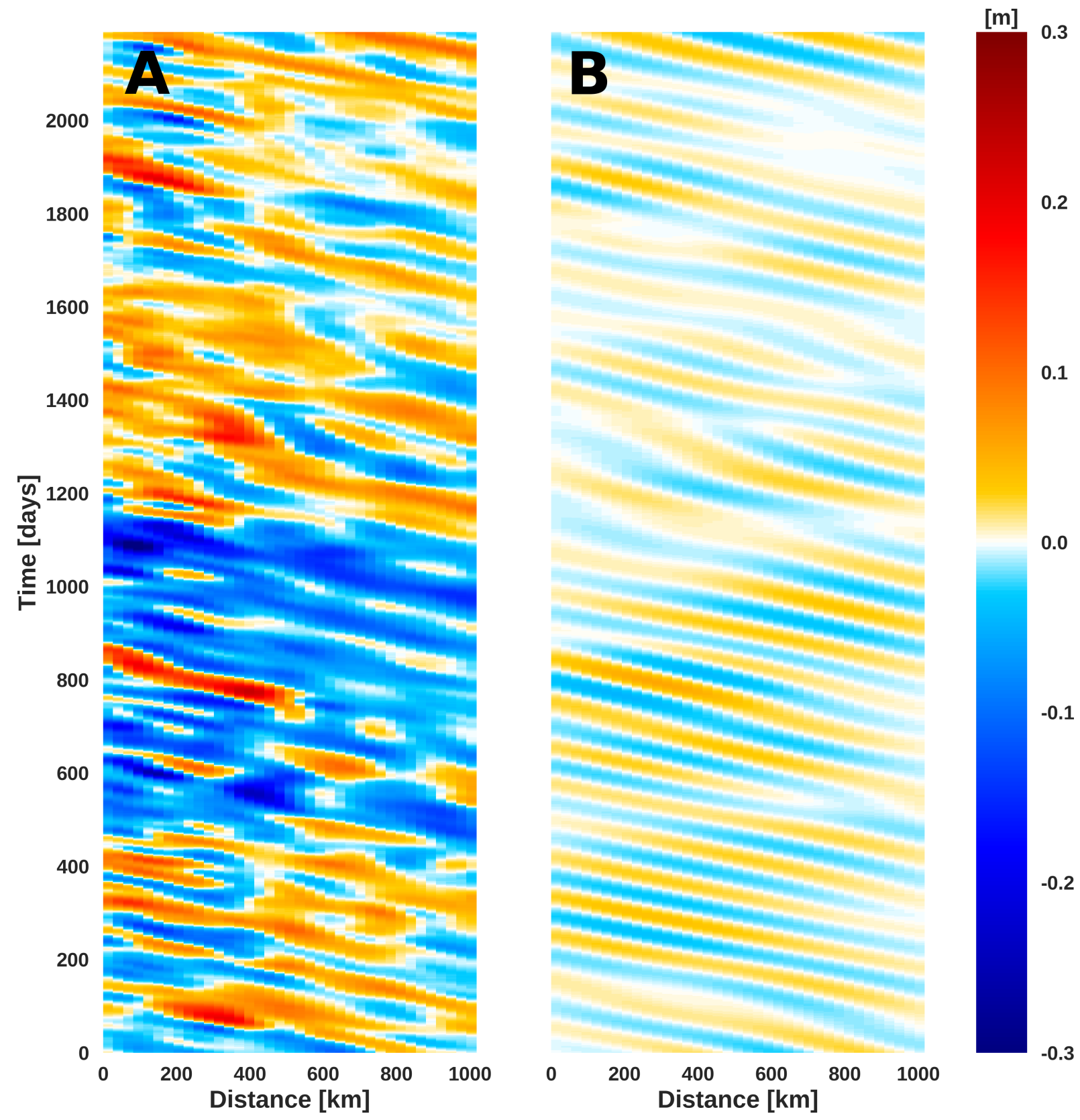

Figure 2.13: Hovmöller diagram for the last six years of data (2009-2015). (A) SLA Hovmöller diagram for the path defined in Figure 2.11. (B) Filtered Hovmöller diagram using FIR2D with the period and wavelength of 92-D.

\subsubsection{South of the Santos Bifurcation}

Variability to the south of the SBi was studied by using the same methodology employed to the north of the SBi.

The frequency spectrum was calculated with the methodology described in section 2.2.2. The spectrum has higher values of energy to the south of the SBi than to the north (Figure 2.14). The maximum value in the south has a mean spectral power of $80 \mathrm{~m}^{2} \mathrm{day}^{-1}$, while the maximum at north has only $\sim 33 \mathrm{~m}^{2} \mathrm{day}^{-1}$. Moreover the $\mathrm{BC}$ to the south presents two maxima in the 
mesoscale period range, 68 and 148 days (red dots). The semiannual variability in this case is not clearly present, as in the spectrum for the northern part. The spectrum has a third maximum around 92 days. Therefore as observed in Figure 2.11A there is variability to the south of the SBi in 92 days period band. Since this third variability maximum is linked to the phenomena already studied in the subsection 2.3.1 we will focus the study of the southern part to periods of 68 days and 148 days, hereafter 68-D and 148-D.

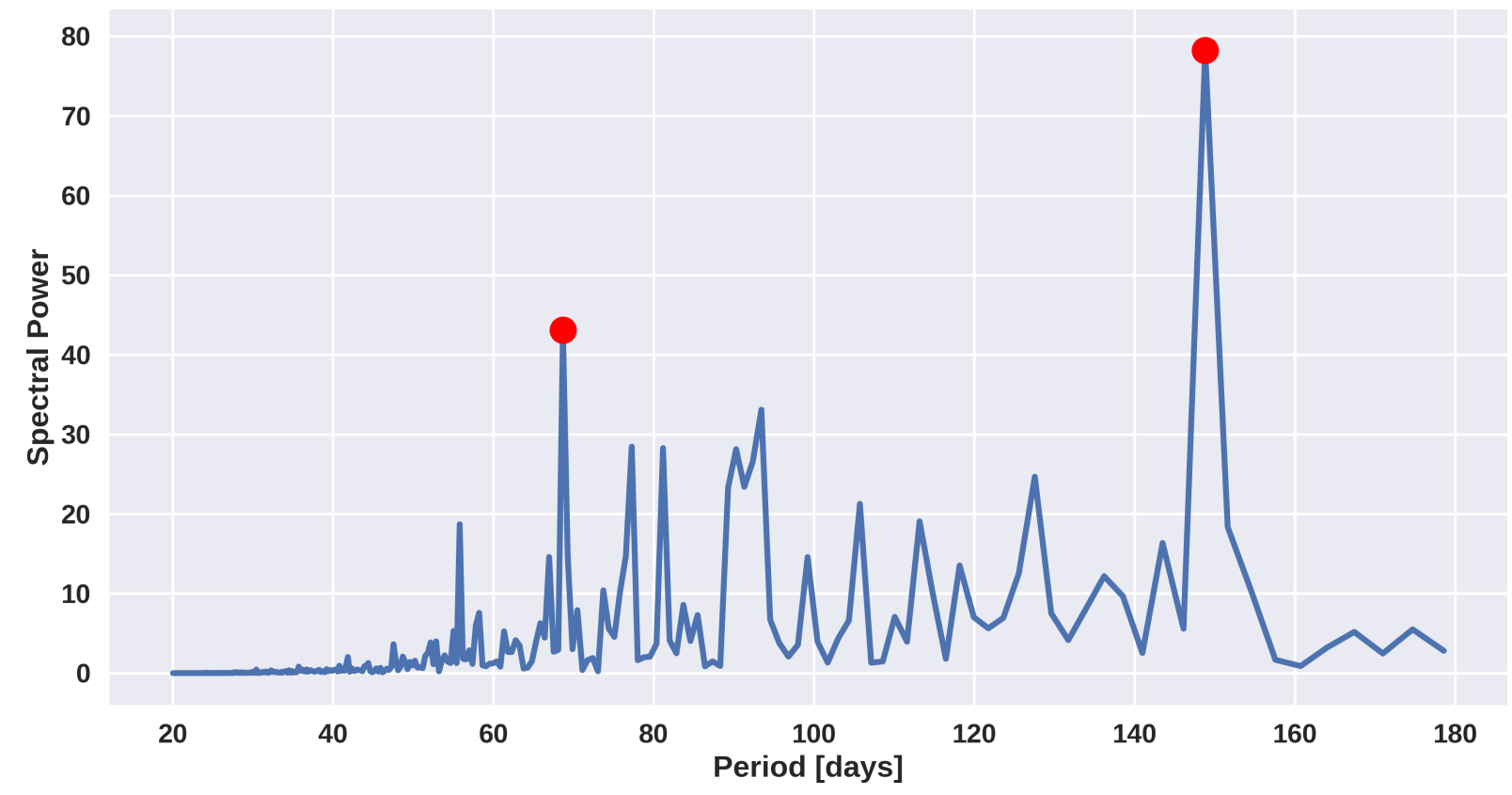

Figure 2.14: Same as the Figure 2.9 but to the south of the bifurcation. Two red dots represent the periods of 68 and 148 days.

We applied the methodology described in section 2.2.2 to determine the wavenumber of both 68-D and 148-D signals (Figure 2.15).

The 68-D signal has a maximum in the wavenumber spectrum of $-0.01630 \mathrm{~km}^{-1}-385 \mathrm{~km}$ wavelength. However because of the data sampling resolution this wavenumber actually represents a probable range of $-0.01770 \mathrm{~km}^{-1} \geq k \geq-0.01400 \mathrm{~km}^{-1}$. Nevertheless this range is smaller $(94 \mathrm{~km})$ than the one of the $92-\mathrm{D}$ signal, since the wavenumber of $68-\mathrm{D}$ signal is not as close to the limit of wavenumber resolution.

The 148-D presents a wavenumber spectrum increasing towards a maximum of $-0.00815 \mathrm{~km}^{-1}$. The spectral resolution limitation is more problematic in this case since the wavenumber of maximum energy is in the limit of wavenumber resolution, being the closest to zero, not considering non-propagating features. Therefore the wavenumber of 148-D is in a range between $-0.00612 \mathrm{~km}^{-1}$ and $-0.00978 \mathrm{~km}^{-1}$. This wavenumber range represents a wavelength range of $400 \mathrm{~km}$. 




Figure 2.15: Spectral determination of most important wavenumber for each maximum in Figure 2.14. (A): spectral energy of Hovmöller diagram $\left[\log _{10} \mathrm{~m}^{2} \mathrm{day}^{-1} \mathrm{~km}^{-1}\right]$. Blue lines represent the box where the spectrum was cut between range of $\pm 10 \%$ of the central period, solid line for 68 day period and dashed for 148. (B): spectral mean power $\left[\mathrm{m}^{2} \mathrm{~km}^{-1}\right]$, black dots represent spectral resolution and red dot dominant wavenumber, solid line for 68 day and dashed for 148 .

The region to the south of the SBi has two dominant mesoscale variability periods and for practical matters, they were analyzed separately.

\section{8 days signal}

The main pathway of the 68-D signal is obtained by the same methods described in subsection 2.2.3. Figure 2.16A shows the correlation field obtained by comparing the time series of altimetry with one in $46.125^{\circ} \mathrm{W}$ and $28.875^{\circ} \mathrm{S}$ (green point), the BC path is also showed.

The main pattern of the 68-D signal is two troughs of correlation, one to the north and one to the south of the chosen point. It is observable in the correlation field that the values after this two minima decrease rapidly, so only one and a half wavelength is clear as a pathway. Therefore half a wavelength from the point of control there is not an obvious pattern of propagation. The 68-D correlation field appears as a wave propagating southwestward not purely parallel to the $\mathrm{BC}$ axis, which makes this signal likely to be linked to the current meandering, or at least the $\mathrm{BC}$ dynamics.

By measuring the distance between the troughs and crests of correlation, we estimated the wavelength of $68-\mathrm{D}$ to be $398 \mathrm{~km}$. This wavelength is $13 \mathrm{~km}$ bigger than the estimated from the spectrum of the BC Hovmöller diagram (Figure 2.15). From this correlation field, we can 
estimate a better axis of propagation of the wave, which we used to make a new Hovmöller diagram specific to the wave path (Figure 2.16B).

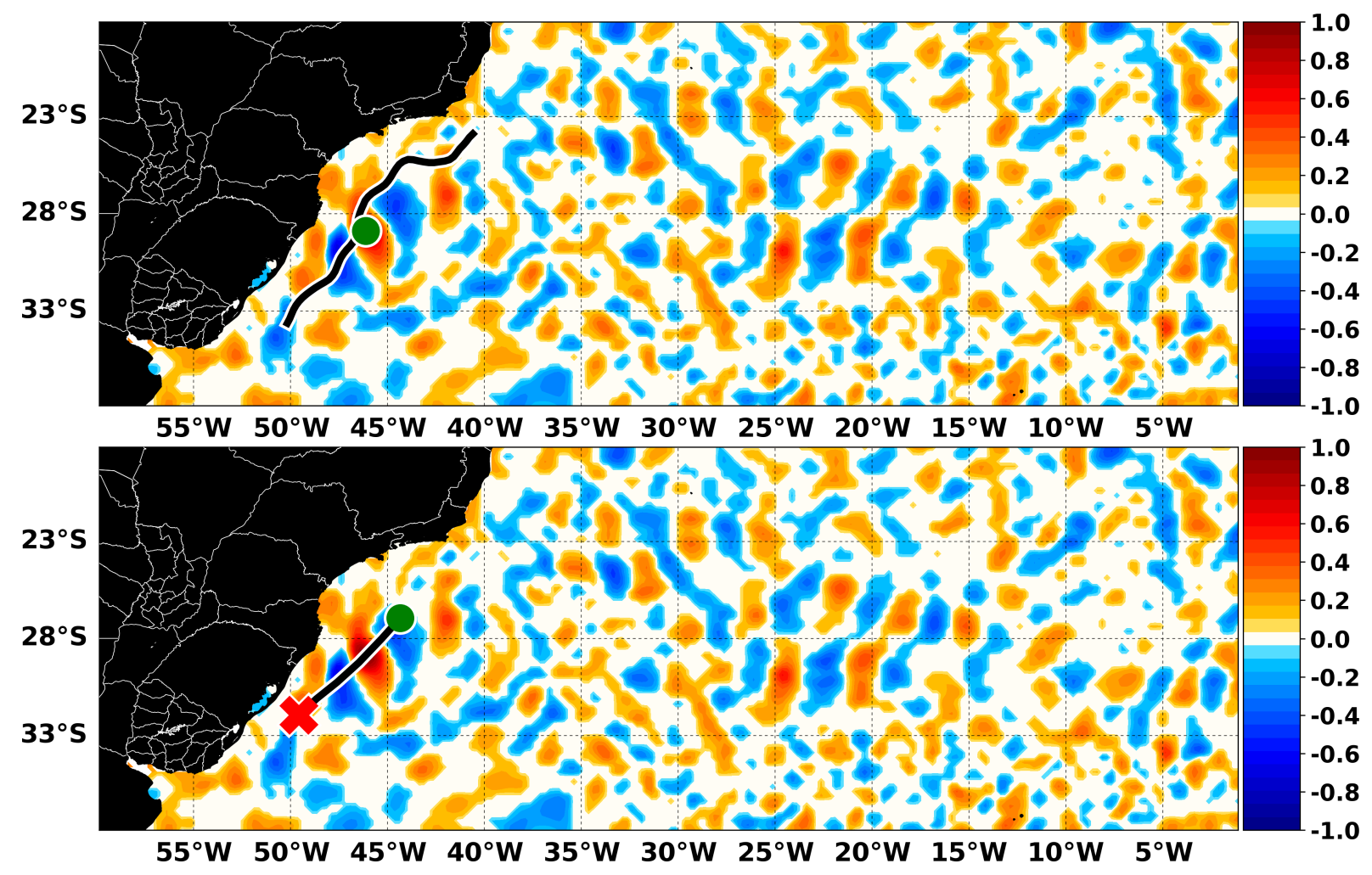

Figure 2.16: Same as Figure 2.11 but with data filtered in 68 day period.

With the new Hovmöller diagram we calculated a maximum wavenumber of $-0.0169 \mathrm{~km}^{-1}$, $371 \mathrm{~km}$ wavelength, by using the method in section 2.2.2(Figure 2.17). Since the new Hovmöller diagram presents only one and a half wavelength, the $68-\mathrm{D}$ wavenumber is closer to the spectral resolution limit than was the case when it was determined for the BC axis pathway (Figure 2.15).

The result of the Hovmöller diagram along the 68-D signal pathway presents southwestward propagation signal (Figure 2.18A). It can be noted that there are signals in other frequency bands besides the 68-D. In order to isolate the 68-D signal, we applied the FIR2D filter, configured with the estimated wavenumber, frequency and direction of propagation (Figure 2.18B).

The pathway of the wave according to Figure $2.16 \mathrm{~B}$ has its northern point at $27^{\circ} \mathrm{S}$. Therefore we do not identify in Figure 2.18A the presence of the SLA discontinuity related to the SBi. The filtered Hovmöller diagram shows the 68 -D wave as a not intermittent phenomena like the 92-D. This signal exists in the entire time series. However in some periods (i.e. day 1400) the 68-D signal is not present in all the pathway. So there are time periods that the wave does not reach the southern point of the estimated pathway (i.e, day 400 and day 1400 in Figure 2.17B). 


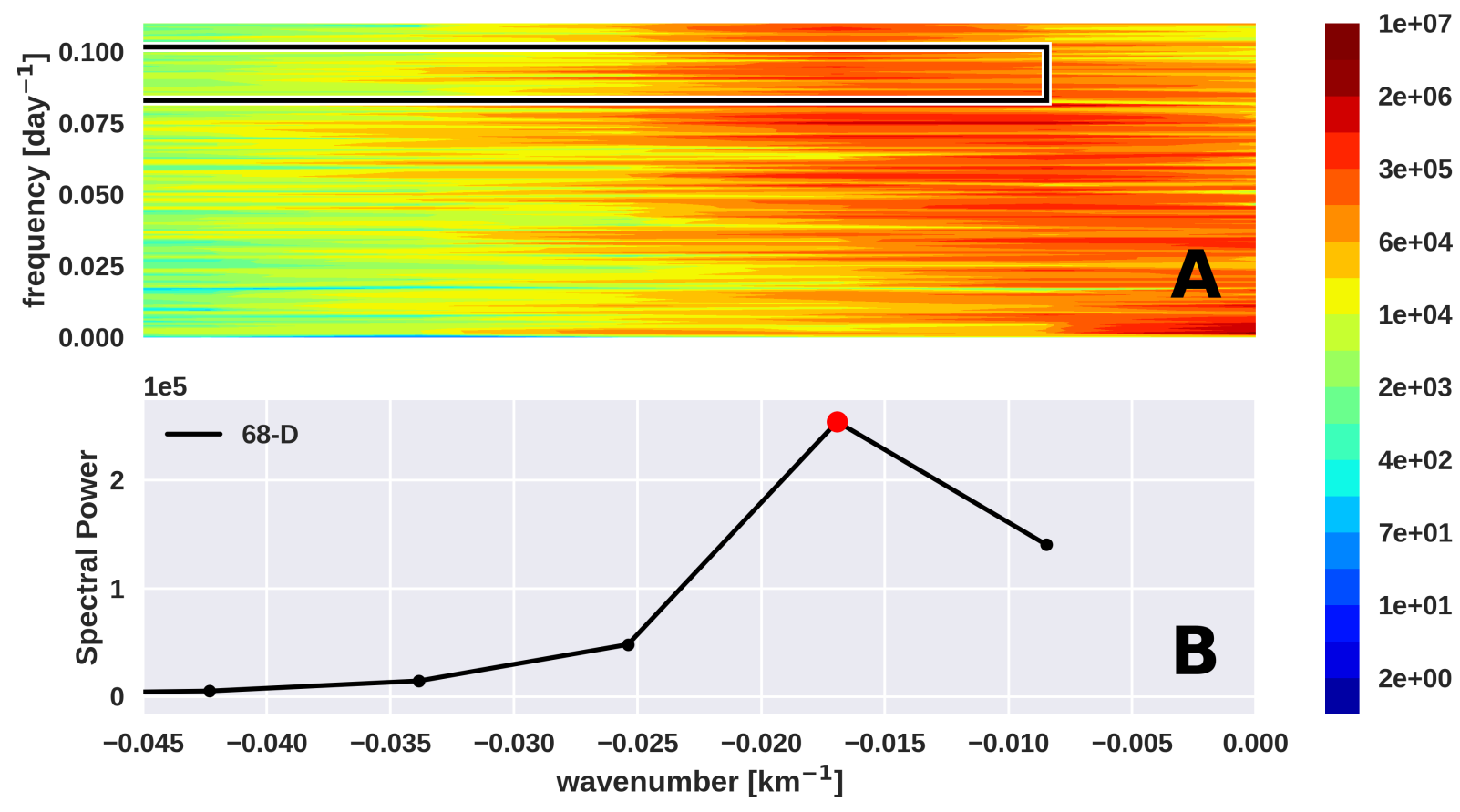

Figure 2.17: Same as Figure 2.15 but for 68 day signal in the new Hovmöller diagram path defined in Figure 2.16B.
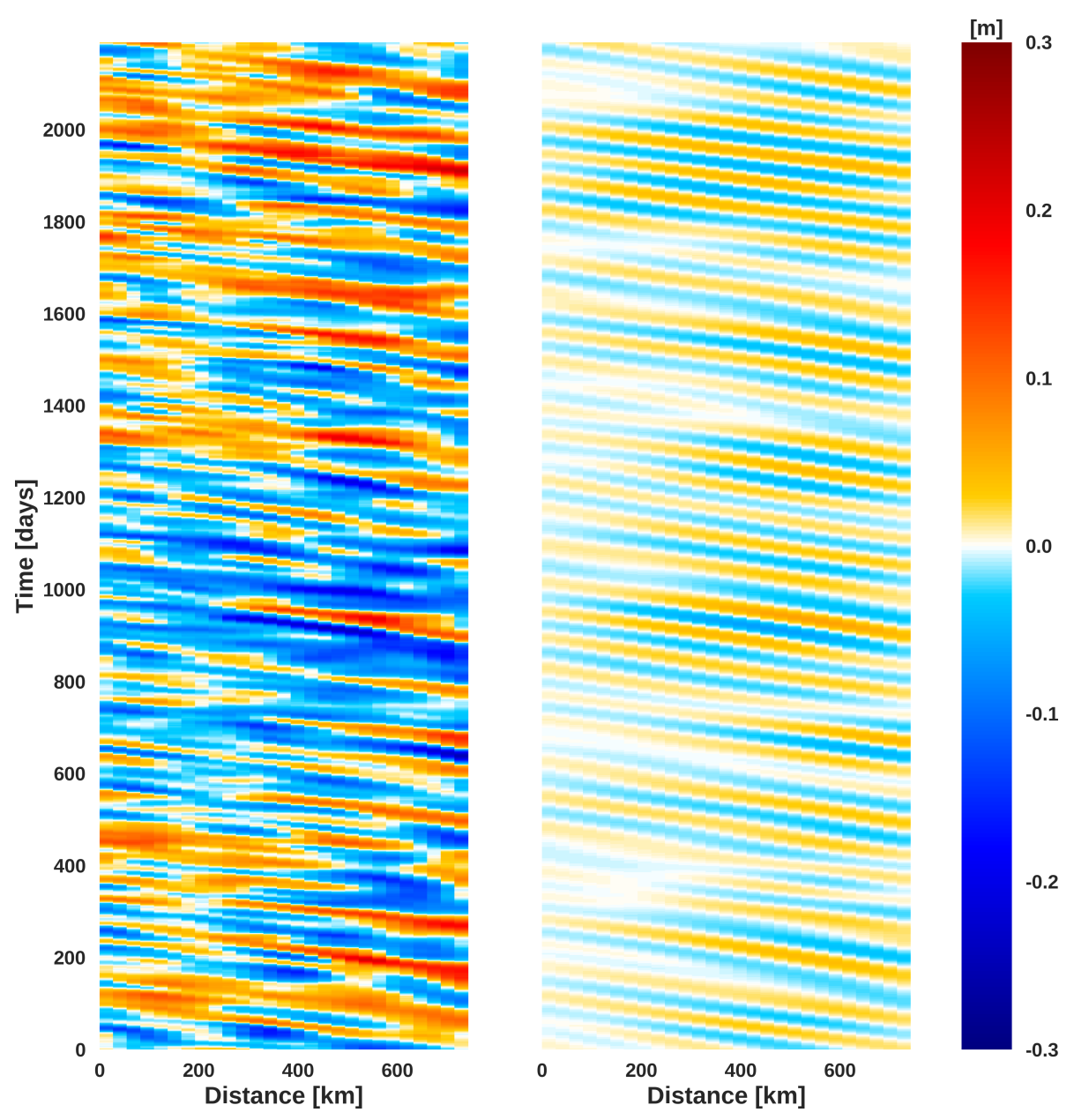

Figure 2.18: Same as Figure 2.13 but for 68-D signal in the new Hovmöller diagram path defined in Figure 2.16B. 
The phase speed was estimated from the filtered Hovmöller diagram by using the Radon transform, and then was obtained an improved estimative of the wavelength. The accurate wavelength for the 68 -D signal is $397 \mathrm{~km}$. This wave explains $21 \%$ of the variance of the SLA along the $\mathrm{BC}$ axis pathway, and it explains $27 \%$ along its propagation pathway from Figure 2.16B. Nonetheless the 62-D wave accounts for at least one fifth of the variance of the $\mathrm{BC}$ within the SB. The increase in explained variance shows the better sampling of the signal with the new pathway.

\section{8 days signal}

By employing the same methodology used to analyze the 92-D and 68-D signals, we calculated the correlation field compared to the time series of the point located at $46.125^{\circ} \mathrm{W}$ and $28.875^{\circ} \mathrm{S}$, which is in the $\mathrm{BC}$ axis and south of the $\mathrm{SBi}$, as was the case in the analysis of the 68-D signal.

The 148-D correlation field presents a preferential pathway through which the wave reaches the $\mathrm{BC}$ in an almost zonal line centered in $28^{\circ} \mathrm{S}$ (Figure 2.19). Moreover there are elongated bands of correlation for the 148-D signal suggesting a wave front propagating westward, similar to the one in $92-\mathrm{D}$. The wave fronts seem to be meridionaly restricted in the north to $23^{\circ} \mathrm{S}$. However within the SB the only clear wave reaching the $\mathrm{BC}$ is the one with a propagation pathway centered in $28^{\circ} \mathrm{S}$. Using this pathway we estimated a wavelength of $739 \mathrm{~km}$ for $148-\mathrm{D}$ wave, considering crests and troughs of correlation.

The 148-D wave does not present a propagation of troughs and crests along the BC axis within the SB. This is due to the fact that the wave phase is not propagated along the current. Moreover the correlation along the current axis is an elongated maximum which is possibly because the 148-D does not induces meandering of the BC. Instead the wave probably inserts(removes) energy from the current causing an increase(decrease) of its signal as a whole within the SB. Therefore, although the 148-D wave does not induces meandering of the $\mathrm{BC}$, it modulates its transport by changing its velocity. 


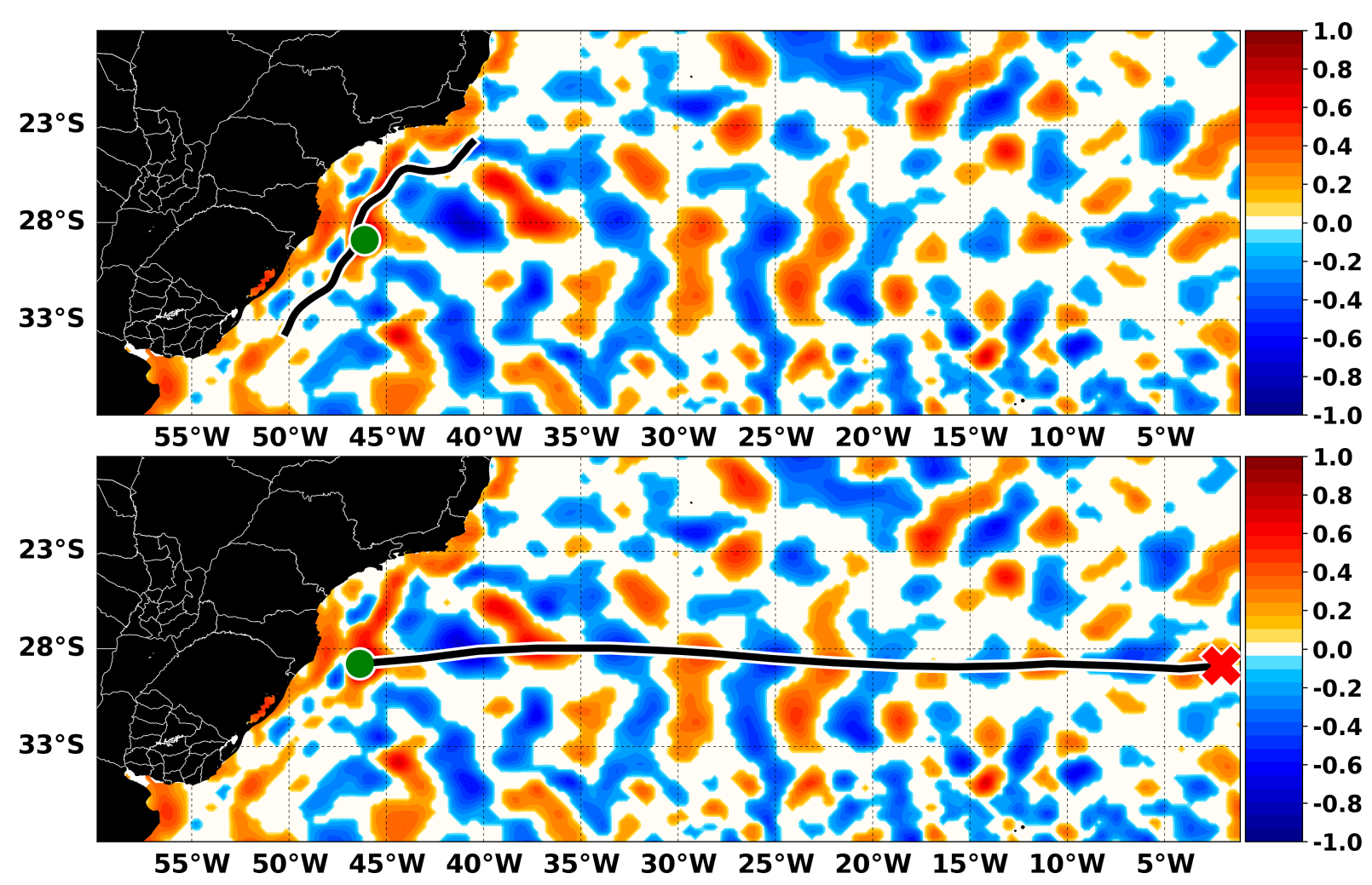

Figure 2.19: Same as Figure 2.11 but with data filtered in 148 day period.

The improved pathway to make the Hovmöller diagram for the 148-D signal can be observed in the Figure 2.19B. Along this pathway, even though there is a decrease in the correlation fronts at $\sim 17^{\circ} \mathrm{W}$, one can observe the alternating correlation pattern associated with a wave in full longitudinal range. Although it may seem from this result that the 148-D propagates towards the $\mathrm{BC}$ from at least $\sim 0^{\circ} \mathrm{E}$, this methodology is not adequate to provide certainty to this conclusion. Further studies are necessary to address this question.

By using the method described in section 2.2.2 for the Hovmöller diagram along the path of the wave (almost zonal at $28^{\circ} \mathrm{S}$ ), we obtained a spectral energy maximum in the wavenumber of $0.00873 \mathrm{~km}^{-1}-719 \mathrm{~km}$ wavelength (Figure 2.20). Wavelengths lower than $\sim 400 \mathrm{~km}$ have almost zero energy and the spectrum increases towards a maximum. Due to the length of the path to the 148-D Hovmöller diagram $(4300 \mathrm{~km})$, this maximum of energy is not as in the spectral limit as was the case when it was estimated from the Hovmöller diagram of the BC (Figure 2.15).

Another difference is that the $148-\mathrm{D}$ wavenumber spectrum does not present a single maximum and decreases rapidly towards wavenumbers near zero, like 68-D and 92-D (Figure 2.17 and Figure 2.12). Instead the spectrum presents a second maximum with a spectral energy close the first. The second maximum have $99.4 \%$ of the total spectral energy of the first. This sec- 


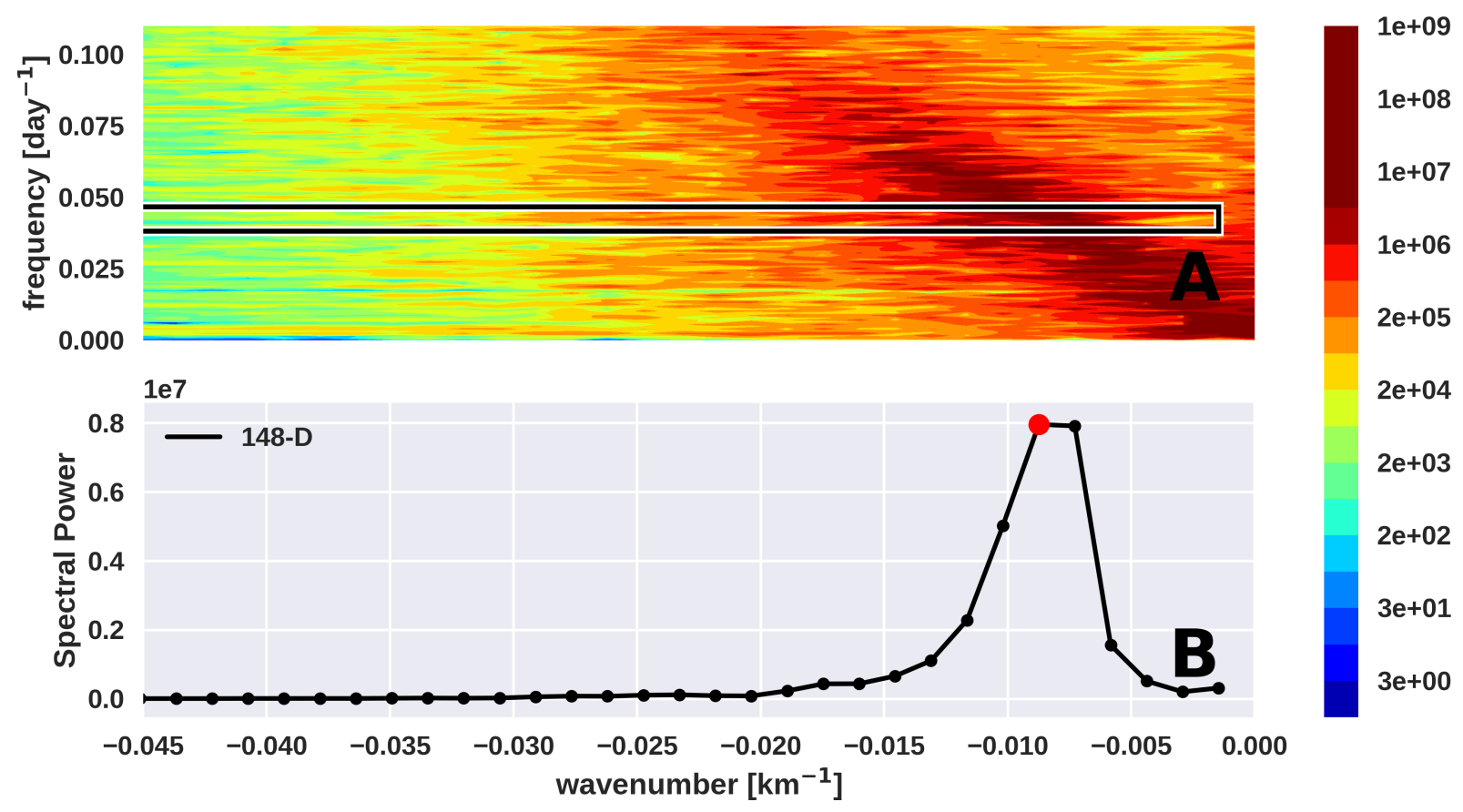

Figure 2.20: Same as Figure 2.15 but for 148 day signal in the new Hovmöller diagram path defined in ??.

ond maximum wavenumber is $-0.00727 \mathrm{~km}^{-1}-864 \mathrm{~km}$. Since the FFT spreads the energy of wavenumbers to a discrete spectrum, the presence of two close maximum is mostly due to the wavelength of 148-D signal being between 719-864 km range.

The Hovmöller diagram of the 148-D pathway presents crests and troughs and a dominance of a westward propagating features with a well defined phase speed (Figure 2.21A). We used the FIR2D filter with a 148 day period and $719 \mathrm{~km}$ wavelength to isolate this dominant signal. The filtered Hövmoller diagram presents a well defined propagating feature along all the pathway defined for the 148 -D signal $(\sim 4000 \mathrm{~km})$. The propagation along the entire $\mathrm{x}$-axis indicates a phenomena that propagates from $5^{\circ} \mathrm{W}$ to $45^{\circ} \mathrm{W}$. Moreover the $148-\mathrm{D}$ is present in the filtered diagram during all the time series. Although its values decrease sometimes (i.e., day 200 in Figure 2.21) indicating this to be a permanent feature at this latitude.

A more accurate value of wavelength of the 148 -D wave is $790 \mathrm{~km}$, as estimated with Radon transform using the filtered Hovmöller diagram. This wavelength explains the unique wavenumber spectrum with two maxima (Figure 2.20B). Since we are observing a phenomena with a wavenumber exactly between the two discrete maxima.

The 148-D wave has a maximum amplitude of $0.075 \mathrm{~m}$ and accounts for an explained variance of $25.7 \%$ of the SLA in its propagation pathway. However, this explained variance decreases when the wave reaches the $\mathrm{BC}$ domain. The $\mathrm{BC}$ variance in its axis explained by the 148-D signal is $9 \%$. This low variance of the SLA along the current axis is probably due to the 

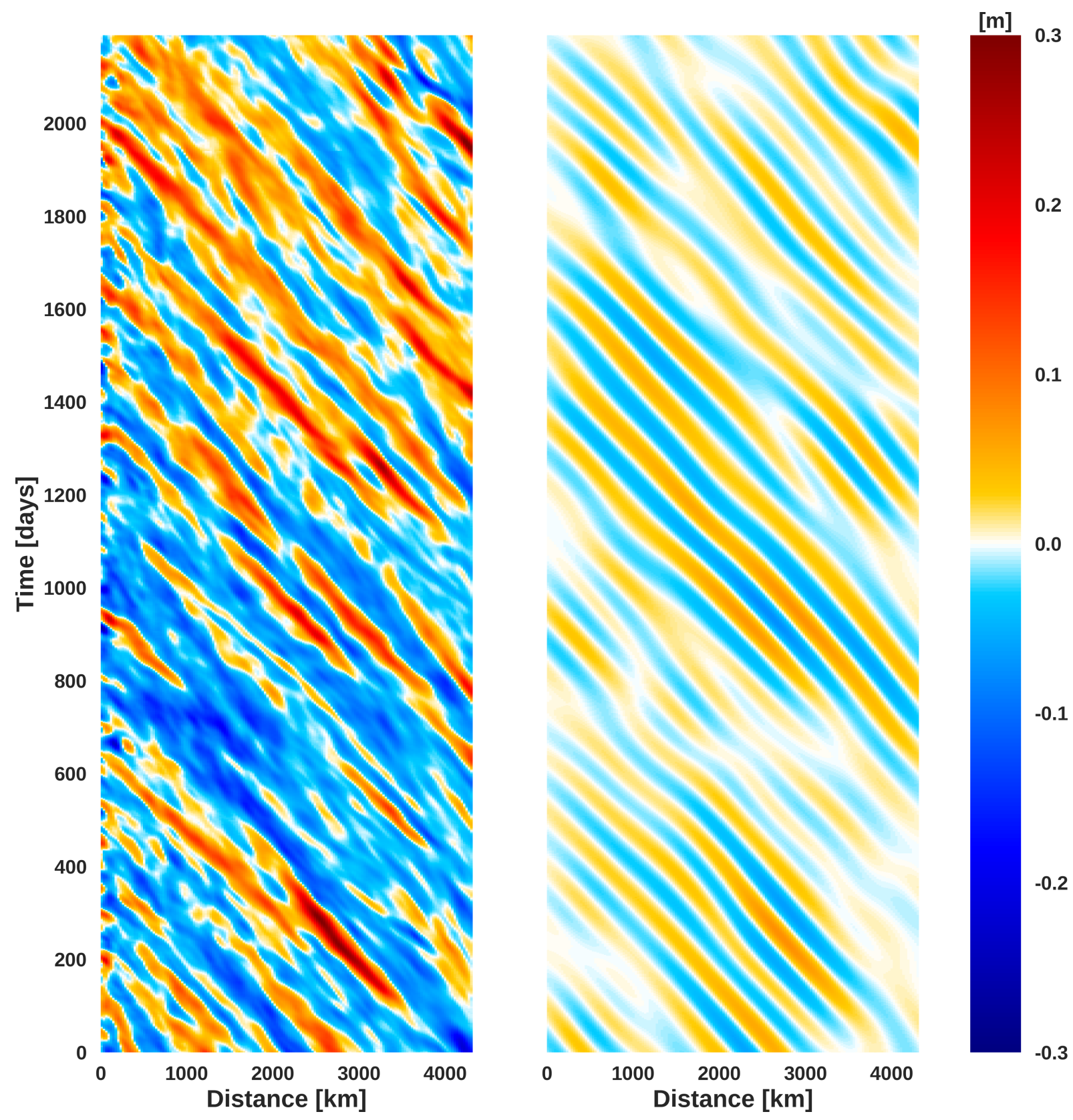

Figure 2.21: Same as Figure 2.13 but for 148 day signal in the new Hovmöller diagram path defined in Figure 2.19B.

way how the wave transfers energy to the current. Although there is a transfer of high values of energy to the current as the $148-\mathrm{D}$ reaches the $\mathrm{BC}$, this is done increasing and decreasing the $\mathrm{BC}$ velocity and therefore its transport. Andres et al. (2008) using satellite altimetry and in situ composit of data obtained an empirical function to estimate the transport of the KC. The authors identified the main variability of the KC transport near the South China Sea in a range of 100-170 days with the maximum of 150 days. Moreover the main variability of both $\mathrm{KC}$ and $\mathrm{BC}$ are related to its transport modulation (Zhang et al., 2001).

Mata et al. (2006) used 6 moorings of current meter data to study the mesoscale variability 
Table 2.1: Main spectral characteristics of each dominant signal to south and north of SBi.

\begin{tabular}{|c|c|c|c|}
\cline { 2 - 4 } \multicolumn{1}{c|}{} & Period [days] & Wavelength $[\mathbf{k m ]}$ & $\mathbf{c}_{p}\left[\mathbf{m s}^{-1}\right]$ \\
\hline \multirow{2}{*}{ North } & 92 & 491 & 0.06 \\
\hline \multirow{2}{*}{ South } & 68 & 397 & 0.07 \\
\cline { 2 - 4 } & 148 & 790 & 0.06 \\
\hline
\end{tabular}

of the EAC. The authors identified the mesoscale band to vary from the three moorings near the slope (to the coastal part of the current) to the three in the outter part of the current (one in the current's core and the other two in the interior ocean). The variability of the EAC is dominated by a period around 60 days near its core and coastal half. The moorings in the core of the EAC have a maximum mesoscale variability in periods near 100 days. No spectral information is available for the two moorings in the interior, however the variability period linked to the current meandering (60 days) is similar to the one observed in this study for the BC at south of the SBi.

We identified the spectral characteristics of the most important variability signals. Its frequencies were obtained with the method in section 2.2.2 and the wavenumbers were estimated with Radon transform. The spectral information of the signals to the north and south of the SBi, as well as the phase speed of the phenomena, are listed in Table 2.1.

Taking in account the presented results so far about the 92-D, 68-D and 148-D signals, we will try to elucidate what are the dynamics driving each one of them. The three waves differ, besides its location to the north or south of the SBi, in the orientation of its propagation axis. Therefore the dynamics of 68-D will be addressed separately from the 92-D and 148-D.

The 68-D wave propagates southwestward near the BC-axis. Therefore the signal of 68-D is probably a variability linked to current meandering. Most of the recent studies of the BC dynamics use a linear approach (Silveira et al., 2008; Rocha et al., 2014). Consequently the importance of nonlinearity in the meandering of the $\mathrm{BC}$ have been neglected.

To access the importance of nonlinearity is to analyze the importance of advective terms. To estimate the importance of advection of velocity compared with its local term, we will use the ratio between both. Considering the total acceleration $\frac{d u}{d t}$ from the equation of motion as

$$
\begin{gathered}
\frac{\partial \vec{u}}{\partial t}+\vec{u} \cdot \nabla \vec{u}, \\
\vec{u}=u \hat{i}+v \hat{j}+w \hat{k},
\end{gathered}
$$


the dimension of each velocity term becomes

$$
\frac{U}{T}+U \frac{U}{L}
$$

The ratio between those two terms is

$$
\frac{U^{2} L^{-1}}{U T^{-1}}=U^{2} T L^{-1} U^{-1}=U T L^{-1}
$$

The phase speed of a wave $\left(C_{p}\right)$ have a dimension of

$$
L T^{-1}
$$

Then the ratio between the local and advective terms of the velocity, hereafter call as $L_{i}$ is given by

$$
L_{i}=U T L^{-1}=U C_{p}^{-1}
$$

being $U$ the tangential velocity. Given the phase speed of the 68-D wave in Table 2.1, to estimate its linearity we need to determine $U$.

Considering a QG framework, $\vec{u}_{g}$ is

$$
\begin{gathered}
u_{g}=-\frac{\partial \psi}{\partial y} \\
v_{g}=\frac{\partial \psi}{\partial x},
\end{gathered}
$$

taking the tangential velocity in meridional direction and the Equation 2.8,

$$
v_{g}=\frac{g}{f_{0}} \frac{\partial \eta}{\partial x}
$$

We calculate $v_{g}$ by discretizing Equation 2.15 so that $\frac{\partial \eta}{\partial x}$ becomes $\frac{\Delta \eta}{\Delta x}$. Then we consider $\Delta \eta$ the difference in SLA between a consecutive crest and a trough and $\Delta x$ is the distance between the same interval, which corresponds to half wavelength. The $L_{i}$ parameter of the 68-D wave is 2.25 .

The meandering of the $\mathrm{BC}$ has recently been study within the SB as a result of baroclinic instability (Rocha et al., 2014). The authors identified unstable waves with the same wavelength at $25^{\circ} \mathrm{S}$, however with twice the phase speed, i.e. half the period. At $28^{\circ} \mathrm{S}$ the authors did not 
observed waves of $400 \mathrm{~km}$ to be unstable. Nonetheless the authors used an unidimensional instability linear model and the results obtained might be due to the limitations of their method, specially the disregard of nonlinearity. Moreover the authors used mooring current meters and analyzed the $\mathrm{BC}$ meandering at $25^{\circ} \mathrm{S}$ and $28^{\circ} \mathrm{S}$ in the BC-axis. The $68-\mathrm{D}$ as identified in the Figure 2.16 does not propagate along the exact current axis, instead a little offshore of it. Therefore this can account for the difference in the waves found by the authors and ours.

At $\sim 23^{\circ}$ S Silveira et al. (2008) studied the quasi-stationary meanders of the BC with a linear baroclinic instability model and observed a similar wave in frequency and wavelength, but with positive phase speed - i.e. northward propagation. These authors studied this as the formation of the Cape Frio Eddy (CFE). The formation of this quasi-stationary eddies could be one possible mechanism to generate the $68-\mathrm{D}$ wave found in our study. The instability wave initially causes the current to meander. After the meander is fully develop and the eddy is shed the current is perturbed. This shedding of the CFE can generate perturbations to the south of CF and be the responsible for the 68-D wave generation.

By utilizing SST data Biló (2015) identified a recurrent formation of cyclonic eddies, associated with a wave-like perturbation, between $27^{\circ} \mathrm{S}$ and $31^{\circ} \mathrm{S}$. The author studied the recurrence of the phenomena, observing an occurence of 5 to 6 events per year. This implies a period of formation of cyclones between 73 and 60 days. The period of this cyclonic features resembles a lot with the 68-D signal. The author identified this structures to be an important mechanism of shelf-slope mass exchanges in this region. However, he obtained a wavelength of almost half of that identified in this study, $219 \mathrm{~km}$ compared to $397 \mathrm{~km}$. Moreover the cyclones occured in the onshore side of the $\mathrm{BC}$, near the shelf break. Taking in consideration the wavelength an localization of the phenomena, we cannot state with certainty that we are looking at the same phenomena described by Biló (2015), even though the period of occurrence is the same.

Nonetheless the 68-D wave can play an important role in shelf-slope water exchanges with cyclones generating at every 68 days, and this can be of great importance to the local natural system, i.e. primary productivity induced by cyclonic meander Campos et al. (2000).

The 92-D and 148-D signals propagate to west, also they propagate as a wave front. Therefore based on this propagation direction we addressed first how these signals are related to first mode RW. The linear dispersion relation is given by

$$
\omega=\frac{-\beta k}{k^{2}+l^{2}+R_{d}^{-2}},
$$


where $\omega$ is the frequency, $k$ is the wavenumber, $R_{d}$ is the deformation radius and $\beta$ is the advection of planetary vorticity Gill (2016). To estimate this dispersion relation in the waves propagating axis we calculated deformation radii using the methodology of Flierl (1978) and the climatological Brunt-Väisälä frequency profile (Figure 2.2). The first baroclinic deformation radius to the latitude of propagation is $51 \mathrm{~km}$. Using the deformation radius and considering an almost zonal propagation, $k^{2} \gg l^{2}$, the dispersion relation becomes

$$
\omega=\frac{-\beta k}{k^{2}+51000^{-2}} \text {. }
$$

Both the 148-D and 92-D signals do not match the Rossby waves (RW) dispersion relation curve (Figure 2.22). However both dispersion relation of the signals are close to the line tangent to the non-dispersive part of the RW, refered as the nondispersive line nondispersive line (NDL). According to Early et al. (2011) the presence of features along this region of the spectrum is an indicative of nonlinear processes. Using a shallow-water model with both linear and nonlinear QG setup, he identified that when the nonlinear terms are negligible and they have only linear waves, there is not the presence of energy along the NDL in the spectrum.

Morten (2017) used a single-layer, shallow-water, beta-plane, quasi-geostrophic, turbulence model to study frequency-wavenumber spectrum, and identified the presence of energy along the NDL in the case characterized by westward propagating coherent eddies.

The fact that these two signal are close to the NDL is probably due to the its nonlinearity and the importance of advective terms. Using the Equation 2.13 the linearity parameter is 1.11 and 1.13 to $92-\mathrm{D}$ and 148-D respectively. However both signals are along the NDL, the 148D signal is closer to the dispersion relation curve of RW than the 92-D. Therefore the 148-D although seemingly a nonlinear phenomena could be a RW not along the dispersion relation curve because of the over simplification of the linear theory used to estimate the dispersion relation of the planetary waves.

Considering the linear theory, the 148-D frequency, wavenumber and the deformation radius, $\beta$ would have to be $2.7657 \times 10^{-11} \mathrm{~m}^{-1} \mathrm{~s}^{-1}$. The local value of $\beta$ at $\sim 28^{\circ}$, axis of 148 -D phenomena, is $2.0157 \times 10^{-11}$. The $\beta$ parameter can be better estimated considering in the linear theory an effective $\beta$ term to get a more accurate linear dispersion relation of RW (e.g. Samelson, 2010). This effective $\beta$ term considers not only the advection of planetary vorticity, but also the background velocity field and the effect of bottom slope. 


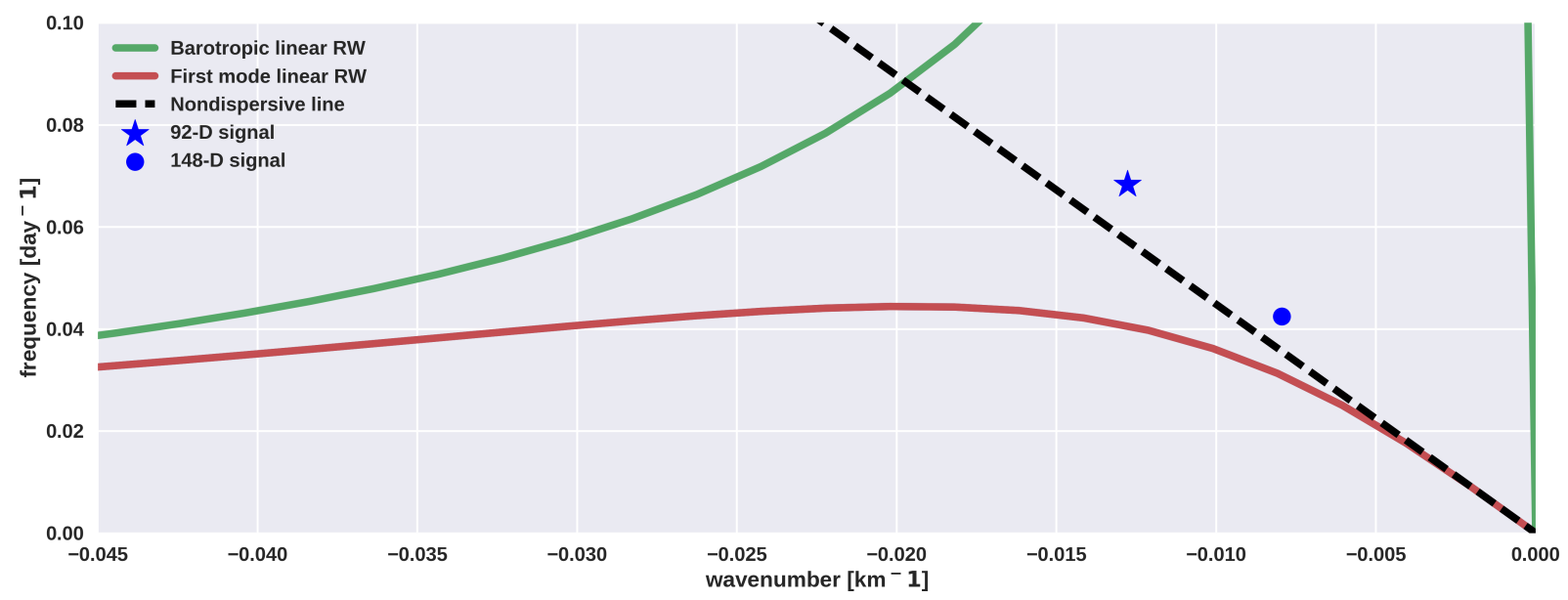

Figure 2.22: Dispersion relation of known phenomena, green line dispersion relation of barotropic and red line first baroclinic mode linear Rossby waves, black dashed line the NDL $f$, blue dot the 148 day signal and blue star the 92 day signal.

Still according to the linear theory of RW

$$
\frac{\omega}{\beta R_{d}} \leq 0.5,
$$

which means that for each deformation radius there is a minimum(maximum) period(frequency). Therefore, considering a fixed period, this means that for each period there is a minimum possible deformation radius and therefore a maximum latitude value, since in the linear theory $R_{d}$ is

$$
R_{d}=\frac{\sqrt{g^{\prime} H}}{\left|f_{0}\right|}
$$

with $H$ the local depth, $g^{\prime}$ the reduced gravity and $\left|f_{0}\right|$ the planetary vorticity. This restriction in latitude is called the critical latitude of RW.

Therefore, for the local $R_{d}$ of $51 \mathrm{~km}$, the critical latitude is $29^{\circ} \mathrm{S}\left(17^{\circ} \mathrm{S}\right)$ for the $148-\mathrm{D}(92-$ D) phenomena. So, considering a linear theory approach the $92-\mathrm{D}$ wave is $8^{\circ}$ past its critical latitude. Taking in account its critical latitude, linear parameter and dispersion relation, it is strongly suggested that the 92-D is not a linear RW.

To further investigate the nonlinearity of this waves, we analyze the spectrum of both waves to access if there are high values of energy along the NDL, in the site of the waves.

\section{Spectrum at $25^{\circ}$}

The 92-D wave has a zonal propagation pathway along the $25^{\circ} \mathrm{S}$ parallel. (Wortham and Wunsch, 2014) using a spectral model identified the world oceans characteristic local zonal and 
meridional wave number, period and phase speed. To the SB at this latitude their results are approximately the same phase speed but a zonal wavelength two times bigger than found in this study, therefore a period two times higher.

The spectrum of the Hovmöller diagram made for the propagation pathway of the 92-D signal has great part of its energy along the NDL but scattered around it. The first maximum of energy is related to non-propagating low-frequency phenomena. However the second maximum is at 100 days and in the same wavelength of the 92-D wave. This second maximum of energy is mostly due to the 92-D signal in this latitude (Figure 2.23).

The spectrum shows a trend to follow the NDL which indicates that the local phenomena are linked to nonlinear terms. Energy in the NDL region is present in the $k-\omega$ spectrum when the variability is dominated by the presence of coherent eddies. Therefore, and also considering the wave-like propagation of fronts, the 92-D signal is most likely to be nonlinear wave instead of a pathway of propagating nonlinear eddies (Wortham and Wunsch, 2014; Morten, 2017).

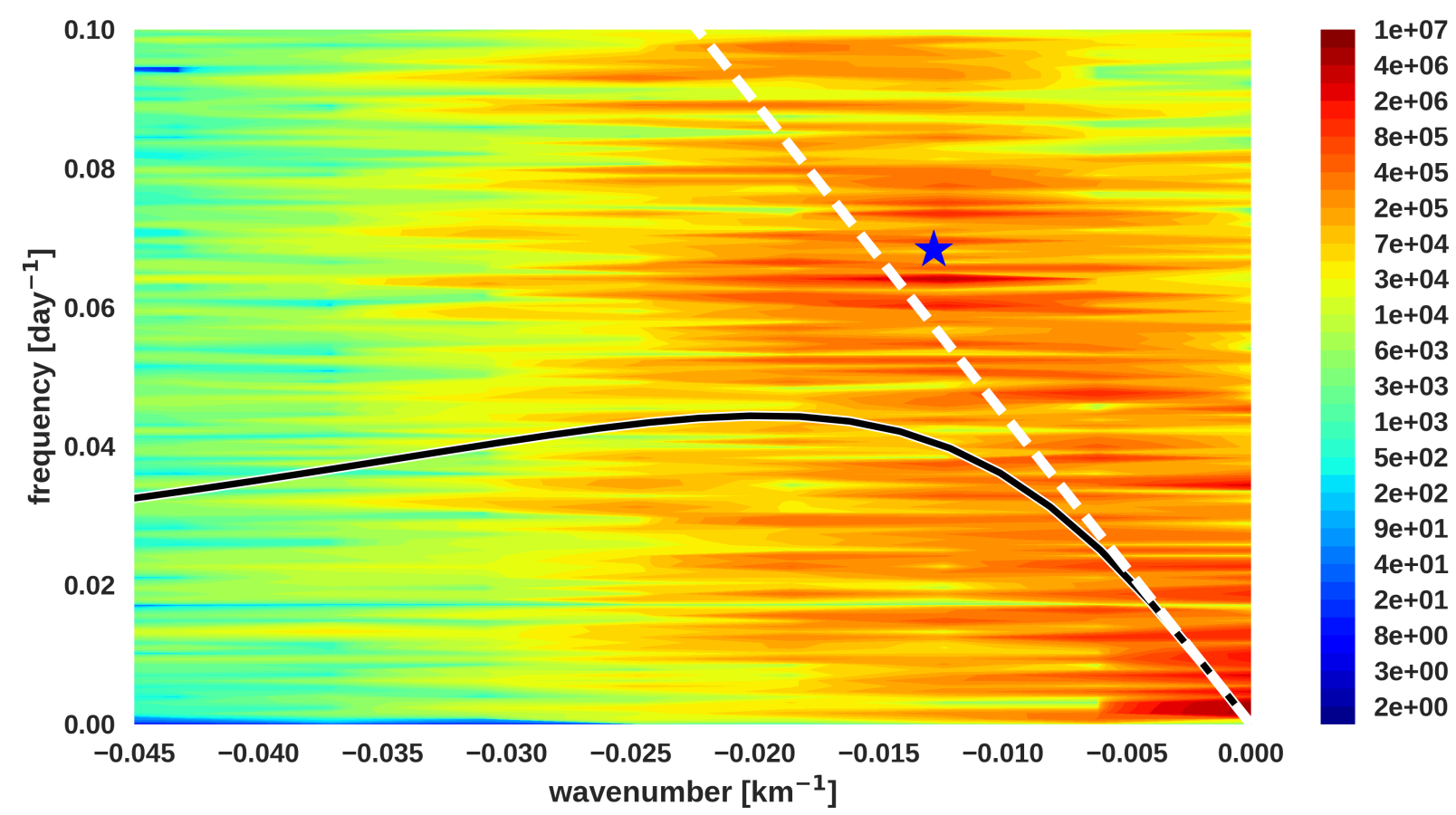

Figure 2.23: Wavenumber frequency spectrum for the 92-D wave pathway. Spectral energy $\left[\log _{10} \mathrm{~m}^{2} \mathrm{day}^{-1} \mathrm{~km}^{-1}\right]$, black solid line the dispersion relation of first mode linear RW, white dashed line the NDL for this waves and blue start the 92-D wave.

\section{Spectrum at $28^{\circ}$}

The $148-\mathrm{D}$ signal propagates along the $28^{\circ} \mathrm{S}$ parallel with a wavelength of $790 \mathrm{~km}$. Wortham and Wunsch (2014) identified in a spectral model a signal with similar wavelength, but a higher period in this latitude, as in the 92-D signal. 
The spectrum for this wave presents a narrower region of high energy, which is mostly restricted to the NDL (Figure 2.24). Moreover it does not present a substantial spectral energy along the RW linear dispersion relation curve. Therefore, there a high activity of nonlinear processesis in this latitude.

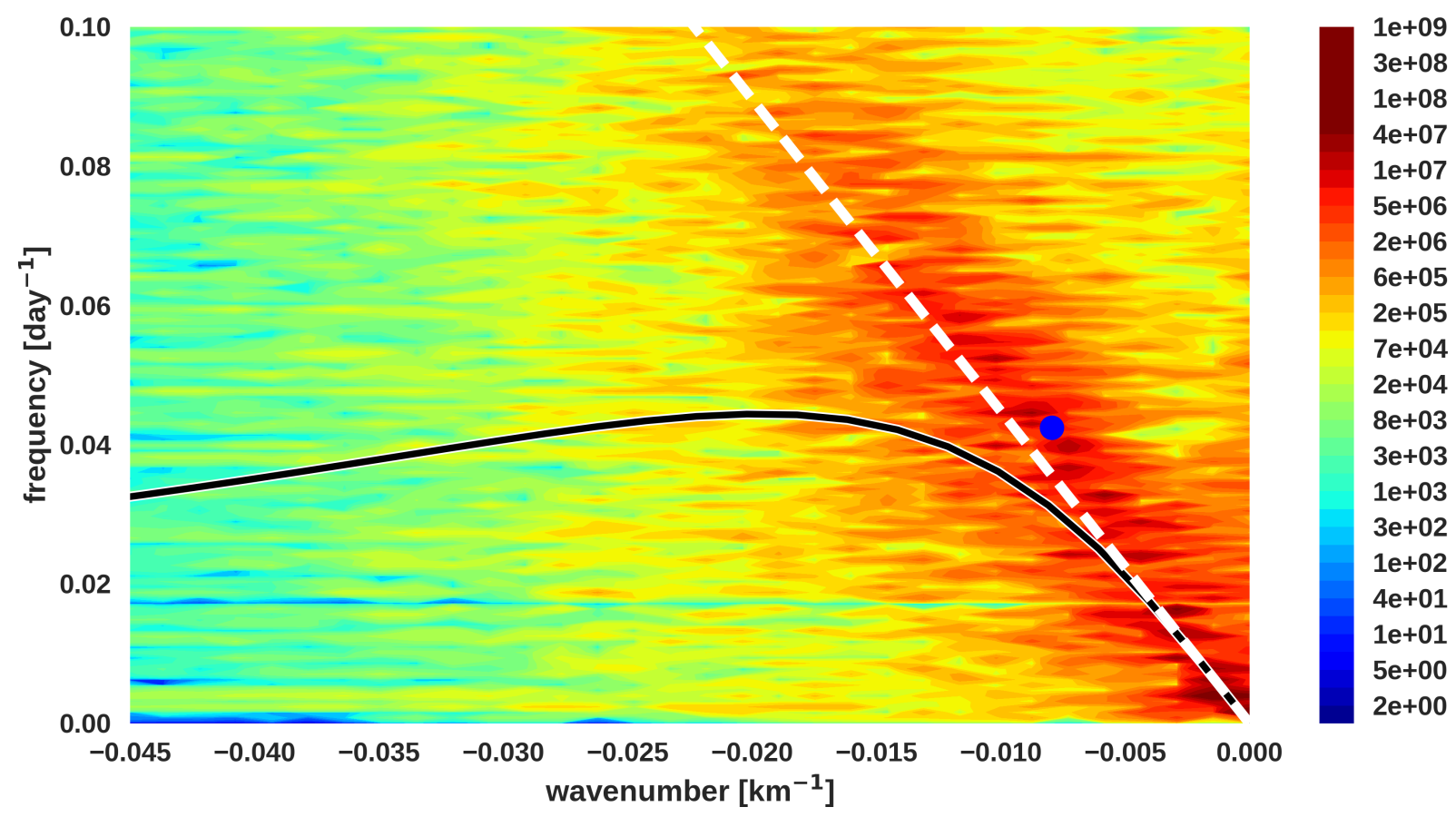

Figure 2.24: Same as Figure 2.23 but for the 148-D wave pathway.

However, considering only the critical latitude of the 148-D signal as a linear wave, there is a possibility that this signal is a RW. Further studies are needed in order to access the possibility that this phenomena is a result of the interaction of propagating linear waves and nonlinear eddies (Polito and Sato, 2015). 


\section{Chapter 3}

\section{Quasi-Synoptic Observations}

In this chapter, we will use in situ observations to provide a three-dimensional view of meanders identified as the main sources of variability of the BC within SB. In particular, we focus on showing evidence of the 68-D vorticity wave, its surface signature and vertical structure. The longer waves associated with westward propagating signals from the interior of the South Atlantic basin were not captured due to the synoptic cruise sampling strategy.

\subsection{Dataset}

\subsubsection{In situ Quasi-Synoptic Velocity Measurements}

The in situ velocity data set used in this work was obtained during the IOUSP-PETROBRAS Oceanographic Expedition "CERES V", conducted by the R/V Alpha Crucis between November 1 st and 23rd, 2013. The velocity data was acquired using a $75-\mathrm{kHz}$ broadband VMADCP with maximum profiling extent of about $500 \mathrm{~m}$ (which is dependent on sea conditions). The data acquisition transects are presented in Figure 3.1. The data was processed with the standard Common Ocean Data Access System (CODAS), following the procedures described in Firing et al. (1995). 


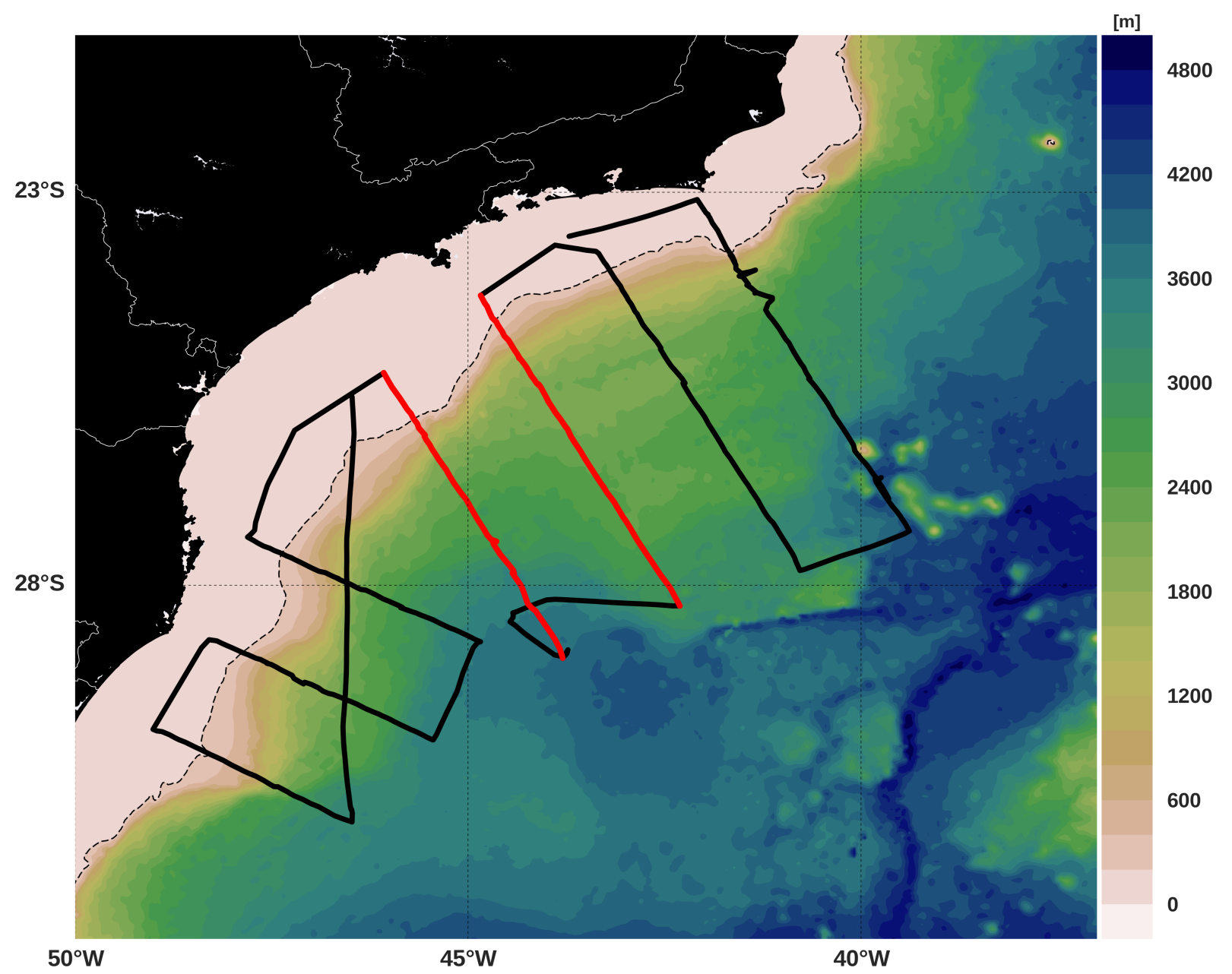

Figure 3.1: The CERES V cruise VMADCP sampling tracks (thick solid black lines). Solid red lines correspond to the transects used in this work to build the velocity sections. The color grading underneath the tracks denotes the bathymetry of the study area. The black dashed line marks the position of the $200 \mathrm{~m}$ isobath, which is the most accepted depth to represent the shelf break in SB.

\subsection{Methods: Objective Mapping}

Objective Analysis (OA) is an optimal interpolation scheme traditionally used in mapping oceanographic data (Bretherton et al., 1976; Carter and Robinson, 1987). The OA is least squares scheme, based on the Gauss-Markov theorem. In this work, we use both scalar and vector versions of $\mathrm{OA}$ to build velocity vertical sections and the horizontal velocity vector and streamfunction maps.

This OA scheme first step consists of approximating (or fitting) the data (or sample) correlation function to a horizontally isotropic Gaussian function given by

$$
C(r)=\left(1-\varepsilon^{2}\right) e^{-r^{2} / l_{c}^{2}},
$$

being $r$ the Euclidian distance between two data points, $\varepsilon$ the uncorrelated error variance, $l$ 
is the correlation length. The fit nonlinearly provides the correlation length and linearly, the sample error variance. The second step consists of applying the Gauss-Markov theorem in the form of:

$$
\hat{\theta}_{\mathbf{j}}=C_{j i} C_{i i}{ }^{-1} \theta_{\mathbf{i}}
$$

where $\hat{\theta}_{\mathbf{j}}\left(\theta_{\mathbf{i}}\right)$ represents the $j$ th grid point (the $i$ th observation location) at which the quantity $\psi$ is interpolated (was measured). $C_{i i}$ is the data autocorrelation function and $C_{j i}$ is the cross-correlation between data and gridded fields. We encourage the reader to seek Carter and Robinson (1987) for more details. We should also mention the technique developed by Bretherton et al. (1976) used to map the streamfuction field from scattered velocity measurements is applied to the CERES V VMADCP velocity vector measurements.

OA schemes considering either Equation 3.1 or its anisotropic version have been successfully used to map scalar and vector fields related to the southwestern boundary currents (da Silveira et al., 1994; Silveira et al., 2000, 2004; Goes et al., 2005; Silveira et al., 2008; Soutelino et al., 2011). In particular, Silveira et al. (2000) (Goes et al. (2005)) introduced free-slip (no-slip) boundary conditions within the OA scheme to constrain the mapped flow in the presence of solid boundary in the area of interest. We opt here to apply no-slip boundary conditions by introducing $v=u=0$ input vector along an isobath, which is taken to be the limit between seawater and land.

\subsection{Results and Discussion}

\subsubsection{Near-Surface Streamfunction Fields}

In order to identify the signature of the 68-D wave in the VMADCP data, we used the vector OA to map the streamfunction $\psi$ directly from the observed $u(x, y)(v(x, y))$, the zonal (meridional) velocity component at a chosen depth. The correlation length and sample error variance used in an a priori correlation function (Equation 3.1) were $1.2^{\circ}$ and 0.1 , respectively. The socalled "observed streamfunction" virtually represents the geostrophic $\psi$ and, therefore the $\psi$ distribution at near-surface can directly compared with the AVISO $\psi$.

The shallowest VMADCP data bin is $30 \mathrm{~m}$. This depth is embedded within the mixed layer and take it as close enough to the surface to be compared with the AVISO ADT field. We also imposed the no-slip boundary condition at the $30 \mathrm{~m}$ isobath, which is found at the inner shelf 
where neither the geostrophic balance is valid nor the $\mathrm{BC}$ is in this region. The $\psi$ map at $30 \mathrm{~m}$ and its accompanying interpolation normalized error are presented in Figure 3.2.

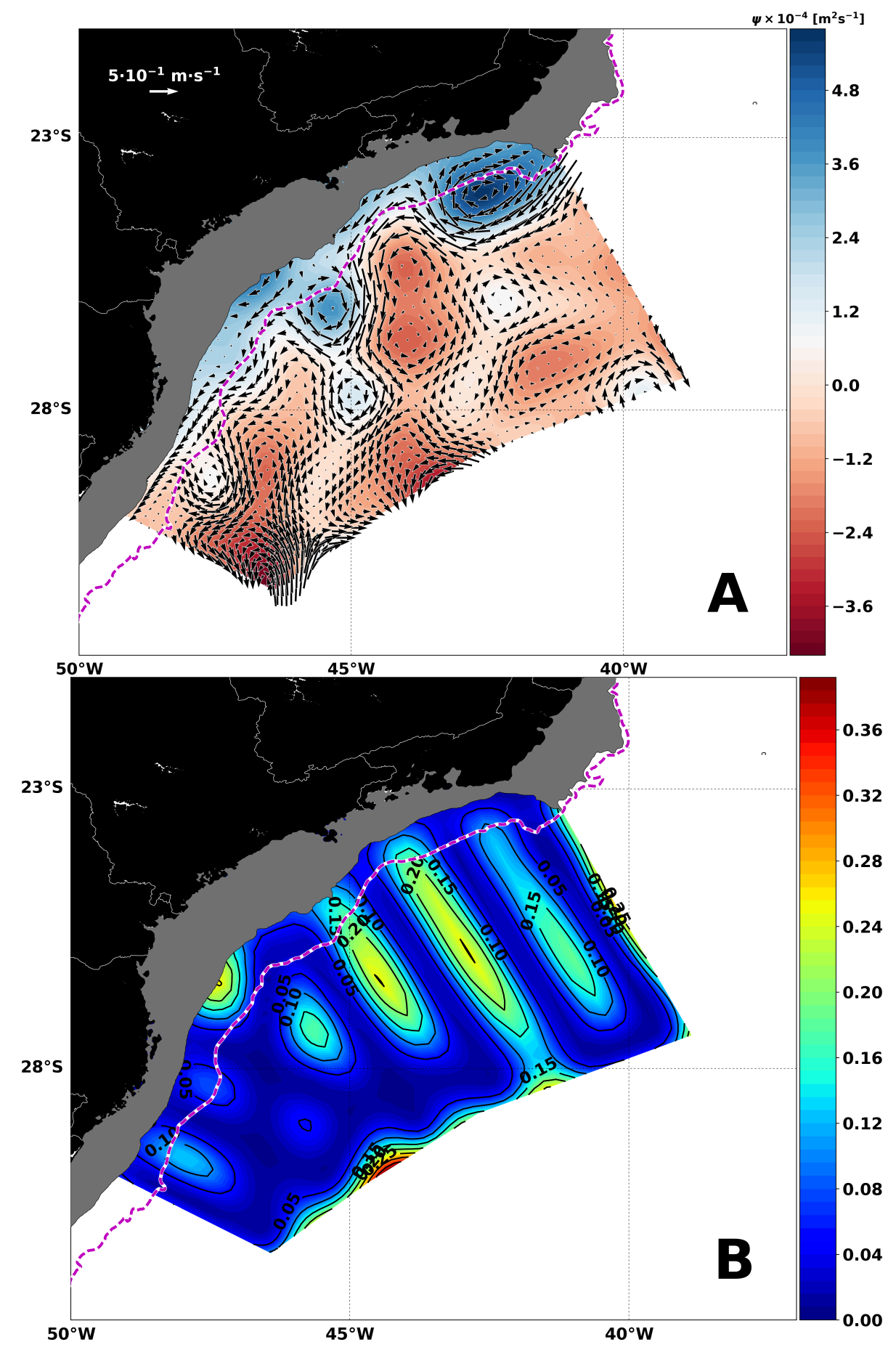

Figure 3.2: Maps of the CERES V. (A): observational streamfunction $\psi$. (B): the associated interpolation error at $30 \mathrm{~m}$. The gray area represents depths shallower than $100 \mathrm{~m}$; the mangenta dashed curve denotes the shelf break position.

The $\psi$ distribution depicted in Figure 3.2 presents a highly meandering BC with incursions (anticyclonic meanders) onto the shelf at $24.5^{\circ} \mathrm{S}$ and $28^{\circ} \mathrm{S}$. Excursions (cyclonic meanders) can be seen at $23^{\circ} \mathrm{S}, 26^{\circ} \mathrm{S}, 28^{\circ} \mathrm{S}$ and $30.5^{\circ} \mathrm{S}$. Oceanward of the BC axis, an anticyclone-cyclone pair 




Figure 3.3: Comparison between the (A) CERES V $\psi_{o}$ and (B) AVISO streamfunction $\psi_{a}$ fields during the cruise period. The black solid line delimits the CERES V sampling area. The gray area represents depths shallower than $100 \mathrm{~m}$; the magenta dashed curve denotes the shelf break position.

is clearly identified between $42^{\circ} \mathrm{W}$ and $46^{\circ} \mathrm{W}$.

The investigation of the $68 \mathrm{D}$ wave signal was conducted using altimetry data in chapter 2 . We here seek to identify if any of the vorticity structures observed during the CERES V cruise are related to those waves, which propagate southwestward parallel to the current axis. Figure 3.3 compares the near-surface $\psi$ (streamfuction from CERES V) with the $\psi_{a}$ (streamfuction for the averaged AVISO data during cruise) distribution. As expected due to averaging, interpolation and synopticity issues, the $\mathrm{BC}$ meander amplitudes are smaller in the AVISO field than that of the CERES $\mathrm{V} \psi$ field. It is probably a precision issue associated with resolving the tides and the geoid at shallower depths. Thus the $\psi_{a}$ field is smoother. Nonetheless, the vortical pair described in the last paragraph is identifiable in the AVISO map as well. In both maps, the cyclone-anticyclone pair exhibits an approximately $400-\mathrm{km}$ extension, which matches the calculated 68-D wavelength.

In order to further pursue whether the vortical pair present in the "raw" AVISO map is related 




Figure 3.4: Comparison between (A) the AVISO streamfunction field $\left(\psi_{a}\right)$ during the CERES $\mathrm{V}$ cruise and (B) its FFT-filtered version for a band centered in 68 days $\left(\psi_{68}\right)$. The gray area represents depths shallower than $100 \mathrm{~m}$; the mangenta dashed curve denotes the shelf break position.

indeed to the 68-D wave, we apply the same filtering process employed in the analysis described in chapter 2. We thus again use a band-pass FFT filter centered in period of 68-Ds and with a range of $10 \%$. The filtered $\psi_{68}$ field Figure 3.4 preserves the presence of both the cyclone and anticyclone bordering the current. The basin interior is characterized by nearly zero velocities and reassures in the spatial domain the findings of chapter 2: the 68-D vorticity waves are intrinsically associated with the $\mathrm{BC}$ axis and motion.

The $\psi_{68}$ map reproduces the same two vortical features within the SB along the BC but the anticyclone-cyclone extent is overestimated in about $\sim 50 \mathrm{~km}$ if compared to both the nonfiltered $\psi_{a}$ and the CERES V $\psi_{o}$. This difference could have occured because the $\psi_{a}$ may have merged the two adjacent anticyclones centered at $\left(24^{\circ} \mathrm{S}, 44^{\circ} \mathrm{W}\right)$ and $\left(26.5^{\circ} \mathrm{S}, 44^{\circ} \mathrm{W}\right)$ as a single one. Aiming to unravel the reason, we rewrite Equation 2.2 in terms of the geostrophic streamfunction using Equation 2.6 to obtain 


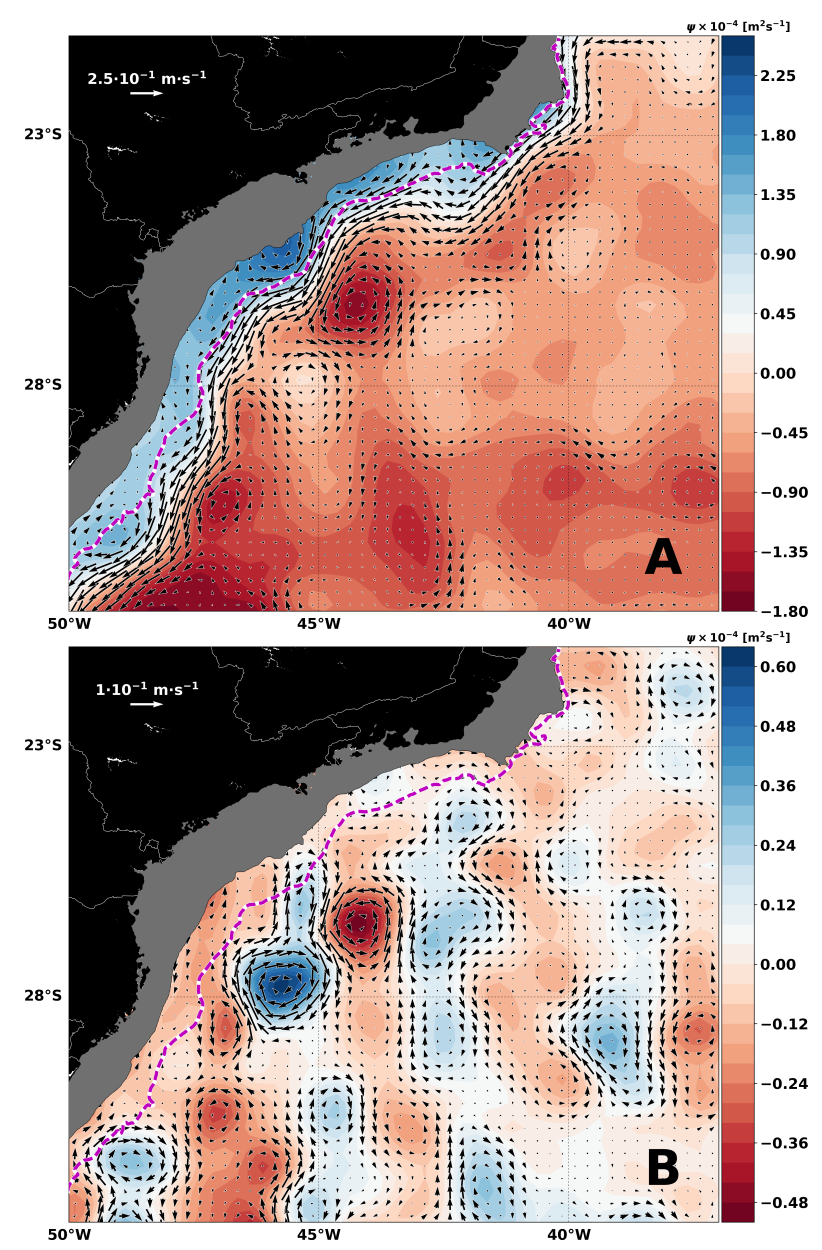

Figure 3.5: The 68-D filtered total and anomaly AVISO streamfunction fields $\left(\psi_{68}\right.$ and $\left.\psi_{68}^{\prime}\right)$ for the CERES V cruise period. The gray area represents depths shallower than $100 \mathrm{~m}$; the mangenta dashed curve denotes the shelf break position.

$$
\psi^{\prime}(x, y, t)=\psi_{a}(x, y, t)-\bar{\psi}(x, y)
$$

where the $\psi_{a}(x, y, t), \bar{\psi}(x, y), \psi^{\prime}(x, y, t)$ definitions are analogous to those of $\eta_{a}(x, y, t), \eta(\bar{x}, y)$, $\eta^{\prime}(x, y, t)$. We opt to present the $\psi_{68}^{\prime}$ field and compare it with the total $\psi_{68}$ (Figure 3.5). It is clearly seen in the anomaly streamfunction field that both anticyclones at $44^{\circ} \mathrm{W}$ are identifiable. The crest and trough of the 68-D vorticity wave pattern is shapely displayed. The masking effect of such feature is due to the $\bar{\psi}(x, y)$ computed from the MDT.

The 68-D wave propagation axis is not fully aligned with the mean BC as well as totally parallel to the shelf break either (Figure 3.6). But it is clear that vortical pair propagates south at the phase speed of $0.07 \mathrm{~m} \mathrm{~s}^{-1}$ estimated in chapter 2 . As it continues to propagate southwestward, the wave train gets nearer the shelf break. Hence, it is likely that it can promote shelf-slope exchange as predicted by Biló (2015). Moreover, the more oblique propagation the wave exhibits relative to the $\mathrm{BC}$ axis, the weaker its signal is (Figure 2.18). One possibility is 
that interaction with topography discontinues the wave pattern; another is the limitation of the AVISO data in mapping accurately features at shallow depths. On the other hand, in the cases the wave propagates exactly parallel to the current axis, its signal is not seen as attenuated in the Hovmöller diagram.
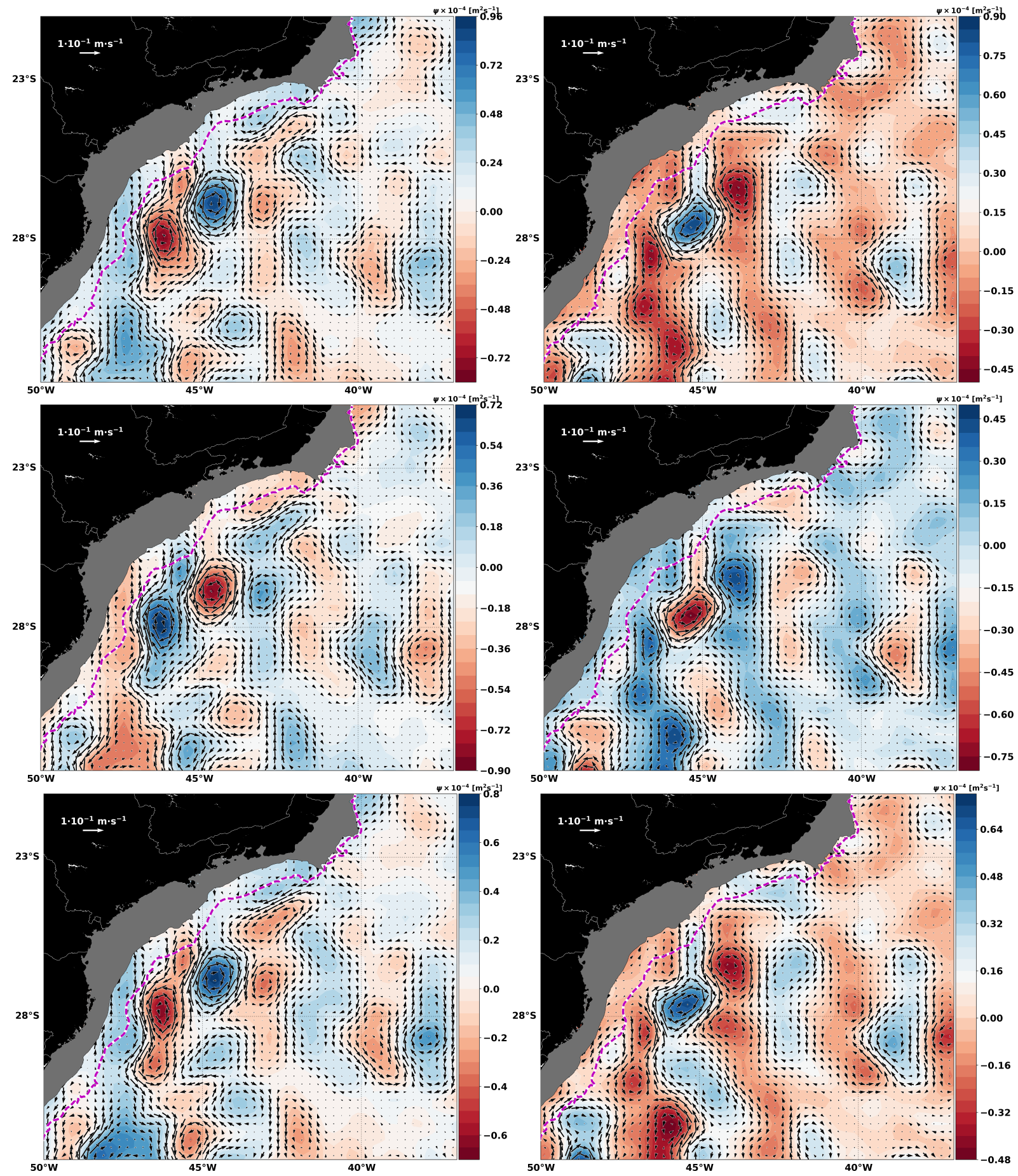

Figure 3.6: The 68-D wave propagation: (A), (B), (C), (D), (E) and (F). The gray area represents depths shallower than $100 \mathrm{~m}$; the magenta dashed curve denotes the shelf break position.

We present in Figure 3.7 a Hovmöller diagram with a 6-year time series span centered in 
time on the CERES IV cruise period. The intent is to produce here an analogous diagram to that shown in Figure 2.18. We repeated the length time to allow the reader a comparison with the figure from chapter 2 in terms of phase speeds (i.e., the troughs or crests distance-time inclination). The anticyclone (to the north) and the cyclone (to the south) of the 68-D wave displayed at Figure 3.3, Figure 3.4, Figure 3.5 and temporally followed through the six panels of Figure 3.6 are marked by black arrows at its most upstream position. We do see a clear southward propagation and a discontinuation at $\sim 400 \mathrm{~km}$ in the distance axis, which coincides with the CSM location (which is marked by a magenta dashed line). The wave structure to the southwest of $400 \mathrm{~km}$ line displays bifurcations and much lower amplitude values of the features. This probably indicate that either the wave ceased to exist somehow or it was reflected since its trajectory may be oblique relative to the mean current path and hit the western boundary.
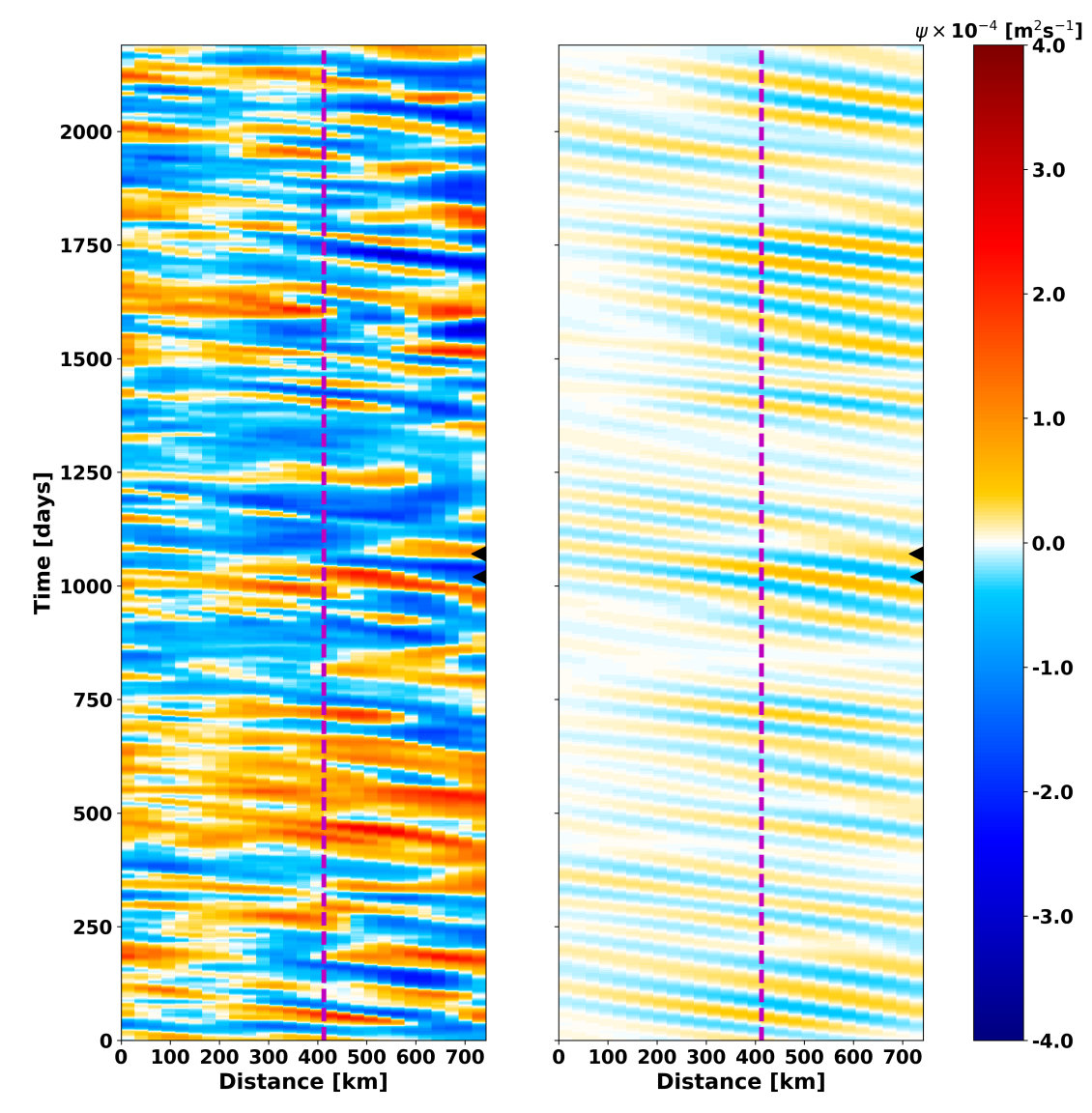

Figure 3.7: Hovmöller diagram of the streamfuction anomaly of the AVISO series centered at the CERES V period. The black arrows mark the anticyclone (crest) and the cyclone (trough) of the 68-D wave captured by the cruise sampling. The magenta dashed line denotes the CSM location. 
We now return to CERES V data aiming a more quantitative comparison between the $\psi$ and $\psi$ fields, rather the more qualitative one depicted in Figure 3.4. This time, however, we compare the observational $\psi$ with the 68-D filtered version. We want prove that the vortical pair detected in both maps is indeed the same feature depicted simultaneously by in situ measurements and remote sensing. Therefore, the features should be located approximately in the same geographical location in both maps, despite the differences of original data coverage and interpolation techniques. In order to do so, let us consider two scalar fields $A(x, y)$ and $B(x, y)$. A simple way to evaluate whether they are parallel to each other is to calculate the Jacobian matrix of their gradients. If they are parallel, then $\nabla A \times \nabla B=0$, i.e.,

$$
J(A, B)=\operatorname{det}\left[\begin{array}{ll}
\frac{\partial A}{\partial x} & \frac{\partial A}{\partial y} \\
\frac{\partial B}{\partial x} & \frac{\partial B}{\partial y}
\end{array}\right]=\frac{\partial A}{\partial x} \frac{\partial B}{\partial y}-\frac{\partial A}{\partial y} \frac{\partial B}{\partial x},
$$

Therefore, if $J(A, B)=0$, so is $\nabla A \times \nabla B=0$ and $A$ and $B$ are parallel. We then calculate the Jacobian field of the filtered data with the cruise data (Figure 3.8). We should note that the Jacobian field is higher where the $\psi$ fields differ more. As expected, the higher values are found near shelf break. Nonetheless the Jacobian values within the two main vorticity structures present in the filtered data are very low, which demonstrates that this cyclone and anticyclone are positioned at similar location in both data sets. The features in the CERES V map are smaller, which explains the increasing of the Jacobian values towards their edge. These size differences can be due to distinct original data resolution, mapping procedures and filtering. 


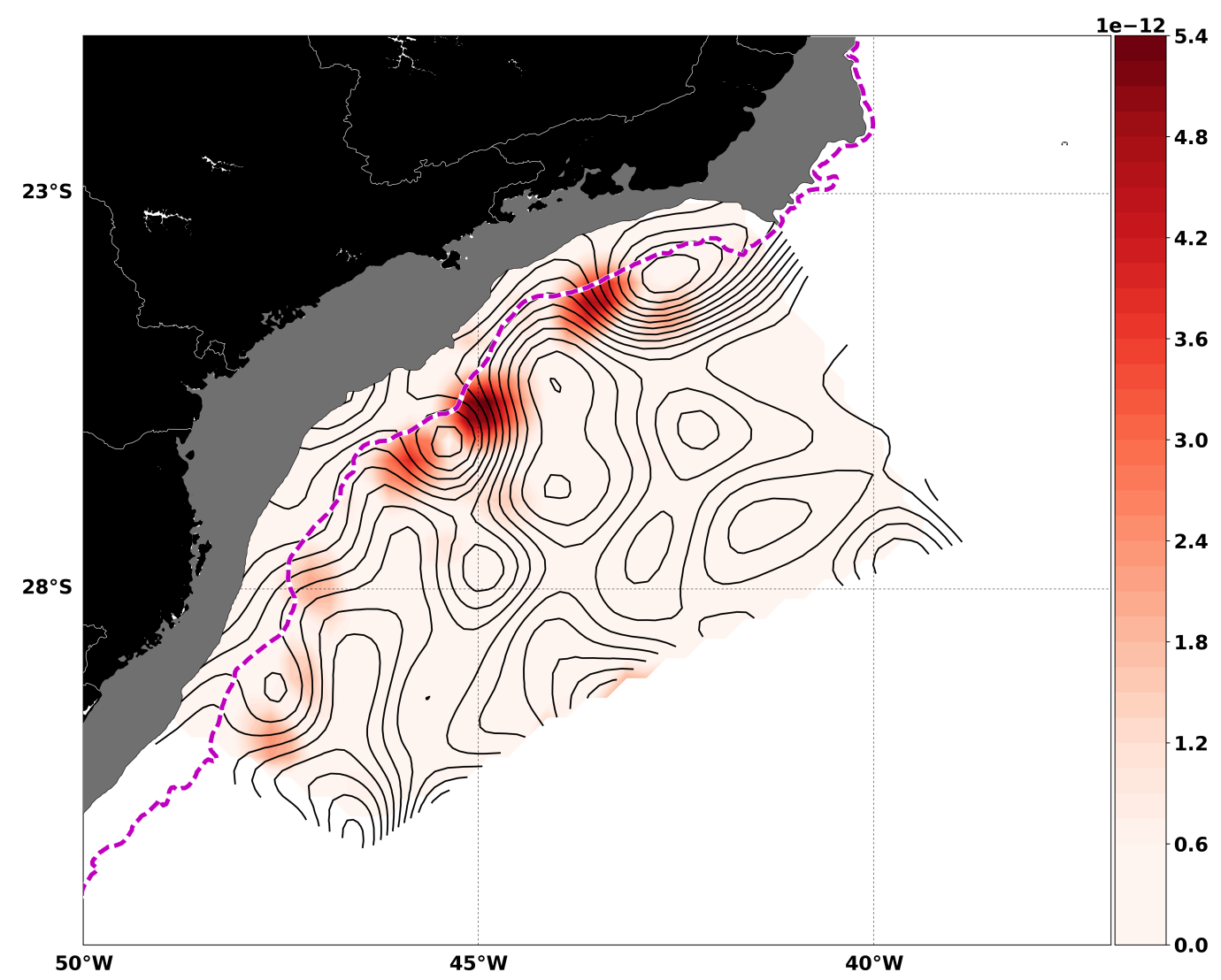

Figure 3.8: The Jacobian between the CERES V $\psi$ field and the filtered AVISO $\psi$ field.

\subsubsection{Velocity Vertical Sections}

In the previous subsection, we identified a 68-D crest-trough vortical pair in the CERES V near-surface streamfunction maps and examined its correspondence on the AVISO streamfunction maps. In the present subsection, we describe two vertical sections of the same situ data set that captured the anticyclone and the cyclone which form the pair. Figure 3.9 displays the VMADCP tracks with the two transects that sampled the eddies in red.

Neither of the red-marked transects crossed the eddy but center. As a matter of fact, both sampled their northeastern borders. Therefore, we do not expect to see velocities comparable to those of the $\mathrm{BC}$ as seen in the $\psi, \psi_{a}, \psi_{68}$ and $\psi_{68}^{\prime}$ horizontal distributions. However, we do expect to comment on their vertical structure. 


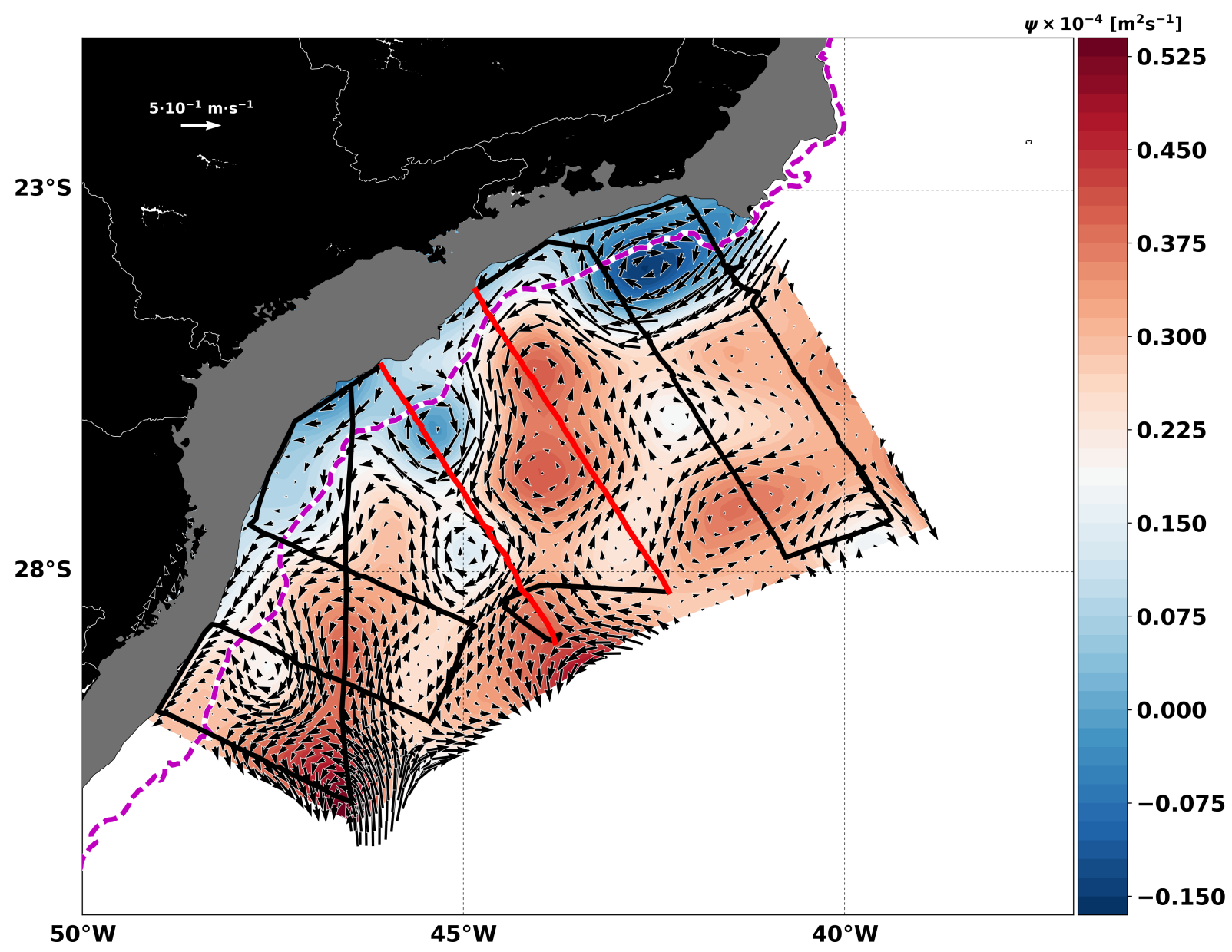

Figure 3.9: The VMADCP tracks (black thick solid lines) overlaid on the CERES V 30m streamfunction field. The red thick solid line highlights the two transects which vertical structure will be shown and described in this subsection. The gray area represents depths shallower than 100 $\mathrm{m}$; the mangenta dashed curve denotes the shelf break position.

\section{Anticyclonic Eddy transect}



Figure 3.10: Vertical section of the VMADCP profiled velocity of transect \#3 (the northern red transect in Figure 3.9). The black area represents the topography, and the magenta dashed line the position of outermost station of LADCP top-bottom profile carried out during the cruise and described by Biló (2015). 
In this transect (Figure 3.10), we note a BC well attached to the shelf break with a maximum velocity of $\sim-0.75 \mathrm{~m} \mathrm{~s}^{-1}$. Although the VMADCP profiling extent did not capture the IWBC domain, the velocities at $450 \mathrm{~m}$ depth are at $\sim-0.05 \mathrm{~m} \mathrm{~s}^{-1}$ and the $\mathrm{BC}$ velocities appear to be decreasing with increasing depth. This shallow $\mathrm{BC}$ is due to the fact that this transect is to the north of the SBi near the slope, and so the BC had not thicken yet. Biló (2015) analyzed the top-bottom current pattern obtained by LADCP in the transect sampled during the CERES V (November 2013) at same position of the northern red one shown in Figure 3.9. The authors described that the $\mathrm{BC}$ reacher $500 \mathrm{~m}$ and the virtually $1500 \mathrm{~m}$-thick IWBC underneath it. Despite our depth constraint the southwestern velocity decrease depicted with VMADCP data suggests a similar current configuration is present in the CERES V cruise.

The BC volume transport is $-14 \mathrm{~Sv}$ in the upper $450 \mathrm{~m}$; its width is $160 \mathrm{~km}$ at the surface, but the cruise did not sampled the whole current structure. Moreover the BC in this transect is leaning towards the shelf, which is in accordance with the pattern of a frontal anticyclonic meander, such as the depicted in the $\psi_{o}$ map (Figure 3.9).

Oceanward of the inner two-lobe structure associated with BC frontal slope, a second eddy sectional distribution can be identified in (Figure 3.10). This is the counterclock rotating feature linked to the 68-D wave and the one we are interested in. Considering its velocity inversion pattern, the inshore (offshore) lobe of the eddy, which is marked by the negative (positive) velocities is centered at $\sim 275 \mathrm{~km}(\sim 350 \mathrm{~km})$ from the transect starting point.

The anticyclone offshore lobe has a maximum velocity of $0.29 \mathrm{~ms}^{-1}$ and a transport of 5.9 Sv. This lobe is $140 \mathrm{~km}$ wide and reaches more than $450 \mathrm{~m}$. The coastal lobe presents minimum velocities of $-0.15 \mathrm{~ms}^{-1}$ and is $70 \mathrm{~km}$ wide. Deeper than $200 \mathrm{~m}$, its signal merges with the one from the BC frontal meander, as seen by inspecting Figure 3.9. The difference in the velocities between the two lobes might be caused by the cruise sampling, i.e., there is a $30^{\circ}$ angle between the line joining the anticyclone centers and the transect orientation. For this reason, the width and velocity between lobes differ importantly. The vertical extent of the better sampled (offshore) lobe is comparable with that of the BC. The BC exhibits higher velocity values (in magnitude) at surface, where its velocity shear is also stronger. Both features seem to be at least $500 \mathrm{~m}$ thick. 


\section{Cyclonic Eddy transect}

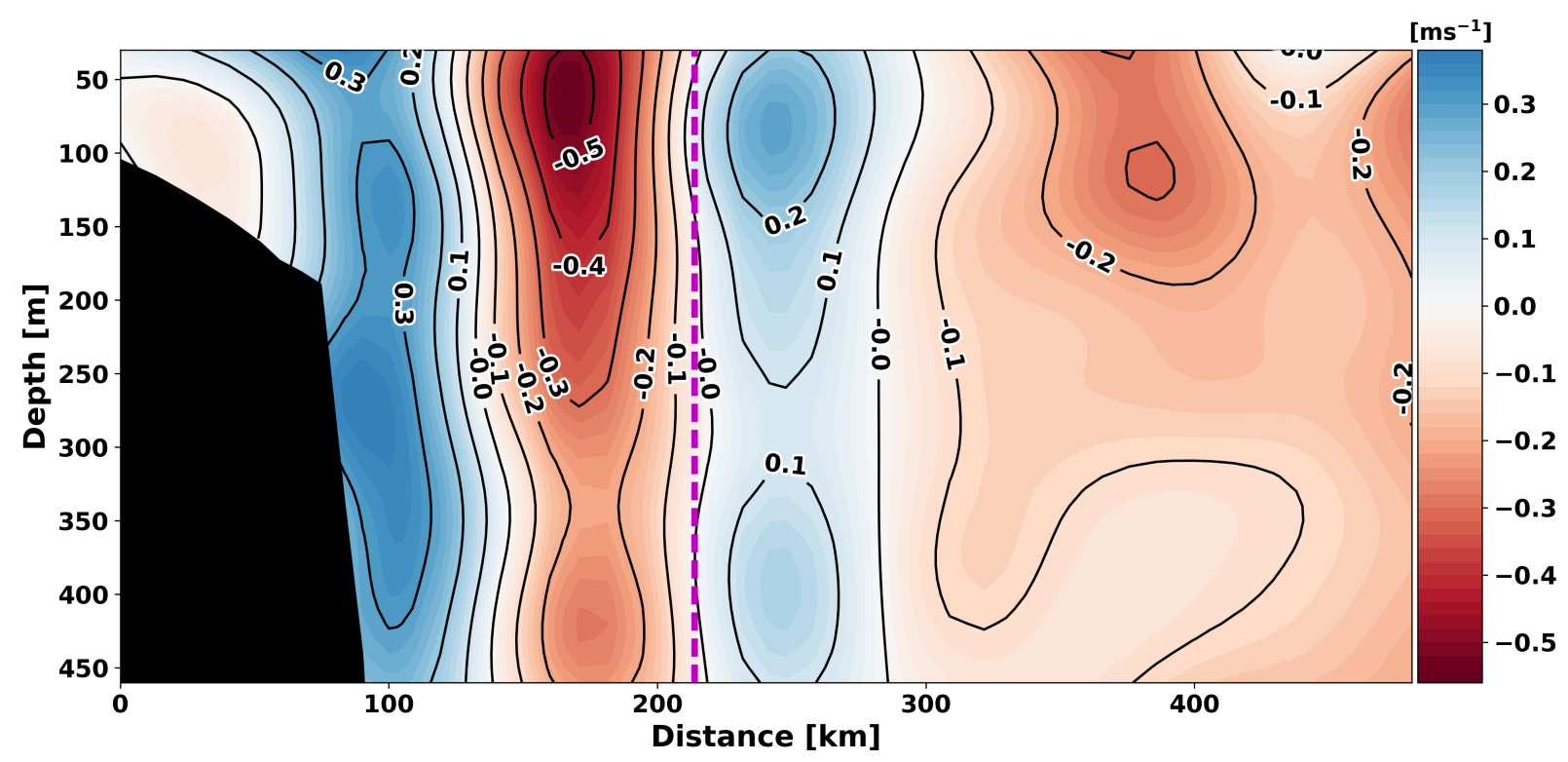

Figure 3.11: Southern red transect in Figure 3.9. Filed contour of cross-transect velocity, black area the shelf break and slope and magenta dashed line the limit of LADCP collected during the cruise and used by Biló (2015).

The transect \#4 (the southern red transect) seems as a virtual mirror image of transect \#3, both displayed in Figure 3.9. We observe a cyclonically meandering BC, which is distant from the shelf break. This frontal cyclonic meander resembles the characteristics of others reported by Campos et al. (1995) from geostrophic estimates. The inshore lobe presents a maximum of $0.38 \mathrm{~m} \mathrm{~s}^{-1}$. The maximum BC velocity is $\sim-0.55 \mathrm{~m} \mathrm{~s}^{-1}$ at its surface core. The BC vertical shear seems to be weaker than that observed in the northern transect and presents a more vertically elongated structure appearing to reach higher depths. At the corresponding CERES IV transect, Biló (2015), through LADCP profiles, identified a BC which extended from the surface to $750 \mathrm{~m}$ depth with the IWBC beneath it and flowing to north. The inner portion of the transect seems still to be to the north of the SBi. As described by Boebel et al. (1999) and Legeais et al. (2013), the bifurcation structure veers to south and develops a cyclonic retroflection at the shallowest depths of the São Paulo Plateau.

Adjacent to the cyclonic frontal BC meander, transect \#4 exhibits vortical lobes of opposite signs associated with the trough of the 68-D wave. The coastal lobe of the 68-D cyclone has a vertical structure similar to that of the current and reaching $0.17 \mathrm{~m} \mathrm{~s}^{-1}$ at $400 \mathrm{~m}$ depth. This lobe maximum velocities are $0.29 \mathrm{~m} \mathrm{~s}^{-1}$ and its horizontal extension is of $88 \mathrm{~km}$, with core depth of $\sim 80 \mathrm{~m}$. The oceanic lobe has a horizontal extension of $\sim 140 \mathrm{~km}$ and a maximum velocity of $-0.31 \mathrm{~m} \mathrm{~s}^{-1}$ with the maximum velocity at $\sim 110 \mathrm{~m}$ depth. Additionally, the volume 
transport of the coastal (oceanic) lobes is $3.33 \mathrm{~Sv}(-6.6 \mathrm{~Sv})$. The discrepancy between these two estimates might be related, as for transect \#3, to the angle at which the ship track crossed the vortical structure. The resemblance of the vertical structure between the 68-D through and the BC suggests that both features present similar dynamical mode composition. Further sampling of the eddies vertical structure ought to be done with longer transects and LADCP profiling covering all their extensions. 


\section{Chapter 4}

\section{Summary and Conclusions}

The goal of this work was to study the subinertial variability of the BC system within the SB, and in order to accomplish that, we primarily used satellite altimetry data and some traditional spectral analysis techniques. We also analyzed quasi-synoptic observations of an oceanographic cruise, which was part of the IOUSP-PETROBRAS CERES Experiment and sampled the whole SB.

The BC thickens and, therefore, changes its vertical structure and dynamical modal composition as it crosses the SB. As it enters the bight by trying to contour $\mathrm{CF}\left(23^{\circ} \mathrm{S}\right)$, the $\mathrm{BC}$ is about $500 \mathrm{~m}$ deep and transports TW and SACW. As the current leaves the bight south of CSM $\left(28^{\circ} \mathrm{S}\right)$, it is $1300 \mathrm{~m}$ deep and also transports AAIW and UCDW at subpycnocline levels. These differences in thickness and accompanying velocity vertical shear is due to the impinging branch of the intermediate SEC and subsequent bifurcation as it hits the slope at central latitudes of the SB. This oceanographic feature is referred in the literatures as the SBi.

We showed that there are different phenomena occurring to the north and to the south of the bifurcation and this might be caused by the SBi feature itself and/or the consequential change in the $\mathrm{BC}$ jet vertical structure downstream. For this reason, we carried out our investigation examining two separate regions: north and south of the SBi axis. We studied the spectra splitting the SB domain in the two areas and focused on the two most important peaks at each portion.

\section{The Northern Study Area}

North of the SBi, we found a spectrum peak in 175 days which we linked to linear Rossby waves, and since it was in the range of semiannual phenomena, we did not further analyzed this period band. The second peak in the northern region of the SB relates to a period of 92 days and 
a wavelength of $490 \mathrm{~km}$. This wave accounts for $\sim 17 \%$ of the BC axis variability and subsequent downstream propagation along the whole SBi extension. By extending our analysis towards the interior of the South Atlantic basin, we identified that the 92-day wave signal propagating from the east as a wave front and reaching the BC. These waves accounted for about $\sim 21 \%$ of the SLA variability at $25^{\circ} \mathrm{S}$ along the front path.

Certainly the question we asked was: what are these waves? Given their nearly-zonal propagation, the northern area spectrum was first compared to the linear first-mode baroclinic planetary Rossby waves dispersion curve. However, in order to be classified as so, the $490 \mathrm{~km}$ wave would have to present a much longer period than 92 days. If we keep this period, their critical latitude would be $17^{\circ} \mathrm{S}$, and the Rossby parameter $\beta$ would have to be much larger. As matter of fact, the identified wave seems to propagate with a phase speed corresponding to a nondispersive linear baroclinic planetary wave of 92 days. We observed that the northern area spectrum concentrates energy in the vicinities of the so-called NDL. In particular, the $(\omega, k)$ pair for the 92-day/490km wave lies near the NDL. The literature has reported that waves with such characteristics are related to nonlinear vorticity waves. Indeed, we calculated the relation between advective and local terms from the momentum equation, and found the nonlinear parameter for this wave to be 1.1. Therefore, we conclude that the 92-day oscillations are nonlinear vorticity waves, which are originated to the east of $35^{\circ} \mathrm{W}$ and propagate zonally towards the $\mathrm{BC}$ axis. These waves then perturb the current exciting oscillatory motions of the same period and which propagate downstream. Our results suggest that the southward propagating wave train are in phase with the incoming zonal wave front and account for $1 / 5$ of the $\mathrm{BC}$ variability in the northern area.

\section{The Southern Study Area}

South of the SBi axis, we identified two different maxima in the $\omega, k$ spectrum calculated using the FFT2D. They correspond to oscillations with periods of 68 and 148 days. It should be mentioned that the third maxima found is associated with the 92-day waves coming from the northern area and propagating south.

The 148-day wave has a length of $\sim 790 \mathrm{~km}$. It is originated in the ocean interior and we were able to track its signal as far as $5^{\circ} \mathrm{W}$. Its propagation is nearly zonal to the west. Such as the 92 day wave described above, this longer wave appears to be a baroclinic first-mode NDL wave. We indeed estimated the nonlinear parameter as 1.13 , virtually matching the classification we gave 
to the 92-day wave in the northern area. We however should comment that the critical latitude of a 148-day linear baroclinic Rossby wave is $29^{\circ} \mathrm{S}$. It is therefore possible the existence of linear Rossby wave with 148-day period, but with a half wavelength of the estimated signal $(420 \mathrm{~km})$. Therefore, in order to match the linear dispersion curve, one possibility is that the ambient potential vorticity gradient of such waves should include other terms other than the planetary $\beta$. The other possibility is an association between a linear wave and a nonlinear eddy, which might propagate at same speed, such as proposed byPolito and Sato (2015). However, given the obtained $\omega, k$ spectrum resemblance to the one presented by Wortham and Wunsch (2014), we classify the 148-day oscillations as nonlinear vorticity waves.

The second spectrum maximum found south of the SBi was related to oscillations of 68day period and $397 \mathrm{~km}$ wavelength. These waves differ from the previously described ones because their existence is limited to vicinities of the BC. There is no evidence of westwardpropagating wave front coming from the ocean interior. Phase speeds have approximately the $\mathrm{BC}$ axis orientation and they can only be clearly detected between $\sim 27^{\circ} \mathrm{S}$ and $\sim 32^{\circ} \mathrm{S}$. This propagating signal accounts with a variance of $\sim 21 \%$ on the BC axis and almost $28 \%$ along the wave ray tracing.

Due to its propagation axis and its wavelength, this was the only of three investigated wavelengths that was possible to search for the evidence in in situ observational data. In CERES V cruise (1-23 November 2013), we identified a anticyclone-cyclone pair in the outer edge of the BC. Using VMADCP data we identified a resemblance between the each eddy and the vertical structure of the BC. This possibly suggests a similar dynamic modal composition a direct link among the features. However, this needs to be further examined since the velocity profiling only reached $450 \mathrm{~m}$ depth and the LADCP observations available reaches only the innermost part of the oceanographic transects.

This wave is directly associated with the $\mathrm{BC}$ axis and thus can be related perturbations due to instability in the current. Despite de recent studies regarding instability of the current, they either did it with current meter data or did not considered the possible effect of the SBi in the region (Rocha et al., 2014; Fernandes et al., 2009).

By positively testing this thesis hypothesis, we can state that the $\mathrm{BC}$ is both locally and remotely forced. While the remote forcing is associated to impinging westward-propagating wave fronts with periods of 92 and 148 days. The local forcing seems to produce 68-day oscillations confined to the vicinities of the current axis. 


\subsection{Future work}

From this work we were able to better understand the variability scales of the $\mathrm{BC}$ within the $\mathrm{SB}$, but there is still a lot to know and understand about the BC system in this region.

To better understand the periodic signals identified in the present work, we propose to process-model to the SB domain. The use a QG nonlinear model or even PE model to access what is the forcing of the locally-formed southward propagating waves. The interaction of the incoming NDL waves with the $\mathrm{BC}$ and the topography should also be pursued through process modeling. Moreover, the dynamical role of the SBi as a both a hydrodynamic barrier as well as a source for perturbations to the $\mathrm{BC}$ and the IWBC should be explored using process modeling.

We also suggest the use of further studies and analyses using available observational data from both quasi-synoptic and time series of currentmeter moorings. Improved spectral techniques like two dimensional wavelets which do not impose constraints in the results like FFT2D (i.e. permanent and recurrent features). 


\section{Bibliography}

Anderson, D. L., and A. Gill (1975), Spin-up of a stratified ocean, with applications to upwelling, Deep Sea Research and Oceanographic Abstracts, 22(9), 583 - 596.

Andres, M., J.-H. Park, M. Wimbush, X.-H. Zhu, K.-I. Chang, and H. Ichikawa (2008), Study of the kuroshio/ryukyu current system based on satellite-altimeter and in situ measurements, Journal of oceanography, 64(6), 937-950.

Azevedo, J. L., D. Nof, and M. M. Mata (2012), Eddy-train encounters with a continental boundary: a south atlantic case study, Journal of Physical Oceanography, 42(9), 1548-1565.

Belo, W. C. (2011), A recirculação interna do giro subtropical do atlântico sul e a circulação oceânica na região do pólo pré-sal da bacia de santos, Ph.D. thesis, Universidade de São Paulo.

Biló, T. C. (2015), The changing brazil current system between 23 s-31 s: vertical structure and mesoscale dynamics, Master's thesis, Universidade de São Paulo.

Boebel, O., R. E. Davis, M. Ollitrault, R. G. Peterson, P. L. Richardson, C. Schmid, and W. Zenk (1999), The Intermediate Depth Circulation of the Western South Atlantic, Geophys. Res. Lett., 26(21), 3329-3332.

Bretherton, F. P., R. E. Davis, and C. B. Fandry (1976), A technique for objective analysis and design of oceanographic experiments applied to MODE 73, Deep-Sea Res., 23, 559-582.

Calado, L., A. Gangopadhyay, and I. Da Silveira (2008), Feature-oriented regional modeling and simulations (forms) for the western south atlantic: Southeastern brazil region, Ocean Modelling, 25(1), 48-64.

Calado, L., I. Da Silveira, A. Gangopadhyay, and B. De Castro (2010), Eddy-induced upwelling off cape são tomé (22 s, brazil), Continental Shelf Research, 30(10), 1181-1188. 
Campos, E. J., and D. B. Olson (1991), Stationary rossby waves in western boundary current extensions, Journal of Physical Oceanography, 21(8), 1202-1224.

Campos, E. J. D., J. E. Gonçalves, and Y. Ikeda (1995), Water mass characteristics and geostrophic circulation in the South Brazil Bight: Summer of 1991, J. Geophys. Res., 100(C9), 18,537-18,550.

Campos, E. J. D., Y. Ikeda, B. M. Castro, S. A. Gaeta, J. A. Lorenzzetti, and M. R. Stevenson (1996), Experiment Studies Circulation in the Western South Atlantic, 77(27), 253-264.

Campos, E. J. D., D. Velhote, and I. C. A. Silveira (2000), Shelf break upwelling driven by the Brazil Current meanders, Geophys. Res. Lett., 27(6), 751-754.

Carter, E. F., and A. R. Robinson (1987), Analysis models for the estimation of oceanic fields, Journal of Atmospheric and Oceanic Technology, 4(1), 49-74.

Chaigneau, A., A. Gizolme, and C. Grados (2008), Mesoscale eddies off peru in altimeter records: Identification algorithms and eddy spatio-temporal patterns, Progress in Oceanography, 79(2), 106-119.

Chelton, D. B., M. G. Schlax, and R. M. Samelson (2011), Global observations of nonlinear mesoscale eddies, Progress in Oceanography, 91(2), 167-216.

Chen, G., Y. Hou, X. Chu, P. Qi, and P. Hu (2009), The variability of eddy kinetic energy in the south china sea deduced from satellite altimeter data, Chinese Journal of Oceanology and Limnology, 27(4), 943-954.

da Silveira, I. C., L. B. Miranda, and W. S. Brown (1994), On the origins of the north brazil current, Journal of Geophysical Research: Oceans, 99(C11), 22,501-22,512.

da Silveira, I. C., G. R. Flierl, and W. S. Brown (1999), Dynamics of separating western boundary currents, Journal of Physical Oceanography, 29(2), 119-144.

Early, J. J., R. Samelson, and D. B. Chelton (2011), The evolution and propagation of quasigeostrophic ocean eddies, J. Phys. Oceanogr., 41(8), 1535-1555.

Fernandes, A. M., I. C. A. da Silveira, L. Calado, E. J. D. Campos, and A. M. Paiva (2009), A two-layer approximation to the Brazil Cirrent-Intermediate Western Boundary Current System between $20^{\circ} \mathrm{S}$ and $28^{\circ} \mathrm{S}$, Ocean Modeling, 29, 154-158. 
Firing, E., J. Ranada, and P. Caldwell (1995), Processing ADCP data with the CODAS software system version 3.1, Tech. rep., Joint Inst. for Mar. and Atmos. Res./NODC, University of Hawaii at Manoa, Honolulu.

Flierl, G. R. (1978), Models of vertical structure and the calibration of two-layer models, $D y$ namics of Atmospheres and Oceans, 2(4), 341 - 381.

Garfield, N. (1990), The Brazil Current at subtropical latitudes, Ph.D. thesis, University of Rhode Island, Rhode Island.

Garzoli, S. L., S. Dong, R. Fine, C. S. Meinen, R. C. Perez, C. Schmid, E. Van Sebille, and Q. Yao (2015), The fate of the deep western boundary current in the south atlantic, Deep Sea Research Part I: Oceanographic Research Papers, 103, 125-136.

Gill, A. E. (2016), Atmosphere-ocean dynamics, Elsevier.

Goes, M., R. Molinari, I. da Silveira, and I. Wainer (2005), Retroflections of the north brazil current during february 2002, Deep Sea Research Part I: Oceanographic Research Papers, 52(4), 647-667.

Gordon, A. L., and C. L. Greengrove (1986), Geostrophic circulation of the brazil-falkland confluence, Deep Sea Research Part A. Oceanographic Research Papers, 33(5), 573-585.

Guerra, L. A. d. A. (2011), Vórtices das agulhas colidem com a corrente do brasil?, Ph.D. thesis, Universidade Federal do Rio de Janeiro.

Hughes, C. W., and B. A. De Cuevas (2001), Why western boundary currents in realistic oceans are inviscid: A link between form stress and bottom pressure torques, Journal of Physical Oceanography, 31(10), 2871-2885.

Johns, W. E., T. N. Lee, F. A. Schott, R. J. Zantopp, and R. H. Evans (1990), The north brazil current retroflection: Seasonal structure and eddy variability, Journal of Geophysical Research: Oceans, 95(C12), 22,103-22,120.

Legeais, J.-F., M. Ollitrault, and M. Arhan (2013), Lagrangian observations in the Intermediate Western Boundary Current of the South Atlantic, 85, 109-126. 
Locarnini, R. A., A. V. Mishonov, J. I. Antonov, T. P. Boyer, H. E. Garcia, O. K. Baranova, M. M. Zweng, C. R. Paver, J. R. Reagan, D. R. Johnson, M. Hamilton, and D. Seidov (2013), World Ocean Atlas 2013, Volume 2: Temperature, Tech. rep., NOAA.

Lorenzzetti, J. A., J. L. Stech, W. L. M. Filho, and A. T. Assireu (2009), Satellite observation of Brazil Current inshore thermal front in the SW South Atlantic: Space/time variability and sea surface temperatures, Cont. Shelf Res., 29(17), 2061-2068.

Mano, M. F., A. M. Paiva, A. R. T. Jr., and A. L. G. A. Coutinho (2009), Energy Flux to a Cyclonic Eddy off Cabo Frio, Brazil, J. Phys. Oceanogr., 39, 2999-3010.

Mata, M. M., S. Wijffels, J. A. Church, and M. Tomczak (2006), Statistical description of the east australian current low-frequency variability from the woce pcm3 array, Marine and freshwater research, 57(3), 273-290.

Meinen, C., A. Piola, R. Perez, and S. Garzoli (2012), Deep western boundary current transport variability in the south atlantic: preliminary results from a pilot array at $34.5^{\circ} \mathrm{s}$, Ocean Science, 8(6), 1041-1054.

Mémery, L., M. Arhan, X. A. Alvarez-Salgado, M. J. Messias, H. Mercier, C. G. Castro, and A. F. Rios (2000), The water masses along the western boundary of the south and equatorial Atlantic, Prog. Oceanog., 47(1), 69-98.

Morten, A.-B. F. G., AJ (2017), Wavenumber-frequency analysis of single-layer shallow-water beta-plane quasi-geostrophic turbulence.

Munk, W. H. (1950), On the wind-driven ocean circulation, Journal of meteorology, 7(2), 8093.

Oliveira, L. R., A. R. Piola, M. M. Mata, and I. D. Soares (2009), Brazil Current surface circulation and energetics observed from drifiting buoys, J. Geophys. Res., 114(C10006).

Pedlosky, J. (2013), Ocean circulation theory, Springer Science \& Business Media.

Polito, P. S., and W. T. Liu (2003), Global characterization of rossby waves at several spectral bands, Journal of Geophysical Research: Oceans, 108.

Polito, P. S., and O. T. Sato (2015), Do eddies ride on rossby waves?, Journal of Geophysical Research: Oceans, 120(8), 5417-5435. 
Rocha, C. B., I. C. A. da Silveira, B. M. Castro, and J. A. M. Lima (2014), Vertical structure, energetics and dynamics of the Brazil Current System at $22^{\circ} \mathrm{S}-28^{\circ} \mathrm{S}$, J. Geophys. Res-Oceans, doi:10.1002/2013JC009143.

Rodrigues, R. R., L. M. Rothstein, and M. Wimbush (2007), Seasonal Variability of the South Equatorial Current Bifurcation in the Atlantic Ocean: A Numerical Study, J. Phys. Oceanogr., 37, 16-30.

Rodrigues, R. R., M. Wimbush, D. R. Watts, L. M. Rothstein, and M. Ollitrault (2010), South atlantic mass transports obtained from subsurface float and hydrographic data, Journal of Marine Research, 68(6), 819-850.

Samelson, R. (2010), An effective- $\beta$ vector for linear planetary waves on a weak mean flow, Ocean Modelling, 32(3), 170-174.

Schmid, C. (2014), Mean vertical and horizontal structure of the subtropical circulation in the south atlantic from three-dimensional observed velocity fields, Deep Sea Research Part I: Oceanographic Research Papers, 91, 50-71.

Schmid, C., H. Schäfer, W. Zenk, and G. Podestá (1995), The vitória eddy and its relation to the brazil current, Journal of physical oceanography, 25(11), 2532-2546.

Schmitz, W. J. (1995), On the interbasin-scale thermohaline circulation, Reviews of Geophysics, $33(2), 151-173$.

Silveira, I. C., J. A. M. Lima, A. C. K. Schimdt, W. Ceccopieri, A. Satori, C. P. F. Francisco, and R. F. C. Fontes (2008), Is the meander growth in the Brazil Current System off Southeast Brazil due to baroclinic instability?, Dynam. Atmos. Oceans, 45, 187-207.

Silveira, I. C. A., L. Calado, B. M. de Castro, M. Cirano, J. A. M. Lima, and A. S. Mascarenhas (2004), On the Baroclinic Structure of the Brazil Current-Intermediate Western Boundary Current at $22^{\circ}-23^{\circ} \mathrm{S}$, Geophys. Res. Lett., 31, 4308.

Silveira, I. C. d., W. S. Brown, and G. R. Flieri (2000), Dynamics of the north brazil current retroflection region from the western tropical atlantic experiment observations (paper 2000jc900129), Journal of Geophysical Research-Part C-Oceans, 105(12), 28,559-28,584. 
Soutelino, R., I. Da Silveira, A. Gangopadhyay, and J. Miranda (2011), Is the brazil current eddy-dominated to the north of 20 s?, Geophysical Research Letters, 38(3).

Soutelino, R. G., A. Gangopadhyay, and I. C. A. da Silveira (2013), The roles of vertical shear and topography on the eddy formation near the site of origin of the Brazil Current, Cont. Shelf Res., 70, 46-60.

SSALTO/Duacs (2014), A new version of SSALTO/Duacs products available in April 2014.

Stommel, H. (1948), The westward intensification of wind-driven ocean currents, Eos, Transactions American Geophysical Union, 29(2), 202-206.

Stommel, H. (1961), Thermohaline convection with two stable regimes of flow, Tellus, 13(2), $224-230$.

Stommel, H. (1965), The Gulf Stream: A Physical and Dynamical Description, University of California Press.

Stramma, L., and M. England (1999), On the wather masses and mean circulation of the South Atlantic Ocean, J. Geophys. Res., 104(C9), 20,863-20,883.

Sverdrup, H. U. (1947), Wind-driven currents in a baroclinic ocean; with application to the equatorial currents of the eastern pacific, Proceedings of the National Academy of Sciences, $33(11), 318-326$.

Talley, L. D., G. L. Pickard, W. J. Emery, and J. H. Swift (2011), Descriptive Physical Oceanography: An Introduction, sixth ed., Academic Press.

Tsuchiya, M. (1985), Evidence of a double-cell subtropical gyre in the south atlantic ocean, Journal of Marine Research, 43(1), 57-65.

Vianna, M. L., V. V. Menezes, and D. P. Chambers (2007), A high resolution satellite-only grace-based mean dynamic topography of the south atlantic ocean, Geophysical Research Letters, 34(24).

Wortham, C., and C. Wunsch (2014), A multidimensional spectral description of ocean variability, Journal of Physical Oceanography, 44(3), 944-966. 
Young, W. R., and P. Rhines (1982), A theory of the wind-driven circulation ii. gyres with western boundary layers, J. Mar. Res, 40, 849-872.

Zemba, J. C. (1991), The structure and transport of the Brazil Current between $27^{\circ}$ and $36^{\circ}$ South, Ph.D. thesis, Massachusetts Institute of Technology and Woods Hole Oceanographic Institution.

Zhang, D., T. N. Lee, W. E. Johns, C.-T. Liu, and R. Zantopp (2001), The kuroshio east of taiwan: Modes of variability and relationship to interior ocean mesoscale eddies, Journal of Physical Oceanography, 31(4), 1054-1074.

Zweng, M. M., J. R. Reagan, J. I. Antonov, R. A. Locarnini, A. V. Mishonov, T. P. Boyer, H. E. Garcia, O. K. Baranova, D. R. Johnson, D. Seidov, and M. M. Biddle (2013), World Ocean Atlas 2013, Volume 2: Salinity, Tech. rep., NOAA. 